NIST Special Publication 1205

\title{
Evaluating the Sustainability Performance of Alternative Residential Building Designs using the BIRDS Low-Energy Residential Database
}

Joshua Kneifel

Eric O’Rear

David Webb

This publication is available free of charge from: http://dx.doi.org/10.6028/NIST.SP.1205
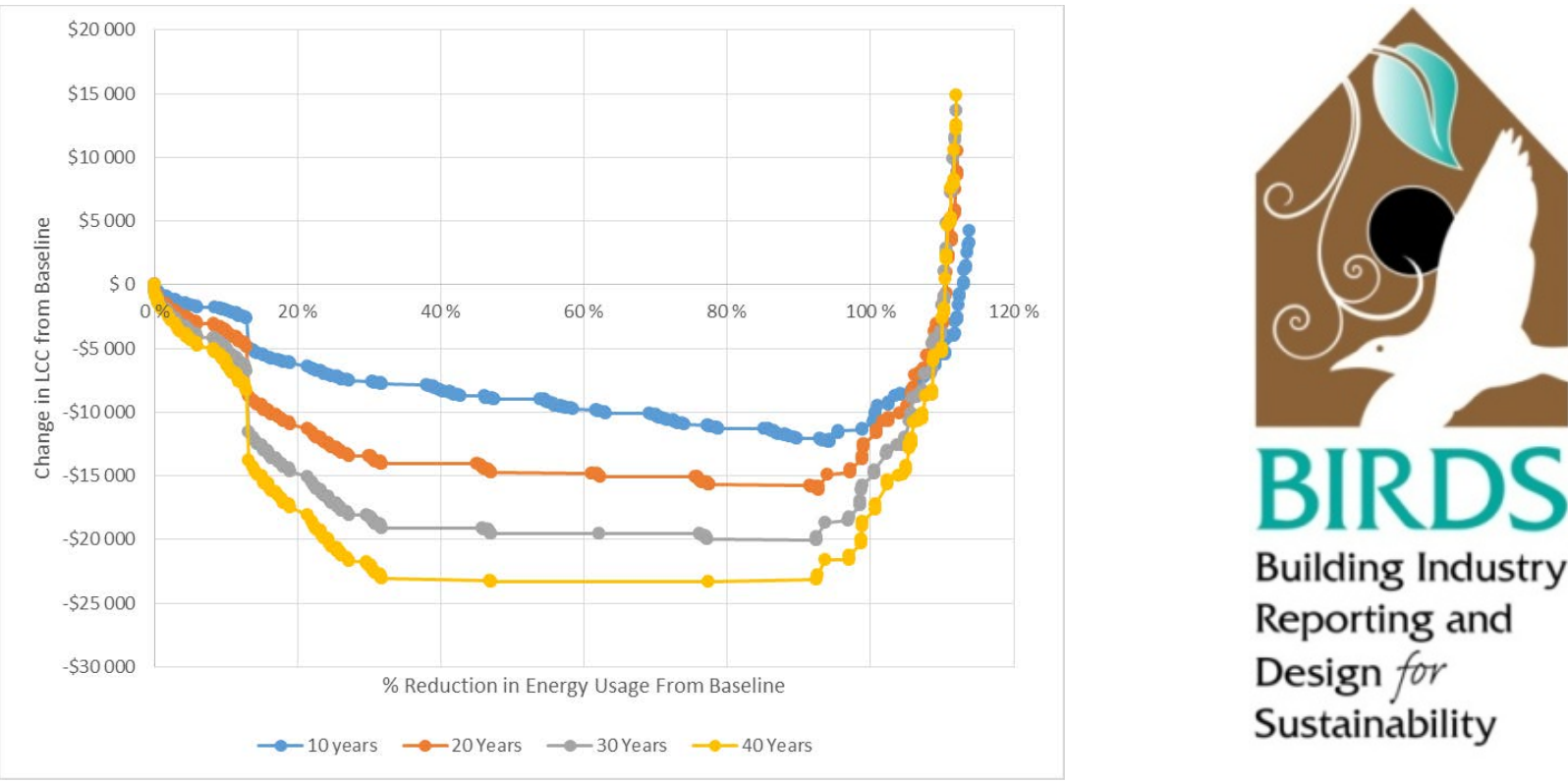

Building Industry Reporting and Design for Sustainability

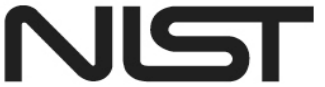

National Institute of Standards and Technology U.S. Department of Commerce 

NIST Special Publication 1205

\title{
Evaluating the Sustainability Performance of Alternative Residential Building Designs using the BIRDS Low-Energy Residential Database
}

\author{
Joshua Kneifel \\ Eric O’Rear \\ David Webb \\ Applied Economics Office \\ Engineering Laboratory
}

This publication is available free of charge from:

http://dx.doi.org/10.6028/NIST.SP.1205

August 2016

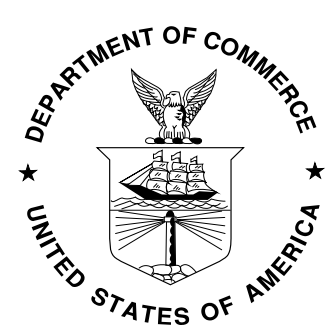

U.S. Department of Commerce

Penny Pritzker, Secretary

National Institute of Standards and Technology Willie May, Under Secretary of Commerce for Standards and Technology and Director 
Certain commercial entities, equipment, or materials may be identified in this document in order to describe an experimental procedure or concept adequately. Such identification is not intended to imply recommendation or endorsement by the National Institute of Standards and Technology, nor is it intended to imply that the entities, materials, or equipment are necessarily the best available for the purpose.

National Institute of Standards and Technology Special Publication 1205

Natl. Inst. Stand. Technol. Spec. Publ. 1205, 107 pages (August 2016) CODEN: NSPUE2

This publication is available free of charge from: http://dx.doi.org/10.6028/NIST.SP.1205 


\begin{abstract}
The recent release of Building Industry Reporting and Design for Sustainability (BIRDS) v3.0 incorporated the energy, environmental, and cost measurements for 240000 residential building designs for a 2-story colonial house based on the NIST Net-Zero Energy Residential Test Facility (NZERTF) located in Gaithersburg, MD for study period lengths ranging from 1 year to 40 years. Focusing on a single location allows for consideration of incremental building energy efficiency improvements instead of the suite of energy efficiency requirements specified in the International Energy Conservation Code (IECC) as was the focus of the residential database incorporated in BIRDS v2.0. Building design specifications included in the database span the five most recent IECC editions through net-zero energy performance. Additional options not included in previous versions of BIRDS are input alternatives for discount rate, home loan financing, and construction quality for a total of 8 cases. The 240000 designs across 8 cases (sets of assumptions) and 40 study periods allows for comparisons across over 75 million records to determine the effects of improving building energy efficiency on the overall sustainability performance.

The purpose of this study is to utilize similar methodology as that used in prior analysis of BIRDS databases to analyze the BIRDS low-energy residential database. Our analysis will entail making comparisons between a Maryland residential code-compliant design (based on 2015 IECC), serving as our baseline, and a series of alternative designs with varying levels of energy efficiency based on energy, economic, and environmental performance. Findings from this study will shed light on the effects of incremental improvements in residential building energy efficiency, as well as the effects of varying the investor's time horizon and other assumptions, on overall sustainability performance in terms of energy efficiency, life-cycle assessment score coupled with life-cycle cost considerations.
\end{abstract}

\title{
Keywords
}

Building economics; economic analysis; life-cycle costing; life-cycle assessment; energy efficiency; residential buildings; low-energy buildings 


\section{Preface}

This study was conducted by the Applied Economics Office in the Engineering Laboratory (EL) at the National Institute of Standards and Technology (NIST). The study is designed to assess the energy use, life-cycle cost, and life-cycle environmental impacts from incorporation of different energy efficiency measures (EEMs) into new residential construction. The intended audience is researchers and policy makers in the residential building sector, and others interested in residential building energy efficiency.

\section{Disclaimers}

The policy of the National Institute of Standards and Technology is to use metric units in all of its published materials. Because this report is intended for the U.S. construction industry that uses U.S. customary units, it is more practical and less confusing to include U.S. customary units as well as metric units. Measurement values in this report are therefore stated in metric units first, followed by the corresponding values in U.S. customary units within parentheses. 


\section{Acknowledgements}

The authors wish to thank all those who contributed ideas and suggestions for this report. They include Dr. David Butry and Dr. Robert Chapman of EL's Applied Economics Office, Dr. William Healy of EL's Energy and Environment Division, and Dr. Nicos S. Martys of EL's Materials and Structural Systems Division. A special thanks to Ms.

Shannon Craig and Priya Lavappa for developing the BIRDS low-energy residential database.

\section{Author Information}

Joshua D. Kneifel

Economist

National Institute of Standards and Technology

Engineering Laboratory

100 Bureau Drive, Mailstop 8603

Gaithersburg, MD 20899-8603

Tel.: 301-975-6857

Email: joshua.kneifel@nist.gov

Eric G. O’Rear

Economist

National Institute of Standards and Technology

Engineering Laboratory

100 Bureau Drive, Mailstop 8603

Gaithersburg, MD 20899-8603

Tel.: 301-975-4570

Email: eric.orear@nist.gov

David H. Webb

Engineering Trainee

National Institute of Standards and Technology

Engineering Laboratory

100 Bureau Drive, Mailstop 8603

Gaithersburg, MD 20899-8603

Tel.: 301-975-2644

Email: david.webb@nist.gov 


\section{Table of Contents}

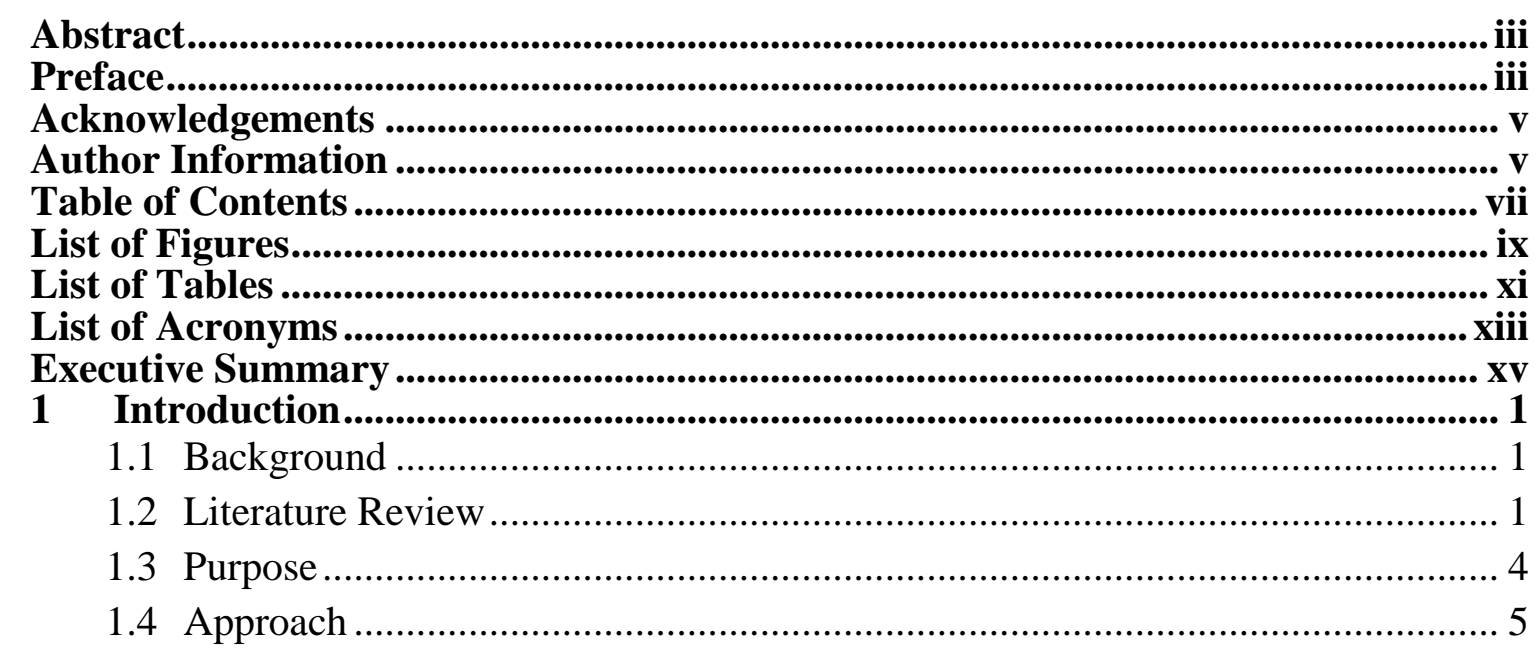

2 BIRDS Low-Energy Residential Database ......................................................... 7

2.1 Alternative Design Options related to the Building Envelope ........................... 7

2.2 Alternative Design Options related to Building Lighting Systems and Interior

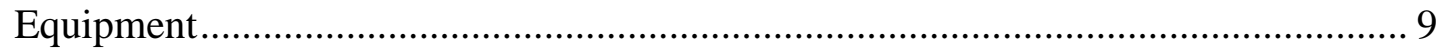

2.3 Baseline Building Design Specifications ..................................................... 11

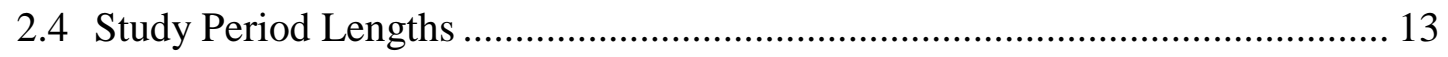

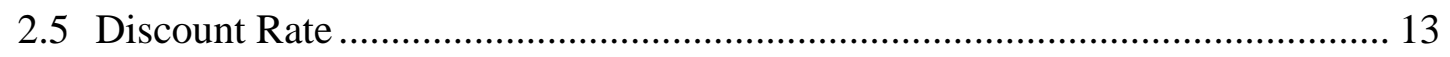

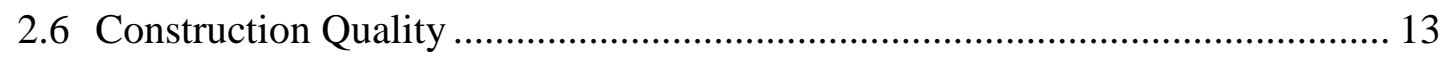

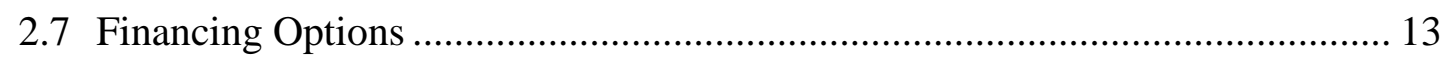

3 Analysis Approach .......................................................................................................... 15

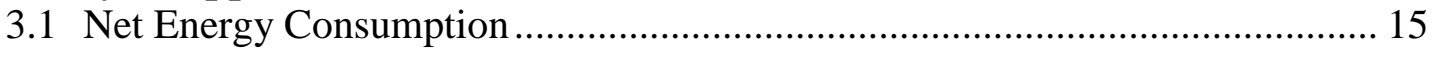

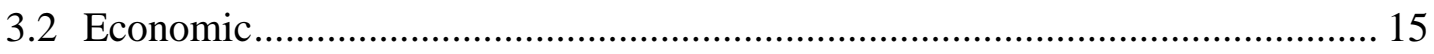

3.2.1 Economic Metrics ............................................................... 15

3.2.2 Matching Analysis to BIRDS version 3.0 Tool ......................... 16

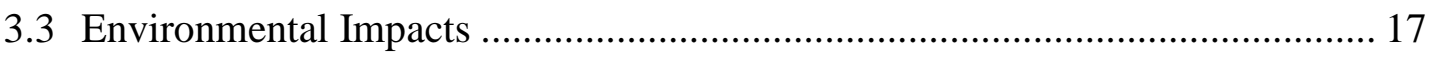

3.4 Pareto Frontier Development and Key Building Design Selection.................... 19

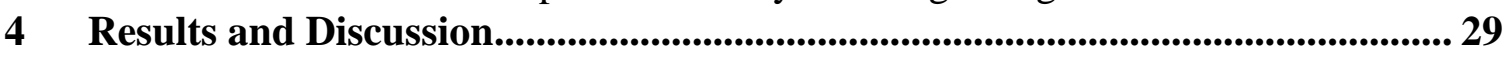

4.1 Energy and Economic Impacts of Incremental Building Design Options ......... 29

4.2 Case 1: 3 \% Discount Rate, Average Construction Quality, 100 \% Cash

Financing 32

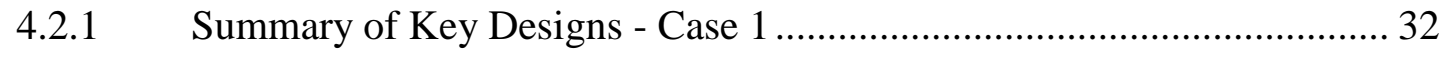

4.2.2 First Cost Analysis of Key Designs - Case 1 .......................................... 33

4.2.3 Future Cost Analysis of Key Designs - Case 1...................................... 35

4.2.4 LCC Analysis and Payback Period of Key Designs - Case 1 ................... 39

4.2.5 Environmental Impact Analysis of Key Designs - Case 1........................ 42

4.3 Case 2: 3 \% Discount Rate, Average Construction Quality, 20 \% Down / 80 \%

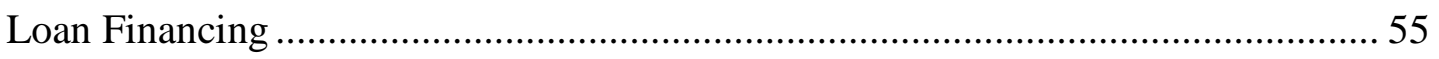

4.3.1 Summary of Key Designs - Case 2 ….............................................. 55 
4.3.2 First Cost Analysis of Key Designs - Case 2 2.......................................... 56

4.3.3 Future Cost Analysis of Key Designs - Case 2........................................ 58

4.3.4 LCC Analysis and Payback Period of Key Designs - Case 2 2................... 59

4.3.5 Environmental Impact Analysis of Key Designs - Case 2........................ 62

4.4 Case 3: 3 \% Discount Rate, Luxury Construction Quality, 100 \% Cash

Financing 62

4.5 Case 4: 3 \% Discount Rate, Luxury Construction Quality, 20 \% Down/80 \%

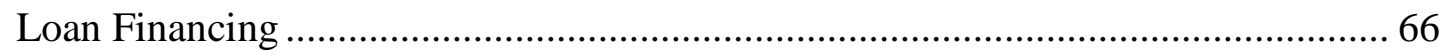

4.6 Case 5: 8 \% Discount Rate, Average Construction Quality, 100 \% Cash

Financing 70

4.6.1 Summary of Key Designs - Case 5 ....................................................... 70

4.6.2 First Cost Analysis of Key Designs - Case 5 ........................................ 72

4.6.3 Future Cost Analysis of Key Designs - Case 5.......................................... 73

4.6.4 LCC Analysis and Payback Period of Key Designs - Case 5.................... 77

4.6.5 Environmental Impact Analysis of Key Designs - Case 5.......................... 80

4.7 Case 6: 8 \% Discount Rate, Average Construction Quality, 20 \% Down/80 \%

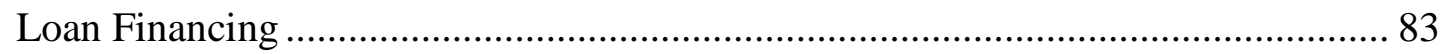

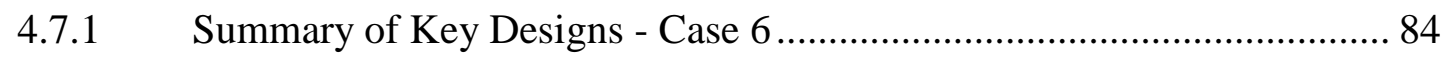

4.7.2 First Cost Analysis of Key Designs - Case 6 .......................................... 86

4.7.3 Future Cost Analysis of Key Designs - Case 6......................................... 87

4.7.4 LCC Analysis and Payback Period of Key Designs - Case 6 6................... 92

4.7.5 Environmental Impact Analysis of Key Designs - Case 6......................... 96

4.8 Case 7 and Case 8..................................................................................... 96

5 Conclusion, Limitations, and Future Research..................................................99

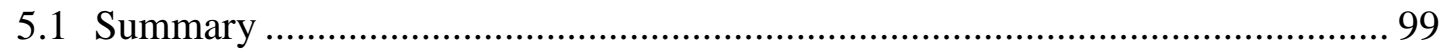

5.2 Limitations and Future Research.................................................................. 100

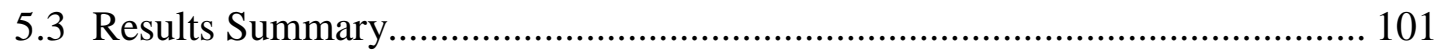

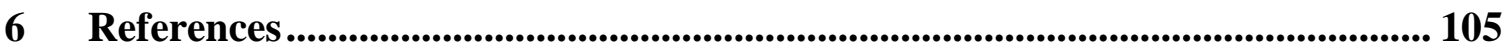




\section{List of Figures}

Figure 3-1 Energy Savings and Change in LCC - 3 \% Discount Rate, "Average” Construction Quality, and 100 \% Cash Financing with Tax Credit Applied.................... 21 Figure 3-2 Energy Savings and Net Savings - 3 \% Discount Rate, “Average” Construction Quality, and 100 \% Cash Financing without Tax Credit Applied .............. 22 Figure 3-3 Energy Savings and Net Savings - 8 \% Discount Rate, “Average” Construction Quality, and $100 \%$ Cash Financing 23

Figure 3-4 Pareto Frontiers for a 3 \% Discount Rate, average Construction Quality, and $100 \%$ Cash Financing.....

Figure 3-5 Pareto Frontiers for a 3 \% Discount Rate, average Construction Quality, and $20 \%$ Cash Financing 25

Figure 3-6 Additional Investment Costs relative to the MCC Design for Points along the 10-Year Pareto Frontier with Data Points of Interest (A through L) ............................... 27

Figure 4-1 Total First Costs for Selected Designs - Case 1 .......................................... 34

Figure 4-2 Incremental First Costs for Selected Designs relative to Baseline - Case 1... 35

Figure 4-3 Present Value of Total Electricity Costs for Selected Designs - Case 1 ........ 37

Figure 4-4 Present Value of Total MRR Costs for Selected Designs - Case 1............... 38

Figure 4-5 Present Value of Residual Value for Selected Designs - Case 1................... 39

Figure 4-6 Present Value of Total LCC for Selected Designs - Case 1 .......................... 40

Figure 4-7 Present Value of the Difference in LCC relative to Baseline for Selected

Designs- Case 1............................................................................................. 41

Figure 4-8 Comparative Differences in Environmental Impacts relative to Baseline for Selected Designs- Case 1 44

Figure 4-9 EIS for Selected Designs using Equal Weighting Approach - Case 1 .......... 48

Figure 4-10 EIS for Selected Designs using BEES Weighting Approach - Case 1........ 49

Figure 4-11 EIS for Selected Designs using SAB Weighting Approach - Case 1.......... 50 Figure 4-12 EIS for Selected Designs using Carbon Only Weighting Approach - Case 1

Figure 4-13 Total First Costs for Selected Designs - Case 2 ....................................... 57

Figure 4-14 Incremental First Costs Relative to Baseline for Selected Designs - Case 257

Figure 4-15 Present Value of Mortgage Loan Payments for Selected Designs - Case 2. 59

Figure 4-16 Present Value of Total LCC for Selected Designs - Case 2 ........................ 60

Figure 4-17 Difference in LCC Relative to Baseline for Selected Designs - Case 2....... 61

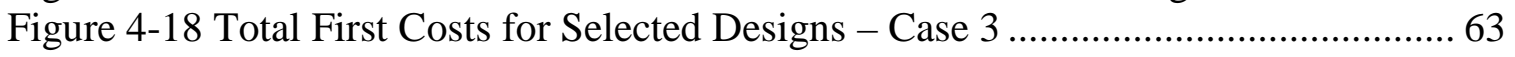

Figure 4-19 Present Value of Residual Value for Selected Designs - Case 3................. 64

Figure 4-20 Present Value of Total LCC for Selected Designs - Case 3 ........................ 65

Figure 4-21 Present Value of Total First Costs for Selected Designs - Case 4............... 67

Figure 4-22 Present Value of Residual Value for Selected Designs - Case 4................. 68

Figure 4-23 Present Value of Total LCC for Selected Designs - Case 4 ........................ 69

Figure 4-24 Present Value of Total First Costs for Selected Designs - Case 5................ 72

Figure 4-25 Present Value of Incremental First Costs relative to Baseline for Selected

Designs - Case 5 .............................................................................................. 73

Figure 4-26 Present Value of Total Electricity Costs for Selected Designs - Case 5 ...... 74

Figure 4-27 Present Value of Total MRR Costs for Selected Designs - Case 5 ............. 75

Figure 4-28 Present Value of Residual Value for Selected Designs - Case 5................. 76

Figure 4-29 Present Value of Total LCC for Selected Designs - Case 5 ........................ 77 
Figure 4-30 Present Value of Incremental Change in LCC Relative to Baseline for Selected Designs - Case 5

Figure 4-31 Environmental Impacts for Alternative Designs Relative to Baseline - Case 5

Figure 4-32 Environmental Impact Scores for the MCC and Alternative Designs using

Equal (left) and BEES (right) Weighting Approaches - Case 5.

Figure 4-33 Environmental Impact Scores for the MCC and Alternative Design using

SAB (left) and Carbon Footprint Only (right) Weighting Approaches - Case 5 ............. 82

Figure 4-34 Legend for EIS Plots in Figure 4-32 and Figure 4-33............................... 83

Figure 4-35 Energy Savings and Net Savings - 3 \% Discount Rate, “Average”

Construction Quality, and $100 \%$ Cash Financing....

Figure 4-36 Present Value of Total First Costs for Selected Designs - Case 6................ 86

Figure 4-37 Present Value of Incremental First Costs Relative to Baseline for Selected

Designs - Case 6 .

Figure 4-38 Discounted Loan Payments for Selected Designs - Case 6........................ 88

Figure 4-39 Present Value of Total Electricity Costs for Selected Designs - Case 6 ...... 89

Figure 4-40 Present Value of Total MRR Costs for Selected Designs - Case 6 ............. 90

Figure 4-41 Present Value of Residual Value Costs for Selected Designs - Case 6........ 91

Figure 4-42 Present Value of Total LCC for Selected Designs - Case 6 ........................ 93

Figure 4-43 Present Value of Incremental LCC Relative to Baseline for Selected Designs

- Case 6. 95 


\section{List of Tables}

Table 2-1 Constructions - Roof, Ceiling, Wall and Foundation .................................... 8

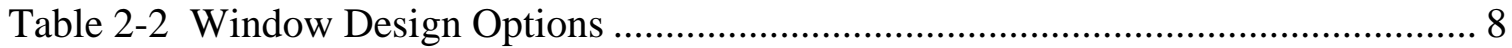

Table 2-3 Air Leakage Rate Design Options ............................................................ 9

Table 2-4 Lighting Wattage Design Options ............................................................... 9

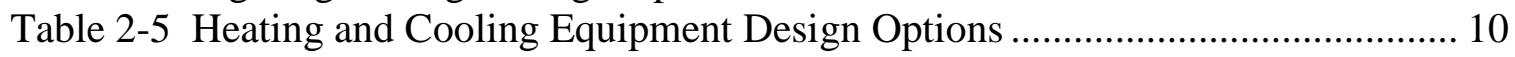

Table 2-6 Domestic Hot Water System Design Options ............................................... 11

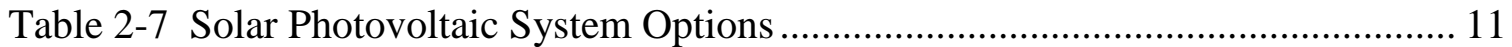

Table 2-8 Design Specifications for MCC Building Simulation ..................................... 12

Table 4-1 Energy Savings (\%) and Net Savings (PV\$) of EEMs on MCC Building

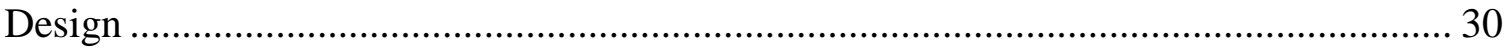

Table 4-2 Selected Key Designs for Case 1................................................................ 32

Table 4-3 Modified Payback Period for Selected Key Designs - Case 1 ....................... 42

Table 4-4 Normalization References: Annual U.S. Contributions ................................ 45

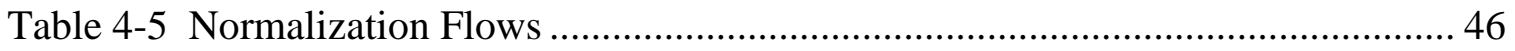

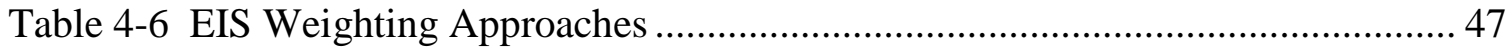

Table 4-7 Normalized Impact by Category and EIS - Equal Weighting ........................ 52

Table 4-8 Normalized Impact by Category and EIS - BEES Weighting ....................... 53

Table 4-9 Normalized Impact by Category and EIS - SAB Weighting ......................... 54

Table 4-10 Selected Key Designs - Case 2 ................................................................ 55

Table 4-11 Modified Payback Period for Selected Designs - Case 2 ............................. 62

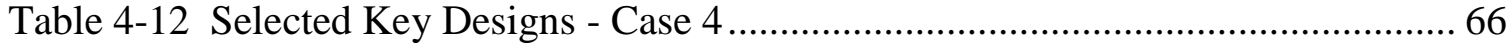

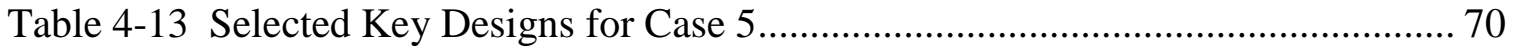

Table 4-14 Normalized Flows for Case 5 ................................................................... 81

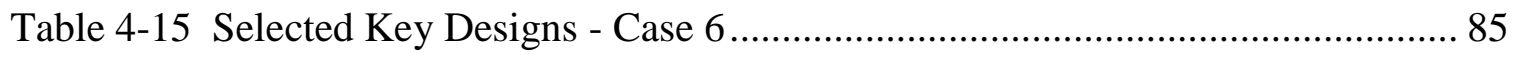

Table 4-16 Modified Payback Period for Selected Key Designs - Case 6 ...................... 96

Table 4-17 Premiums from Luxury Construction Quality for Case 7 and Case 8.......... 97

Table 5-1 Energy Savings for Selected Key Designs by Case .................................... 101

Table 5-2 Change in LCC for Selected Key Designs by Case .................................... 102

Table 5-3 Change in LCC for LCC-NZE Design With/Without Federal Renewable

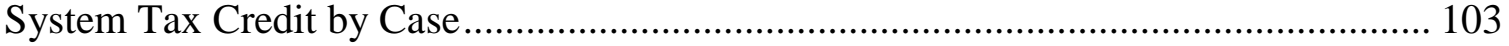




\title{
List of Acronyms
}

\author{
Acronym Definition \\ AEO Applied Economics Office \\ AFUE Annual Fuel Utilization Efficiency \\ AIRR Adjusted Internal Rate of Return \\ ASHRAE American Society of Heating, Refrigerating and Air-Conditioning Engineers \\ BIRDS Building Industry Reporting and Design for Sustainability \\ CBECS Commercial Building Energy Consumption Survey \\ CH4 Methane \\ CO2 Carbon Dioxide \\ CO2e Carbon Dioxide Equivalent \\ DOE Department of Energy \\ EEFG EnergyPlus Example File Generator \\ eGRID Emissions and Generation Resource Integrated Database \\ EIA Energy Information Adminstration \\ EL Engineering Laboratory \\ EPA Environmental Protection Agency \\ FEMP Federal Energy Management Program \\ FERC Federal Energy Regulatory Commission \\ HVAC Heating, Ventilating, and Air-Conditioning \\ I-P Inch-Pounds (Customary Units) \\ IECC International Energy Code Council \\ ISO International Organization for Standardization \\ LCA Life-Cycle Assessment \\ LCC Life-Cycle Cost \\ LEC Low Energy Case \\ $\mathrm{MBH}$ thousand Btu per hour \\ MRR Maintenance, Repair, and Replacement \\ N2O Nitrous Oxide \\ NAHB National Association of Home Builders \\ NERC North American Electric Reliability Corporation \\ NIST National Institute of Standards and Technology \\ PNNL Pacific Northwest National Laboratory \\ PV Photovoltaics \\ ROI Return on Investment \\ S-I System International (Metric Units) \\ SEER Seasonal Energy Efficiency Ratio \\ SHGC Solar Heat Gain Coefficient \\ SPV Single Present Value \\ UPV* Uniform Present Value Modified for Fuel Price Escalation
}




\section{Executive Summary}

The recent release of Building Industry Reporting and Design for Sustainability (BIRDS) v3.0 incorporated the energy, environmental, and cost measurements for 240000 residential building designs for a 2-story colonial house based on the NIST NZERTF located in Gaithersburg, MD for study period lengths ranging from 1 year to 40 years. Focusing on a single location allows for consideration of incremental building energy efficiency improvements instead of the suite of energy efficiency requirements specified in the International Energy Conservation Code (IECC) as was the focus of the residential database incorporated in BIRDS v2.0. Building design specifications included in the database span the five most recent IECC editions through net-zero energy performance. Additional options not included in previous versions of BIRDS are input alternatives for discount rate, home loan financing, and construction quality for a total of 8 cases. The 240000 designs across 8 cases (sets of assumptions) and 40 study periods allows for comparisons across over 75 million records to determine the effects of improving building energy efficiency on the overall sustainability performance.

The purpose of this study is to utilize similar methodology as that used in prior analysis of BIRDS databases to analyze the BIRDS low-energy residential database. Our analysis will entail making comparisons between a Maryland residential code-compliant design (based on 2015 IECC) serving as our baseline and a series of alternative designs at varying levels of energy efficiency based on energy, economic, and environmental performance. Findings from this study will shed light on the effects of incremental improvements in residential building energy efficiency, as well as the effects of varying the investor's time horizon and other assumptions, on overall sustainability performance.

Results are analyzed across a number of metrics. Energy performance is measured using the percent reduction in net energy consumption relative to the 2015 IECC baseline design. Economic performance is measured using total life-cycle costs (LCC), difference in LCC (if LCC are greater than the baseline), and net savings (when LCC are lower than the baseline). Additionally, the different components of LCC, first costs, future costs, and residual value are analyzed in detail. Environmental performance is measured using TRACI 2 environmental impact categories and a normalized weighted average of those impact categories. Energy, economic, and environmental comparisons are made across study period lengths, discount rates, construction quality, and financing options.

Pareto frontiers were developed for each of the 8 cases identified and 5 key building designs were selected based on different potential goals of a home purchaser: (1) minimize LCC, (2) maximize energy savings, (3) maximize energy savings without increasing LCC relative to the baseline design, and (4) minimize LCC while reaching net-zero energy performance. 
The most detailed analysis is completed for the initial set of assumptions, which assumes a $3 \%$ discount rate, "average" construction quality, and $100 \%$ all cash upfront purchase. Reaching higher levels of energy efficiency typically requires additional investments during construction in order to obtain future energy cost savings. The most energy efficient design leads to energy savings of $114 \%$ relative to the baseline design, which means there is excess electricity production that is sold back to the utility, although the design realizes LCC that are $\$ 4282$ greater than the baseline design. The higher first costs are not offset by the future energy cost savings. The most energy efficient design that has the same LCC as the baseline design realizes nearly the same level of energy savings $(113 \%)$ as the most energy efficient design, but at lower LCC ( $\approx \$ 0$ change in LCC compared to the baseline). The design that reaches net-zero energy performance at the lowest LCC realizes lower LCC than the baseline design by $\$ 10749$, implying that it is feasible to reach net-zero cost-effectively given the underlying assumptions. The design that leads to the lowest LCC leads to energy savings of $94 \%$ and LCC savings of $\$ 12344$ relative to the baseline design. Based on the underlying assumptions, it is possible to reach near net-zero performance cost-effectively.

Analysis for the other 7 cases focuses on how changing the 3 key assumptions impact the results. Some of the results vary depending on the combination of assumptions. However, even under the worse set of assumptions considered, the design that leads to the lowest LCC still leads to energy savings of $26 \%$ relative to the baseline design and the greatest energy savings for the same LCC as the baseline design is $78 \%$, showing that energy efficiency requirements in current energy codes can continue to be increased in a costeffective manner.

The selection of the construction quality impacts the first costs of a building design because increasing the quality of building components, such as high-end cabinets or trim, leads to greater construction costs. However, the quality of the construction is assumed to not impact the energy performance of a building design. As a result, changing the construction quality assumption from "average" to "luxury" leads to no change in the relative energy performance of the building design. Additionally, both the baseline design and the key design of interest realize the same increase in first costs while not impacting future costs. Therefore, the difference in LCC between the two designs remains the same regardless of the assumed construction quality.

Overall, a higher discount rate decreases the cost-competiveness of high levels of energy savings while financing a purchase through an 80/20 loan instead of $100 \%$ cash upfront increases the cost competitiveness of additional energy savings. The combination of the assumed discount rate and selected financing option has a significant impact on the energy and economic performance of the key designs considered in this study. For an all cash purchase, a higher discount rate decreases the energy savings for both the minimum LCC design and the design that realizes the greatest energy savings for the same LCC as 
the baseline design. Additionally, the minimum LCC design realizes a decreased net savings from \$12 344 to \$5904. While the energy savings for the most energy efficient design and the lowest LCC design that reaches net-zero energy performance are not impacted by the discount rate, the change in LCC is increased by over \$24 000 and $\$ 16000$, respectively. The lowest LCC design that reaches net-zero energy performance shifts from being cost-effective relative to the baseline design under a $3 \%$ discount rate to realizing higher LCC than the baseline under an $8 \%$ discount rate.

The impacts of increasing the discount rate differ under an 80/20 loan as the financing option. The impact of using a higher discount rate does not change the relative energy performance (less than $1 \%$ ) while increasing LCC for all designs. The most energy efficient design shifts from having lower LCC than the baseline design by $\$ 1097$ assuming a $3 \%$ discount rate to having higher LCC by $\$ 4130$ assuming a $3 \%$ discount rate. The minimum LCC design and design that reaches net-zero energy performance at the lowest LCC maintain lower LCC than the baseline design, although the net savings is decreased for both designs.

Another key factor that is not explicitly addressed in the case-by-case analysis and that impacts the economic performance of the key designs relative to the baseline is financial incentives for energy efficiency and renewable energy. The only incentive included in this analysis is the $30 \%$ federal tax credit for installing a solar PV system. However, the BIRDS low-energy residential database does not include any financial incentives at this time. This financial incentive, as well as others, should be included as options within future versions of BIRDS because they can have significant impacts on home purchasers.

The analysis in this study is limited in scope and would be strengthened by including sensitivity analysis and expanding the BIRDS database and metrics. Additional energy efficiency measures (EEMs), fuel types, discount rates, building constructions (e.g., wall types), and building types (e.g., single-story home or low-rise apartment building) would expand the scope of the database. Uncertainty analysis on these factors as well as other factors, such as occupancy and behavior patterns and financing options, should be considered in future analysis.

Energy, environmental, and economic performance are but three attributes of building performance. The BIRDS model assumes that its building prototypes all meet minimum technical performance requirements. However, there may be significant differences in technical performance not evaluated in BIRDS, such as indoor environmental quality performance, which may affect energy, environmental, and economic considerations.

The extensive BIRDS low-energy residential database can be used to answer many more questions than posed in this report, and is available to the public through BIRDS v3.0 that allows others access to the database for their own research on building energy efficiency and sustainability. 


\section{Introduction}

\subsection{Background}

Building stakeholders need practical metrics, data, and tools to support decisions related to sustainable building designs, technologies, standards, and codes. The Engineering Laboratory (EL) of the National Institute of Standards and Technology (NIST) has addressed this high priority national need by extending its metrics and tools for sustainable building products, known as Building for Environmental and Economic Sustainability (BEES), to entire buildings. These entire or "whole" building sustainability metrics have been developed based on innovative extensions to life-cycle assessment (LCA) and life-cycle costing (LCC) approaches involving whole-building energy simulations to address building sustainability measurement in a holistic, integrated manner that considers complex interactions among building materials, energy technologies, and systems across dimensions of performance, scale, and time. The measurement system evaluates the sustainability of both the materials and the energy used by a building over time. It assesses the "carbon footprint” of buildings as well as 11 other environmental performance metrics, and integrates economic performance metrics to yield science-based measures of the business case for investment choices in high-performance green buildings.

Building Industry Reporting and Design for Sustainability (BIRDS) applies the new sustainability measurement system to an extensive whole-building performance database NIST has compiled for this purpose. The energy, environmental, and cost data in BIRDS measure building operating energy use through detailed energy simulations, building materials use through innovative life-cycle material inventories, and building costs over time. The most recent version of BIRDS (v3.0) incorporated the energy, environmental, and cost measurements for 240000 residential building designs for a 2-story colonial house based on the NIST Net-Zero Energy Residential Test Facility (NZERTF) located in Gaithersburg, MD for study period lengths ranging from 1 year to 40 years. Focusing on a single location allows for consideration of incremental building energy efficiency improvements instead of the suite of energy efficiency requirements specified in the International Energy Conservation Code (IECC). Building design specifications included in the database span the five most recent IECC editions through net-zero energy performance. Additional options not included in previous versions of BIRDS are input alternatives for discount rate, home loan financing, and construction quality. The sustainability performance of buildings designed to meet current energy codes can be compared to a number of alternative building designs in an effort to determine the effects of improving building energy efficiency on the overall sustainability performance.

\subsection{Literature Review}

The U.S. Department of Energy (DOE), through DOE-funded national laboratories, is on the forefront of whole building energy simulation development, including reference building prototypes for both new and existing commercial and residential buildings. To meet statutory 
requirements, DOE tasks the Pacific Northwest National Laboratory (PNNL) with estimating the energy use and energy cost savings associated with the standard/code building requirements relative to a baseline edition for each new edition of ASHRAE 90.1 for commercial buildings and IECC for residential buildings. PNNL has also begun to incorporate some LCC estimates into their analysis.

Adopting newer editions of ASHRAE 90.1 for new commercial buildings leads to reductions in energy consumption and energy costs. PNNL (2009a) estimates the impacts for each state of adopting ASHRAE 90.1-2007 as the commercial building energy code relative to the state's current energy code, which vary across states. The annual energy use savings and energy cost savings are estimated for three Department of Energy (DOE) benchmark buildings -- a mediumsized office building, a non-refrigerated warehouse, and a mid-rise apartment building--for 97 cities located across the United States. Halverson et al. (2011a) estimates that, on average, adoption of ASHRAE 90.1-2007 reduces site energy by $4.6 \%$ relative to ASHRAE 90.1-2004. Halverson et al. (2011b) estimates an $18.5 \%$ reduction in site energy use, on average, from the adoption of ASHRAE 90.1-2010 relative to ASHRAE 90.1-2007 while Halverson et al. (2014) estimates a 7.6 \% reduction from building to meet ASHRAE 90.1-2013 relative to ASHRAE 90.12010 .

Adopting newer editions of IECC for new residential buildings leads to reductions in energy consumption and energy costs. PNNL (2009b) estimates the impact of adoption of 2009 IECC for residential buildings for each state relative to its current energy code, including a summary of the changes in energy efficiency construction requirements and the estimated energy use and energy cost savings. Lucas et al. (2012) estimates the energy and life-cycle cost savings for adoption of newer editions of the IECC across climates zones for a single-family dwelling and apartment building across different foundation types. Relative to 2006 IECC, the adoption of 2009 IECC and 2012 IECC leads to average reductions in energy costs of $11 \%$ and $32 \%$, respectively. Additionally, all climate zones realize reductions in life-cycle costs with the coldest climate zones realizing the greatest life-cycle cost savings and Zone 1 (maritime climate) realizing greater life-cycle cost savings than zones characterized as having hot-humid, hot-dry, mixed-dry, or mixed-humid climate conditions (Zone 2 through Zone 4).

Mendon et al. (2013) estimates the LCC effectiveness of 2009 IECC and 2012 IECC relative to 2006 IECC for 109 U.S. cities. Mendon et al. (2014) is the most recent PNNL analysis, looking at the impacts of 2015 IECC, which are found to lead to a minimal reduction (1.1\% on average) in energy use relative to 2012 IECC.

The National Association of Home Builders (NAHB) Research Center has completed similar analyses as those presented by PNNL. NAHB (2012a) develops a methodology to calculate energy performance in residential buildings, including simulation modeling assumptions for a "standard reference house" based on national average characteristics. NAHB (2012b) and NAHB (2012c) estimate the cost-effectiveness of constructing to meet 2009 IECC and 2012 IECC relative to 2006 IECC, respectively. Constructing to meet 2009 IECC reduces site energy 
consumption by $10.7 \%$ with an average payback period of 5.6 years. Constructing to meet 2012 IECC reduces site energy consumption by three times that of 2009 IECC (33.9\%), but has a higher average payback period of 10.4 years because the initial additional costs are much higher for building to meet 2012 IECC versus 2009 IECC.

NIST has expanded on the DOE and PNNL research by increasing the number of locations considered in its analysis, including life-cycle costing and life-cycle assessment results, and considering a range of study periods. Kneifel (2010) creates a framework to simultaneously analyze the impacts of improving energy efficiency on energy use, energy costs, life-cycle costs, and carbon emissions through an integrated design context for new commercial buildings. The paper compares the savings of constructing 11 prototype commercial buildings to meet the building envelope requirements of ASHRAE 90.1-2007 and a "Low Energy Case," relative to ASHRAE 90.1-2004, for 16 cities in different climate zones across the contiguous United States. The paper finds minimal improvements in energy efficiency from building to meet ASHRAE 90.1-2007 relative to ASHRAE 90.1-2004 while significant savings are found by building to meet the "Low Energy Case." The "Low Energy Case” is often cost-effective on a first cost basis and is always cost-effective over the longer study period lengths.

Kneifel (2011a) expands on the framework and analysis in Kneifel (2010) by analyzing the impact of adopting the building envelope requirements of ASHRAE 90.1-2007 and a "Low Energy Case" relative to ASHRAE 90.1-2004 in terms of energy use, energy costs, energy-related carbon emissions, and life-cycle costs for 228 cities across the U.S. with at least one city in each state. Analysis includes 4 study period lengths (1, 10, 25, and 40 years). The paper finds that, on average, the more energy efficient building designs are cost-effective. However, there is significant variation across states in terms of energy use savings and life-cycle cost-effectiveness driven by both climate and construction costs. There is also significant variation across cities within a state, even cities located within the same climate zone. These variations are a result of differences in local material and labor costs as well as energy costs.

Kneifel (2013a) analyzes 12540 whole-building energy simulations in the Building Industry Reporting and Design for Sustainability (BIRDS) database covering 11 building types in 228 cities across all U.S. states for 9 study period lengths (1, 5, 10, 15, 20, 25, 30, 35, and 40 years). Current state energy code performance is compared to the performance of alternative ASHRAE 90.1 Standard editions to determine whether more stringent energy standard editions are costeffective in reducing energy consumption and energy-related carbon emissions. This analysis includes a "Low Energy Case” (LEC) building design based on ASHRAE 189.1-2009, which increases energy efficiency beyond the ASHRAE 90.1-2007 design. Results are analyzed in detail for the ASHRAE 90.1-2007 and LEC designs. Results are aggregated at the state level for seven states (Alaska, Colorado, Florida, Maryland, Oregon, Tennessee, Wisconsin) to estimate the magnitude of total energy use savings, energy cost savings, life-cycle cost savings and energyrelated carbon emissions reductions that could be attained by adoption of a more stringent state energy code for commercial buildings. 
Kneifel (2013b), Kneifel (2013c), Kneifel (2013d), and Kneifel (2013e) implement the analysis approach developed in Kneifel (2013a) for an individual state and analyze each state in the Northeast, Midwest, South, and West Census Regions, respectively. The results for each state, both on a percentage and aggregate basis, are compared across the Census Region to determine the driving factors for variation across states in the relative impacts of adopting more stringent state energy codes. The results are aggregated to the Census Region level to estimate the total region-wide impacts. Kneifel (2013f) analyzes the results developed in Kneifel (2013a, 2013b, 2013c, 2013d, 2013e) from the BIRDS new commercial database, and summarizes the results into the key nationwide trends and important interpretations for energy efficiency in new commercial buildings.

In a later study, the authors analyzed 9120 whole-building energy simulations in the Building Industry Reporting and Design for Sustainability (BIRDS) new residential database. The database covers 10 building types in 228 cities located across the U.S. for 9 study periods. The performance of buildings designed to meet current state residential energy codes is compared to their performance when meeting 2012 IECC requirements for their state. Research findings show that stricter state energy codes lead to cost-effective reductions in energy use and life-cycle carbon emissions. Estimated savings for each building type were aggregated up to both the state and national levels using city-level new residential building construction data. The report suggested that for a 10-year study period, nationwide adoption of the 2012 IECC may generate sizeable average reductions in energy use, energy costs, life-cycle carbon emissions, and lifecycle costs of $19.2 \%, 15.2 \%, 11.2 \%$, and $1.7 \%$, respectively (Kneifel and O'Rear 2015b).

In work related to the analysis completed in this study, Kneifel and O'Rear (2015) compared the sustainability performance (energy, economic, and environmental) metrics of the NIST NZERTF design to a 2015 IECC compliant building design using whole-building energy simulation, lifecycle costing, and life-cycle impact assessment. Additionally, a preliminary analysis was conducted to evaluate the impacts of incrementally adopting energy-efficient measures on a building design's sustainability performance.

\subsection{Purpose}

The purpose of this study is to utilize a similar methodology as that used in Kneifel and O'Rear (2015) to analyze the BIRDS low-energy residential database. Our analysis will entail making comparisons between a 2015 IECC compliant residential design serving as our baseline and a series of alternative designs at varying levels of energy efficiency based on energy, economic, and environmental performance. Findings from this study will shed light on the effects of incremental improvements in building energy efficiency, as well as varying the investor's time horizon and other assumptions, on overall sustainability performance. 


\subsection{Approach}

This study uses the BIRDS low-energy residential database to observe the sustainability performance of alternative residential building designs. The low-energy residential database is a compilation of whole-building energy simulations, building construction cost data, maintenance, repair, and replacement rates and costs, and environmental flows data for 240000 designs based on NIST's NZERTF in Gaithersburg, MD. The analysis compares the performance of a 2015 IECC compliant residential design to the performance of alternative building designs at differing levels of energy efficiency to reveal the potential for savings in energy use, environmental impact reductions, and differences in life-cycle costs stemming from incremental improvements in energy efficiency.

Results are analyzed across a number of metrics. Energy performance is measured using the percent reduction in net energy consumption relative to the 2015 IECC baseline design. Economic performance is measured using total LCC, difference in LCC (if LCC are greater than the baseline), and net savings (when LCC are lower than the baseline). Additionally, the different components of LCC, first costs, future costs, and residual value are analyzed in detail. Environmental performance is measured using TRACI 2 environmental impact categories and a normalized weighted average of those impact categories. Energy, economic, and environmental comparisons are made across study period lengths, discount rates, construction quality, and financing options. 


\section{BIRDS Low-Energy Residential Database}

The operating energy component of the BIRDS low-energy residential database was built following the framework developed in Kneifel (2010) and further expanded in Kneifel (2013a), Kneifel (2013b), and Kneifel et al (2016). The BIRDS new low-energy residential database includes the results of 240000 incremental whole-building energy simulations covering requirements defined in the five most recent IECC editions (2003, 2006, 2009, 2012, and 2015), the NIST NZERTF, and incremental energy efficiency measures (EEMs) across 40 study period lengths. The assumed location in all simulations is Gaithersburg, MD.

\subsection{Alternative Design Options related to the Building Envelope}

The new low-energy database offers alternative energy efficiency options for each aspect of the building envelope. Table 2-1 lists the construction options for the roof, ceiling, wall, and foundation. Five options are available for exterior wall construction. The first two use common practice or "typical" framing, which uses $5.1 \mathrm{~cm} \mathrm{x} 10.2 \mathrm{~cm}-40.6 \mathrm{~cm}$ (2 in x 4 in - 16 in) on center (OC) framing. The last three use "advanced framing" which uses $5.1 \mathrm{~cm}$ x $15.2 \mathrm{~cm}-61.0$ $\mathrm{cm}$ (2 in x 6 in - 24 in) OC framing. The thicker framing allows for greater levels of insulation within the wall cavity while reducing the linear feet of framing, leading to less thermal transfer. Option 2, Option 4, and Option 5 use both blown-in insulation in the wall cavity and rigid insulation on the exterior of the wall, with the overall level of thermal resistance increasing from option to option. Four combinations are available for the basement wall and basement slab constructions, which include $\mathrm{R}_{\mathrm{SI}^{-}}-1.4(\mathrm{R}-8), \mathrm{R}_{\mathrm{SI}^{-}}-1.8$ (R-10), and $\mathrm{R}_{\mathrm{SI}^{-}}-3.9$ (R-22) for the wall and $\mathrm{R}_{\mathrm{SI}^{-}}-0$ (R-0) and $\mathrm{R}_{\mathrm{SI}^{-}}-1.8$ (R-10) for the slab, the last of which is only available in combination with the $\mathrm{R}_{\mathrm{SI}}-3.9$ (R-22) wall insulation. For the roof/ceiling assembly, Option 1 and Option 2 use blow-in insulation on the attic floor. ${ }^{1}$ The remaining three options install insulation in the roof assembly. Blown-in cellulose insulation is used in the rafters, while rigid insulation is added to the exterior of the roof.

\footnotetext{
${ }^{1}$ Ductwork is assumed to be entirely within the conditioned space (not located in the attic) for all building designs.
} 
Table 2-1 Constructions - Roof, Ceiling, Wall and Foundation

\begin{tabular}{llccccc}
\multicolumn{2}{l}{ Wall Constructions } & Option $\mathbf{1}$ & Option 2 & Option 3 & Option 4 & Option 5 $\dagger$ \\
\cline { 2 - 7 } Exterior Wall & Framing & Typical & Typical & Advanced & Advanced & Advanced \\
\cline { 2 - 7 } & Insulation & $\mathrm{R}_{\mathrm{SI}}-2.3$ & $\mathrm{R}_{\mathrm{SI}}-2.3+0.9$ & $\mathrm{R}_{\mathrm{SI}}-3.5$ & $\mathrm{R}_{\mathrm{SI}}-3.5+2.1$ & $\mathrm{R}_{\mathrm{SI}}-3.5+4.2$ \\
& $(\mathrm{R}-13)$ & $(\mathrm{R}-13+5) *$ & $(\mathrm{R}-20)$ & $(\mathrm{R}-20+12) *$ & $(\mathrm{R}-20+24)^{*}$ \\
\hline
\end{tabular}

* Interior Wall Cavity + Exterior Continuous Insulation; †NZERTF Design

\begin{tabular}{|c|c|c|c|c|c|}
\hline \multicolumn{2}{|c|}{ Foundation Constructions } & Option 1 & Option 2 & Option 3 & Option $4 \dagger$ \\
\hline \multirow[t]{2}{*}{ Basement } & Wall & $\begin{array}{c}\mathrm{R}_{\mathrm{SI}}-1.41 \\
\text { (R-8) }\end{array}$ & $\begin{array}{c}\mathrm{R}_{\mathrm{SI}}-1.76 \\
(\mathrm{R}-10)\end{array}$ & $\begin{array}{l}\mathrm{R}_{\mathrm{SI}}-3.9 \\
(\mathrm{R}-22)\end{array}$ & $\begin{array}{l}\mathrm{R}_{\mathrm{SI}}-3.9 \\
(\mathrm{R}-22)\end{array}$ \\
\hline & Slab & $\begin{array}{l}\mathrm{R}_{\mathrm{SI}}{ }^{-0} \\
(\mathrm{R}-0)\end{array}$ & $\begin{array}{l}\mathrm{R}_{\mathrm{SI}^{-}}-0 \\
(\mathrm{R}-0)\end{array}$ & $\begin{array}{l}\mathrm{R}_{\mathrm{SI}}{ }^{-0} \\
(\mathrm{R}-0)\end{array}$ & $\begin{array}{l}\mathrm{R}_{\mathrm{SI}}-1.8 \\
(\mathrm{R}-10)\end{array}$ \\
\hline
\end{tabular}

†NZERTF Design

\begin{tabular}{|c|c|c|c|c|c|c|}
\hline \multicolumn{2}{|c|}{ Roof/Ceiling Constructions } & Option 1 & Option 2 & Option 3 & Option 4 & Option $5 \dagger$ \\
\hline \multirow[t]{2}{*}{ Roof/Ceiling } & Roof & $\mathrm{R}_{\mathrm{SI}^{-}}-0$ & $\mathrm{R}_{\mathrm{SI}^{-}}-0$ & $\begin{array}{l}\mathrm{R}_{\mathrm{SI}^{-}}-7.92+0.7 \\
(\mathrm{R}-45+4)^{* *}\end{array}$ & $\begin{array}{c}\mathrm{R}_{\mathrm{SI}}-7.92+2.64 \\
(\mathrm{R}-45+15)^{* *}\end{array}$ & $\begin{array}{c}\mathrm{R}_{\mathrm{SI}}-7.92+5.28 \\
(\mathrm{R}-45+30) * *\end{array}$ \\
\hline & Ceiling & $\begin{array}{c}\mathrm{R}_{\mathrm{SI}^{-}}-6.69 \\
\text { (R-38) }\end{array}$ & $\begin{array}{c}\mathrm{R}_{\mathrm{SI}}-8.63 \\
(\mathrm{R}-49)\end{array}$ & $\mathrm{R}_{\mathrm{SI}^{-}}-0$ & $\mathrm{R}_{\mathrm{SI}^{-}}-0$ & $\mathrm{R}_{\mathrm{SI}^{-}}-0$ \\
\hline
\end{tabular}

** Insulation in the Rafters + Exterior Roof Insulation; †NZERTF Design

As shown in Table 2-2, the low-energy database offers 8 different options for window specifications based on three parameters: U-factor, Solar Heat Gain Coefficient (SHGC), and Visible Transmittance (VT). This approach allows the rated window performance to be modeled while simplifying window materials and constructions in the simulation. Window parameter values are based on minimum requirements specified in editions of the IECC and Building Science Corporation (BSC) window specifications for the NZERTF. ${ }^{2}$

Table 2-2 Window Design Options

\begin{tabular}{|lcccccc|} 
Parameter & Units & Option & Option & Option & Option & Option \\
& & $\mathbf{1}$ & $\mathbf{2}$ & $\mathbf{3}$ & $\mathbf{4}$ & $\mathbf{5}$ \\
\hline U-Factor* & $\mathrm{W} / \mathrm{m}^{2}-\mathrm{K}$ & 2.57 & 2.28 & 2.00 & 2.00 & 1.14 \\
& $\left(\mathrm{Btu} / \mathrm{h} \cdot \mathrm{ft}^{2}-\mathrm{F}\right)$ & $(0.45)$ & $(0.40)$ & $(0.35)$ & $(0.35)$ & $(0.20)$ \\
\hline SHGC & Fraction & 0.60 & 0.60 & 0.60 & 0.40 & 0.25 \\
\hline VT & Fraction & 0.40 & 0.40 & 0.40 & 0.40 & 0.40 \\
\hline †NZERTF Design & & & & & \\
\hline
\end{tabular}

\footnotetext{
${ }^{2}$ Using these parameters assumes no difference in performance regardless of the window type (awning or double hung).
} 
Three options are available for infiltration or air leakage rates (expressed in air changes per hour at $50 \mathrm{~Pa}\left(\mathrm{ACH}_{50}\right)$ using blower door test) as shown in Table 2-3. Option 1 is based on 2009 IECC, which sets the maximum for Maryland's climate to be $7.00 \mathrm{ACH}_{50}$. Note that 2003 IECC and 2006 IECC set no maximum limit on air leakage and assumed to have the same requirement as 2009 IECC for the purpose of this study. Option 2 and Option 3 assume infiltration rates of 3.00 ACH based on 2012 IECC and 0.63 ACH based on the measured air leakage of the NZERTF, respectively. For simulation purposes, the air changes per hour are converted to a measure of effective leakage area (ELA) and split between the two conditioned floors of the building design based on the fractional volume associated with each floor.

\section{Table 2-3 Air Leakage Rate Design Options}

\begin{tabular}{lccc} 
Design Option & \multicolumn{3}{c}{ Assumed ELA (cm²) } \\
\hline $\begin{array}{l}\text { Option 1 } \\
\text { (2003 \& 2006 / 2009 IECC) }\end{array}$ & No Maximum / 7.00 & 1473.3 & 1343.3 \\
\hline $\begin{array}{l}\text { Option 2 } \\
\text { (2012/2015 IECC) }\end{array}$ & 3.00 & 403.6 & 368.1 \\
\hline $\begin{array}{l}\text { Option 3 } \\
\text { (NZERTF) }\end{array}$ & 0.63 & 132.6 & 120.9 \\
\hline
\end{tabular}

\subsection{Alternative Design Options related to Building Lighting Systems and Interior Equipment}

Table 2-4 shows the four different options available for lighting. Each option is described in terms of overall minimum efficiency level and the required lighting wattage for each floor. Wattage by floor varies by the fraction of light fixtures that use high efficiency bulbs. The different lighting efficiency options are based on a "typical/baseline” lighting mix from Hendron and Engebrecht (2010), requirements defined in editions of the IECC, and the NZERTF. For additional details on the interior lighting design options, refer to Kneifel et al. (2016).

Table 2-4 Lighting Wattage Design Options

\begin{tabular}{lcccc} 
& \multicolumn{3}{c}{ Watts (W) by Floor by Lighting Option } \\
& $\begin{array}{c}\text { Option 1 } \\
\mathbf{( 2 0 0 3 / 2 0 0 6 )}\end{array}$ & $\begin{array}{c}\text { Option 2 } \\
\mathbf{( 2 0 0 9 )}\end{array}$ & $\begin{array}{c}\text { Option 3 } \\
(\mathbf{2 0 1 2 / 2 0 1 5 )}\end{array}$ & $\begin{array}{c}\text { Option 4 } \\
\text { (NZERTF) }\end{array}$ \\
\hline Fraction Efficient Lighting & $34 \%$ & $50 \%$ & $75 \%$ & $100 \%$ \\
\hline $\mathbf{1}^{\text {st }}$ Floor Total Wattage & 142 & 113 & 94 & 80 \\
\hline $\mathbf{2}^{\text {nd }}$ Floor Total Wattage & 147 & 118 & 98 & 83 \\
\hline
\end{tabular}

Two design options are available for heating and cooling systems in the low-energy database. As described in Table 2-5, Option 1 is the "standard efficiency" system that meets the minimum 
federal efficiency and IECC requirements. It is a minimum efficiency air-to-air heat pump, with a Seasonal Energy Efficiency Ratio (SEER) of 13 for cooling mode, a Heating Seasonal Performance Factor (HSPF) of 7.7 for heating mode, and dedicated outdoor air mechanical ventilation through the central air ductwork to meet minimum ventilation required by ASHRAE 62.2-2010. The second option includes a multispeed air-to-air heat pump with dehumidification-only mode, and SEER and HSPF ratings of 15.8 and 9.05, respectively. Dedicated outdoor air ventilation is delivered through a Heat Recovery Ventilator (HRV) using a separate set of ductwork, which provides outdoor air to meet ASHRAE 62.2 specifications while minimizing the thermal load impacts of the outdoor air entering the building. Both options include a supplemental electric resistance heating element with an efficiency of 0.98 . Its purpose is to supplement the heat pump when the heat pump cannot satisfy household thermal loads. See Kneifel et al. (2016) for additional details on the components of each HVAC system option.

\section{Table 2-5 Heating and Cooling Equipment Design Options}

\begin{tabular}{lll}
\multirow{2}{*}{$\begin{array}{c}\text { Design Option } \\
\text { Option 1 }\end{array}$} & Type \& Efficiency & Air-to-air heat pump (SEER 13/HSPF 7.7) \\
\cline { 2 - 3 } & Ventilation & Min. Outdoor Air $(0.04 \mathrm{m3} / \mathrm{s})$ \\
\hline \multirow{2}{*}{ Option 2† } & Type \& Efficiency & Air-to-air heat pump w/dehumidification (SEER 15.8/HSPF 9.05) \\
\cline { 2 - 3 } & Ventilation & Separate HRV system $\left(0.04 \mathrm{~m}^{3} / \mathrm{s}\right)$ \\
\hline †NZERTF Design & \\
\hline
\end{tabular}

Table 2-6 shows the alternative design options for the domestic hot water (DHW) system. Option 1 includes an installed 189 L (50 gal) "standard" electric water heater with an efficiency of 0.95. Option 2 includes an air-to-water heat pump water heater with a Coefficient of Performance (COP) of 2.36. The third design option combines the electric water heater from Option 1 with a two-panel solar thermal system. The closed-loop solar thermal system uses a 50/50 water/glycol mix to indirectly heat the water in a 302.8 L (80 gal) storage tank through a heat exchanger. The standard efficiency electric water heater then draws water from the storage tank and will further heat the water if necessary to meet the target exit temperature. The fourth and final option has a similar setup as Option 3, except the electric water heater is replaced by the heat pump water heater. For additional details on the components of the DHW system, refer to Kneifel (2012), Kneifel (2015), and Kneifel et al. (2015). 
Table 2-6 Domestic Hot Water System Design Options

\begin{tabular}{lll}
\multirow{2}{*}{$\begin{array}{l}\text { Design Option } \\
\text { Option } 1\end{array}$} & Water Heater & System Components \\
\cline { 2 - 3 } & Solar Thermal System & None \\
\hline \multirow{2}{*}{ Option 2} & Water Heater & 189 L (50 gal) heat pump water heater (COP 2.36) \\
\cline { 2 - 3 } & Solar Thermal System & None \\
\hline Option 3 & Water Heater & 189 L (50 gal) electric water heater $(0.95$ efficiency) \\
\cline { 2 - 3 } & Solar Thermal System & 2 panel, 302.8 L (80 gal) solar thermal storage tank \\
\hline Option 4† & Water Heater & 189 L (50 gal) heat pump water heater (COP 2.36) \\
\cline { 2 - 3 } & Solar Thermal System & 2 panel, 302.8 L (80 gal) solar thermal storage tank \\
\hline †NZERTF Design &
\end{tabular}

The five options shown in Table 2-7 for the roof-mounted solar photovoltaic (PV) system are included in the low-energy residential database: $0.0 \mathrm{~kW}, 2.5 \mathrm{~kW}, 5.1 \mathrm{~kW}, 7.6 \mathrm{~kW}$, and $10.2 \mathrm{~kW}$. Each of the options is based on the system installed on the roof of the NZERTF, which includes 4 horizontal rows of eight $320 \mathrm{~W}$ panels with two inverters. The five options are based on the removal of one string at a time until no strings are installed with adjustments to the number and size of the inverters accordingly. The assumed degradation rate of solar PV production is $0.5 \%$ annually. Refer to Kneifel (2012) and Kneifel et al. (2015) for additional details on the solar PV systems.

Table 2-7 Solar Photovoltaic System Options

\begin{tabular}{|cc|}
\hline Design Option & System Size (kW) \\
\hline Option 1 & 0 \\
\hline Option 2 & 2.5 \\
\hline Option 3 & 5.1 \\
\hline Option 4 & 7.6 \\
\hline Option 5 & 10.2 \\
\hline
\end{tabular}

\subsection{Baseline Building Design Specifications}

Conducting this analysis requires a comparison to be made across thousands of building designs within the low-energy database relative to some baseline building design. Because the database considers buildings for Gaithersburg, MD, our baseline building is representative of typical construction for the area. Maryland's current building code is based on 2015 IECC. Therefore, the prescriptive path requirements from 2015 IECC are used to define the components of our baseline building design. From this point on, the baseline building design will be referred to as the "Maryland Code-Compliant” or MCC design. 
Specifications for the MCC building design are listed in Table 2-8, including efficiency requirements for the building envelope and building systems. Typical framing with $\mathrm{R}_{\mathrm{SI}}-2.3(\mathrm{R}-$ 13) batt insulation in the wall cavity with an additional $\mathrm{R}_{\mathrm{SI}^{-}}-0.9$ (R-5) of rigid insulation on the exterior of the wall is assumed to be the exterior wall construction. The second floor ceiling (attic floor) is insulated with $\mathrm{R}_{\mathrm{SI}^{-}}-8.6$ (R-49) of blown-in cellulose insulation. Building windows have a U-factor and SHGC of $1.99 \mathrm{~W} / \mathrm{m}^{2}-\mathrm{K}\left(0.35 \mathrm{Btu} / \mathrm{h} \cdot \mathrm{ft}^{2}-\mathrm{F}\right)$ and 0.40 , respectively. The 2015 IECC allows a maximum air change rate of $3.00 \mathrm{ACH}_{50}$ for locations located in Climate Zone 4 (i.e., Gaithersburg, MD). The air change rate has been converted to an effective leakage area (ELA) and split between the first and second floors (conditioned spaces) according to the fractional volumes for each.

Table 2-8 Design Specifications for MCC Building Simulation

\begin{tabular}{|c|c|c|}
\hline $\begin{array}{l}\text { Building } \\
\text { Category }\end{array}$ & Specifications & MCC \\
\hline Windows & $\begin{array}{l}\text { U-Factor } \\
\text { SHGC }\end{array}$ & $\begin{array}{c}1.99 \mathrm{~W} / \mathrm{m}^{2}-\mathrm{K}\left(0.35 \mathrm{Btu} / \mathrm{h} \cdot \mathrm{ft}^{2}-\mathrm{F}\right) \\
0.40\end{array}$ \\
\hline $\begin{array}{c}\text { Framing and } \\
\text { Insulation }\end{array}$ & $\begin{array}{c}\text { Framing } \\
\text { Exterior Wall } \\
\text { Basement Wall } \\
\text { Basement Floor } \\
\text { Roof/Ceiling Assembly }\end{array}$ & $\begin{array}{c}5.1 \mathrm{~cm} \mathrm{x} 10.2 \mathrm{~cm}-40.6 \mathrm{~cm} \mathrm{OC} \mathrm{(2} \mathrm{in} \mathrm{x} 4 \text { in }-16 \text { in OC) } \\
\mathrm{R}_{\mathrm{SI}^{-}}-3.5 \text { or } \mathrm{R}_{\mathrm{SI}^{-}}-2.3+0.9(\mathrm{R}-20 \text { or } \mathrm{R}-13+5) * \dagger \\
\mathrm{R}_{\mathrm{SI}}-1.8(\mathrm{R}-10) \dagger \\
\mathrm{R}_{\mathrm{SI}}-0(\mathrm{R}-0) \dagger \\
\text { Ceiling: } \mathrm{R}_{\mathrm{SI}^{-}}-8.6(\mathrm{R}-49)\end{array}$ \\
\hline $\begin{array}{l}\text { Air Change } \\
\text { Rate }\end{array}$ & $\begin{array}{c}\text { Air Change Rate - Blower Door Test } \\
\text { Effective Leakage Area }\end{array}$ & $\begin{array}{c}3.00 \mathrm{ACH}_{50} \\
1^{\text {st }} \text { Floor }=403.6 \mathrm{~cm}^{2}\left(62.6 \mathrm{in}^{2}\right) \\
2^{\text {nd }} \text { Floor }=368.1 \mathrm{~cm}^{2}\left(57.1 \mathrm{in}^{2}\right)\end{array}$ \\
\hline Lighting & Efficient Lighting (\%) & $75 \%$ efficient built-in fixtures \\
\hline HVAC & $\begin{array}{l}\text { Heating/Cooling } \\
\text { Outdoor Air** }\end{array}$ & $\begin{array}{l}\text { Air-to-air heat pump (SEER 13/HSPF 7.7) } \\
\text { Min. Outdoor Air (0.04 m3/s) }\end{array}$ \\
\hline $\begin{array}{l}\text { Domestic Hot } \\
\text { Water }\end{array}$ & $\begin{array}{l}\text { Water Heater } \\
\text { Solar Thermal }\end{array}$ & 50 gal (189 L) electric water heater (0.95 efficiency) \\
\hline \multicolumn{3}{|c|}{$\begin{array}{l}\text { * Interior Wall Cavity + Exterior Continuous Insulation } \\
\text { ** Minimum outdoor air requirements are based on ASHRAE 62.2-2010 } \\
\text { † Units: } \mathbf{m}^{2} \mathrm{~K} / \mathbf{W}\left(\mathrm{ft}^{2} \mathrm{~F} /[\mathrm{Btu} / \mathrm{h}]\right)\end{array}$} \\
\hline
\end{tabular}

Based on requirements for lighting efficiency, 75 \% of the MCC design's built-in lighting fixtures are high-efficiency, using linear fluorescent, compact fluorescent (CFL), and light emitting diode (LED) bulbs. Heating and air conditioning demands are satisfied using a federal minimum efficiency air-to-air heat pump with a SEER rating and HSPF of 13 and 7.7, respectively. The MCC design provides constant dedicated outdoor air through the HVAC system to maintain indoor air quality requirements. The domestic hot water system includes a $189 \mathrm{~L}$ (50 gal) electric water heater with an efficiency of 0.95 . 


\subsection{Study Period Lengths}

Forty study period lengths are available for BIRDS v3.0 users, allowing for different ownership investment time horizons. A 1-year study period is representative of a developer who intends to sell a property soon after it is constructed. A 5-year to 15-year study period best represents most homeowner's time horizon because few owners are concerned about costs realized beyond a decade into the future. The 20-year to 40-year study periods better represent homeowners who intend for the house to be their long-term or "final" home. BIRDS sets the maximum study period at 40 years for consistency with requirements for federal building life-cycle cost analysis defined in the Energy Independence and Security Act of 2007. The longer the study period, technological obsolescence becomes a more significant issue, data becomes less certain, and costs realized towards the end of the study period become significantly discounted. For the analysis in this study, five study periods are considered: 1 year, 10 years, 20 years, 30 years, and 40 years.

\subsection{Discount Rate}

Discount rates account for the time-value of money in LCC analysis by converting all future costs associated with a building's operation and maintenance, repair, and replacement, to present value dollars. BIRDS v3.0 includes the option for either a $3 \%$ discount rate or an $8 \%$ discount rate. The $3 \%$ rate is based on 10-year Treasury note yields, and the Department of Energy's accepted discount rate for evaluating federal energy conservation projects. The $8 \%$ discount rate better represents the long-run real (inflation adjusted) rate of return from investments in equities. Moving from a lower discount rate to a higher one leads to future costs being valued less relative to initial costs.

\subsection{Construction Quality}

BIRDS v3.0 now considers two types of construction quality as defined in RSMeans (2015), average and luxury. Residential buildings of luxury construction quality typically offer more amenities than those that are average quality. For example, compared to average construction, luxury homes are likely to have more hardwood floors throughout, granite countertops in the kitchen, and luxury grade kitchen cabinets. The workmanship and the materials used by the construction company will be of luxury quality as well. In BIRDS, differences in construction quality only affect the first cost component of the total life-cycle cost measure because there is no impact on the operating energy performance of the building design in the analysis.

\subsection{Financing Options}

Two financing options are available in BIRDS v3.0. The first option is a full cash purchase where the building is paid for upfront without any financing. The other is an $80 \%$ financing option where the homeowner receives a loan at $4.88 \%$ APR (Annual Percentage Rate) for $80 \%$ 
of the initial investment cost of the building, and is responsible for providing a $20 \%$ down payment upfront. 


\section{Analysis Approach}

The analysis of the new BIRDS Low-Energy Residential Database in this report compares the baseline single-family dwelling (i.e., MCC design) to more energy-efficient design alternatives based on the three primary aspects of building sustainability performance: energy consumption, economics, and environmental impacts. Because the MCC design serves as the baseline building, all design alternatives that are less energy-efficient than the baseline are excluded for the analysis. This exclusion was done for two reasons: (1) this approach simplifies the analysis; and (2) the building community is largely interested in reducing energy used by buildings. Consideration will not likely be given for those designs that are less energy-efficient.

\subsection{Net Energy Consumption}

The annual net energy performance for each of the 240000 building designs is computed using the EnergyPlus v8.3 whole-building simulation software and JEPlus parametric simulation tool. The annual net energy consumption (total energy consumption minus total on-site energy production) of the baseline (MCC) design is compared to more energy efficient building designs. ${ }^{3}$ This comparison reveals the annual new energy savings earned from incrementally changing aspects of 10 different building components, including building envelope and systems. For example, the MCC design uses high-efficiency lighting in only $75 \%$ of its built-in lighting fixtures. A comparison across design alternatives might compare its energy use to that of an almost identical building design incorporating $100 \%$ efficient lighting.

For simplicity, it is assumed that all buildings maintain their energy efficiency throughout the study period. In other words, annual energy consumption remains constant over the study period. We believe this assumption to be reasonable given that the costs of maintaining the building, along with regularly maintaining and replacing the building's systems, are reflected in the analysis. However, the on-site energy production by the solar PV system does change over time based on a constant annual performance degradation rate of $0.5 \%$ over the system's lifetime.

\subsection{Economic}

\subsubsection{Economic Metrics}

The economic performance of each building design is evaluated using life-cycle cost (LCC) methodology as defined in Handbook 135 (Fuller and Petersen 1996). The LCC for a building accounts for all costs of constructing, operating, and disposing of a building for a given study period length. This report summarizes an economic evaluation using three primary LCC metrics: LCC, net savings (NS), and discounted payback (DPB). In calculating LCC, the sum of the costs $\left(C_{t}\right)$ realized in each year $(t)$ of the study period $(N)$ is discounted using discount rate $d$ into

\footnotetext{
${ }^{3}$ Net energy consumption and the associated LCC analysis assumes net metering for electricity consumption and production.
} 
present value terms as shown in Equation 1. When comparing a baseline building design to some alternative, the design with the lower LCC is the more cost-effective alternative.

$$
L C C=\sum_{t=0}^{N} \frac{C_{t}}{(1+d)^{t}}
$$

Building LCCs can also be expressed based on its individual components as shown in Equation (2). In this equation, LCC is the sum of the present value initial investment costs $(I)$ plus present value energy-related operating costs $(E)$ plus present value non-energy related maintenance, repair, and replacement costs (MMR) minus the present value of the building's residual value $(R V)$. The RV refers to the value of the building and its components at the end of the study period.

$$
L C C=I+E+M R R-R V
$$

Net savings (NS) is a supplementary measure of economic evaluation used to compare the cost-effectiveness of one project over another. As shown in Equation (3), it is the difference between the LCC for the baseline building $\left(L C C_{M C C}\right)$ and the LCC for the design alternative $\left(L C C_{i}\right)$. A NS greater than zero implies that the design alternative $i$ is preferable to the baseline case.

$$
N S_{i}=L C C_{M C C}-L C C_{i}
$$

Another supplemental measure of economic evaluation is the discounted payback. Discounted payback, or DPB, is the time needed to recover all initial investment costs taking into account the time value of money. It is generally used in decision analysis in comparing a baseline project to some alternative. The project that recovers its costs in the shortest period of time is deemed the better project. Equation (4) shows that the modified payback period $(y)$ for a given project alternative is found by comparing the total discounted savings associated with the alternative with the initial investment costs $\left(\Delta I_{0}\right)$ associated with the alternative. Savings in each year $t$ refers to the difference between operational cost savings $\left(S_{t}\right)$ and any additional investmentrelated costs $\left(\Delta I_{t}\right)$. For this analysis, $\left(S_{t}-\Delta I_{t}\right)$ is the sum of the discounted present value of all operating energy costs and maintenance, repair, and replacement costs for year $t$. For additional details on the economic evaluation measures, see Fuller and Petersen (1996)

$$
\sum_{t=1}^{y} \frac{\left(S_{t}-\Delta I_{t}\right)}{(1+d)^{t}} \geq \Delta I_{0}
$$

The economic analysis performed in this study utilizes the three aforementioned LCC measures to reveal the economic viability of a number of building design options depicted in the BIRDS Low-Energy Residential Database. It also considers the implications of varying the assumptions for discount rates, financing options, construction quality, and study period lengths.

\subsubsection{Matching Analysis to BIRDS version 3.0 Tool}


While the analysis herein focused on the inclusion of the Solar Investment Tax Credit (ITC) assuming a rational actor, the BIRDS database does not. This decision is primarily due to the fact that the ITC extension prescribes a ramping down of the tax credit. In order to keep BIRDS flexible, it makes sense to use the raw values absent the tax credit and allow users to apply any incentives on their own. Future versions of BIRDS will include a tax credit option, however, it is possible to obtain such a dataset from the BIRDS 3.0 database. The tax credit is assumed to be applied at year zero, making it an upfront cost reduction that is not affected by discount rate.

Only the assumed cost of the solar PV system per Watt needs to be known and the assumed $30 \%$ tax credit can be applied. For BIRDS 3.0 the assumed solar PV system installation cost, which includes all aspects of the installation, is \$3.90 per Watt (Barbose and Darghouth 2015). In order to bring the BIRDS reported values to match those in this analysis the following formula can be used:

$$
L C C_{\text {Tax Credit }}=L C C_{\text {No Tax Credit }}-0.3 * \$ 3.90 / \text { Watt } * \text { Installed Wattage }
$$

For example, the BIRDS output for the LCC of the most efficient design is \$182 877 for a 10year study period and Case 1 economic variables. Using the above formula, the LCC with the tax credit included is as follows:

$$
L C C_{\text {Tax Credit }}=\$ 184675-0.3 * \$ 3.90 / \text { Watt } * 10200=\$ 172741
$$

The BIRDS tool allows users to download a “.csv” file containing all results for the selected designs, allowing easy manipulation of the entire data set when using the appropriate software. Note the large number of calculations and the fact inputs are stored in ".csv" files and converted to floating point precision during runtime means minor rounding and precision errors can accrue. These errors are minimal when compared to the scale of the results.

\subsection{Environmental Impacts}

As in the previous versions of BIRDS, the new low-energy database assesses the environmental impact performance of a building design based on a hybrid life-cycle assessment (LCA) approach. This hybrid approach combines "bottom-up,” processed based environmental flow data with "top-down" input-output environmental flow data to compute the environmental flows over the building's life-cycle (Suh and Lippiatt 2012). The environmental flows (non-energyrelated flows) for the baseline design (i.e., MCC) are estimated using the input-output environmental flows, which are expressed as a flow per dollar. According to Equation (5), the flows for the baseline design $\left(L C A_{M C C, i}\right)$ are calculated by multiplying the baseline construction costs $\left(\right.$ Const $\left._{M C C}\right)$ and the maintenance, repair, and replacement costs $\left(M R R_{M C C}\right)$ over the study period by the associated flows (Flow/\$), indexed on $i$ (an array of 12 environmental impact categories).

$$
L C A_{M C C, i}=\text { Const }_{M C C} * \text { Flow } / \$_{\text {Const }, i}+M R R_{M C C} * F l o w / \$ M R R, i
$$


Bottom-up, processed-based LCA data are used to derive the environmental flows associated with changes to the baseline building's envelope and/or systems that are captured by the alternative building designs. Building envelope product flows are expressed as flows per unit of area. Building equipment flows are expressed as the flows per installed unit.

The above calculation does not account for the flows associated with the operation of the building. Building operation refers to the energy consumed by the building over the study period. All energy-related environmental flows are derived using bottom-up, processed-based LCA data. Because electricity is the sole energy source consumed by all building designs in the BIRDS Low-Energy Residential Database, all energy-related environmental flows are from electricity consumption. According to Equation (6), energy-related flows for each building design are calculated by multiplying the flow per unit of electricity (Flow $/ U N I T_{\text {Elec }}$ ) by the total number of units of electricity consumed $\left(U N I T_{E l e c}\right)$, indexed on $i$.

$$
\text { Elec }_{i}=U_{N} I T_{\text {Elec }} * \text { Flow } / U N I T_{\text {Elec }, i}
$$

Since annual energy consumption remains constant over the study period, the energy-related environmental flows also remain constant over the study period. This result is not the case with initial non-energy related flow calculations. These flows must be allocated over the study period. This allocation can be done using either one of two approaches. The first considers flows associated with the initial construction as being realized in Year 0, with those flows being "sunk" before the building becomes operable. A drawback of this approach is that the environmental flows embodied in the building materials overwhelm future environmental flows (e.g., operating energy-related flows) for shorter study period lengths even though most of those flows are embodied in the building until its disposal at the end of its life. The second approach annualizes the embodied flows by equally dividing the flows over the lifetime of the building product or component. Since this approach is more consistent with the life-cycle costing residual value method, we consider environmental flows on an annualized basis.

Table 3-1 lists the twelve environmental categories considered in the analysis of building designs in the BIRDS Low-Energy Residential Database. Global Warming Potential (GWP) measures the degree to which anthropogenic factors contribute to the greenhouse effect phenomenon through the release of harmful greenhouse gases (GHG) like carbon dioxide. Acidification Potential refers to acidifying compounds (e.g., $\mathrm{NO}_{\mathrm{x}}$ and $\mathrm{SO}_{2}$ ) either dissolving in water or fixing themselves on solid particles, which have harmful effects on trees, soil, buildings, animals, and humans within an ecosystem. The primary anthropogenic contributors to acidification are the combustion of fossil fuels and biomass. Ozone Depletion refers to the thinning of Earth's stratospheric ozone layer, which can lead to unwanted changes in ecosystems and agriculture. A measure of the impacts industrial-based pollutants have on surrounding ecosystems is Ecological Toxicity or "Ecotoxicity." Water Consumption in BIRDS refers to the overall water use (cradle-to-grave) net of evapotranspiration. Smog formation is caused by sunlight reacting with ground-level emissions released from industrial sources and vehicles. The addition of mineral 
nutrients such as nitrogen and phosphorous to the soil or water is referred to as Eutrophication Potential. These foreign mineral deposits can have unwanted effects on the local ecosystem. Primary Energy Consumption includes the energy use from building operation and that is embodied within the building products. Carcinogens and Non-Carcinogens refer to the cancerous and non-cancerous effects, respectively, of exposure to industrial and natural substances. The effects of exposure for either category range from illness to permanent disability and even death. Respiratory Effects refer to the aggravation of existing respiratory conditions, or the cause of more serious respiratory conditions caused by the release of criteria air pollutants during fossil fuel combustion, vehicle operation, electricity generation, etc.

\section{Table 3-1 Environmental Impact Categories}

\begin{tabular}{|ll|}
\hline Category & Unit \\
\hline Global Warming Potential (GWP) & $\mathrm{kg} \mathrm{CO}$ e \\
\hline Acidification Potential & $\mathrm{mol} \mathrm{H}+$ eq \\
\hline Ozone Depletion & $\mathrm{kg} \mathrm{CFC-11} \mathrm{eq}$ \\
\hline Ecotoxicity & $\mathrm{CTUe}$ \\
\hline Water Consumption & $\mathrm{kg}$ \\
\hline Land Use & $\mathrm{Acre}$ \\
\hline Smog Formation & $\mathrm{kg} \mathrm{O}$ eq \\
\hline Eutrophication Potential & $\mathrm{kg} \mathrm{N} \mathrm{eq}$ \\
\hline Primary Energy Consumption & $1000 \mathrm{Btu}$ \\
\hline Carcinogens & $\mathrm{CTUh}$ \\
\hline Non-Carcinogens & CTUh \\
\hline Respiratory Effects & $\mathrm{kg} \mathrm{PM10} \mathrm{eq}$ \\
\hline
\end{tabular}

\subsection{Pareto Frontier Development and Key Building Design Selection}

Selection of the key building designs evaluated in this study was completed using a series of economic analyses based on changes in the assumptions for the discount rate, construction quality, and financing, and an assumed study period length of 10 years. Although the BIRDS Low-Energy Residential Database does not include any financial incentives, this analysis considers the inclusion of the recently extended $30 \%$ Investment Tax Credit (ITC) for renewable energy systems.

As previously discussed in Section 2, two options are available in the database for discount rate, construction quality, and financing assumptions. Our study uses a full factorial analysis for the three variables to develop the Pareto frontiers for all combinations, identifies key designs that are optimal for a given objective (e.g., minimizing LCC), and calculates the net present value for the key designs. A Pareto frontier is a set of all options, in this case designs, that are possible "best" choices depending on how one views the trade-offs between the associated variables (LCC and percent energy reduction for Figure 3-4). Any design not on the frontier is never an optimal 
choice as there will always be a design on the frontier that performs better in at least one variable while performing just as well in all others. The net present value calculations include total first costs, incremental first costs of building design features, total energy costs, total MRR costs, total residual value, total LCC, net savings, and modified payback period.

The first step in identifying the key building designs is to plot all data points given each combination of discount rate, construction quality, and financing option. Figure 3-1 shows the percent change in annual net energy consumption relative to the MCC design on the horizontal axis (x-axis) and the absolute difference in LCC between the MCC design and each design alternative assuming a 10-year study period, $3 \%$ discount rate, "average" construction quality, and $100 \%$ cash financing on the vertical axis (y-axis). It is difficult to interpret Figure 3-1 due to the sheer number of data points (240 000), however two trends are observable.

First, the repeating "peaks" are the result of the grouping of data points with the same design elements, but with different solar PV system capacities. The peak to the furthest left (A) corresponds to the no solar PV system option, and each subsequent peak to the right represents the next largest solar PV system option. This creates the first five visible "peaks" when viewing the plot from left to right. The drop from the fifth "peak" to the sixth "peak" (B) is a result from reducing the building's air leakage from $7.00 \mathrm{ACH}_{50}$ to $3.00 \mathrm{ACH}_{50}$. The sixth and seventh "peaks" correspond to the $7.6 \mathrm{~kW}$ and $10.2 \mathrm{~kW}$ system capacities within the $3.00 \mathrm{ACH}_{50}$ grouping. The last "peak" (C) corresponds to the $10.2 \mathrm{~kW}$ solar PV system grouping with an air change rate of $0.63 \mathrm{ACH}_{50}$. The reason for the similarities in the groupings of different building designs when changing the size of the solar PV system is a result of the relative independence of the solar PV system and energy consumption of a building. 


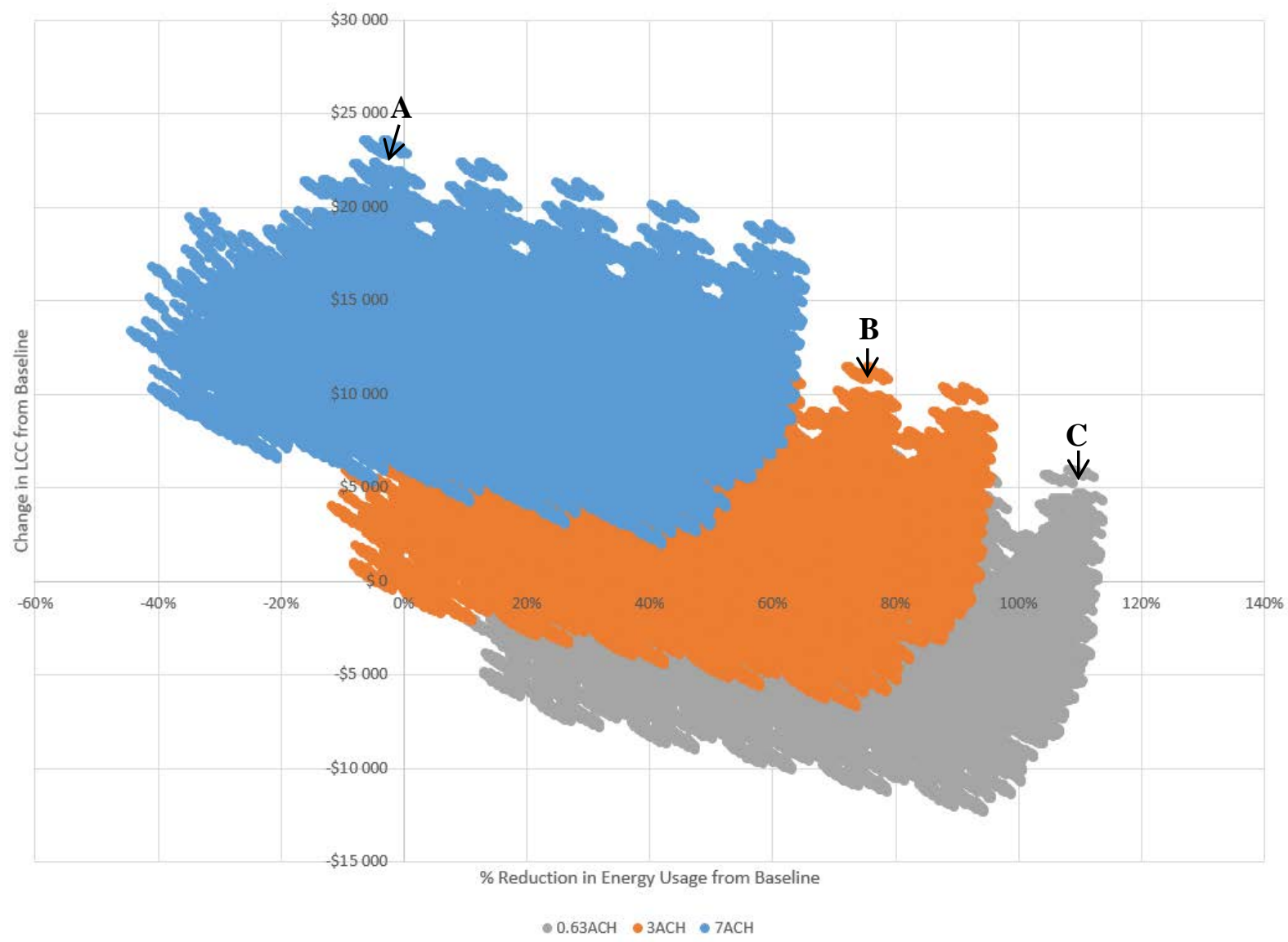

Figure 3-1 Energy Savings and Change in LCC - 3 \% Discount Rate, “Average” Construction Quality, and 100 \% Cash Financing with Tax Credit Applied

Second, assuming a 10-year study period, the addition of a solar PV system proves to be a cost-effective strategy. Given the $30 \%$ tax credit, the greatest reduction in LCC occurs near $100 \%$ reduction in net energy consumption (net-zero energy building design). Not only does the addition of the system improve the overall net energy performance of the building design, it simultaneously increases net savings (NS). Absence of the tax credit would lead to a reversal of this trend as initial solar PV system costs are incapable of being recouped given a relatively moderate study period length as shown in Figure 3-2. 


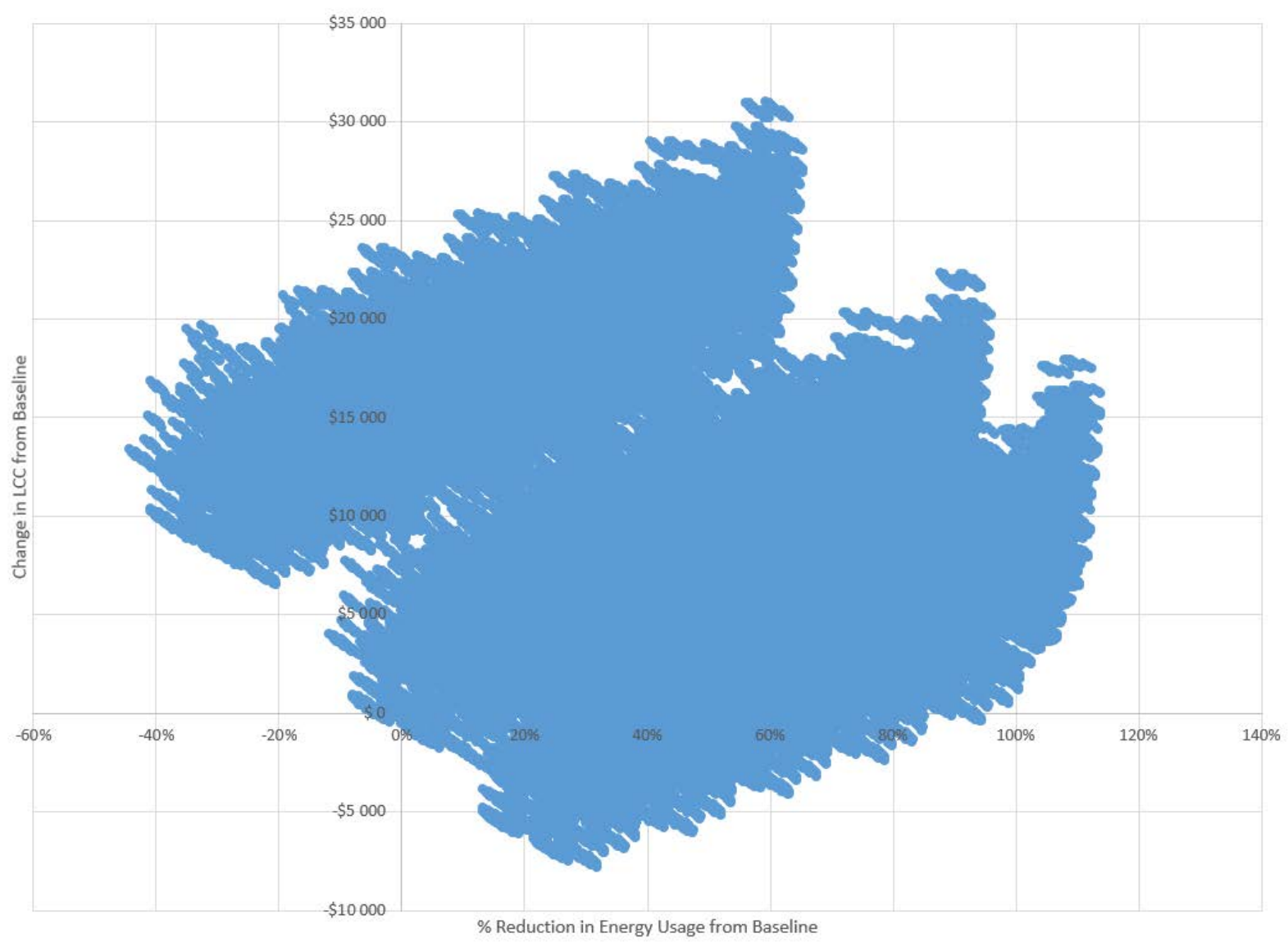

Figure 3-2 Energy Savings and Net Savings - 3 \% Discount Rate, “Average” Construction Quality, and 100 \% Cash Financing without Tax Credit Applied

All other combinations of discount rate, construction quality, and financing reveal similar trends as this initial case except for one: $8 \%$ discount rate, “average” construction quality, and $100 \%$ cash purchase. As shown in Figure 3-3, the lowest LCC is realized between $20 \%$ and $40 \%$ energy savings, which is much lower than the previous case that occurs near net-zero performance. The higher discount rate leads to a lower net present value for future energy cost savings, leading to fewer EEMs that are cost-effective to incorporate into the building design. 


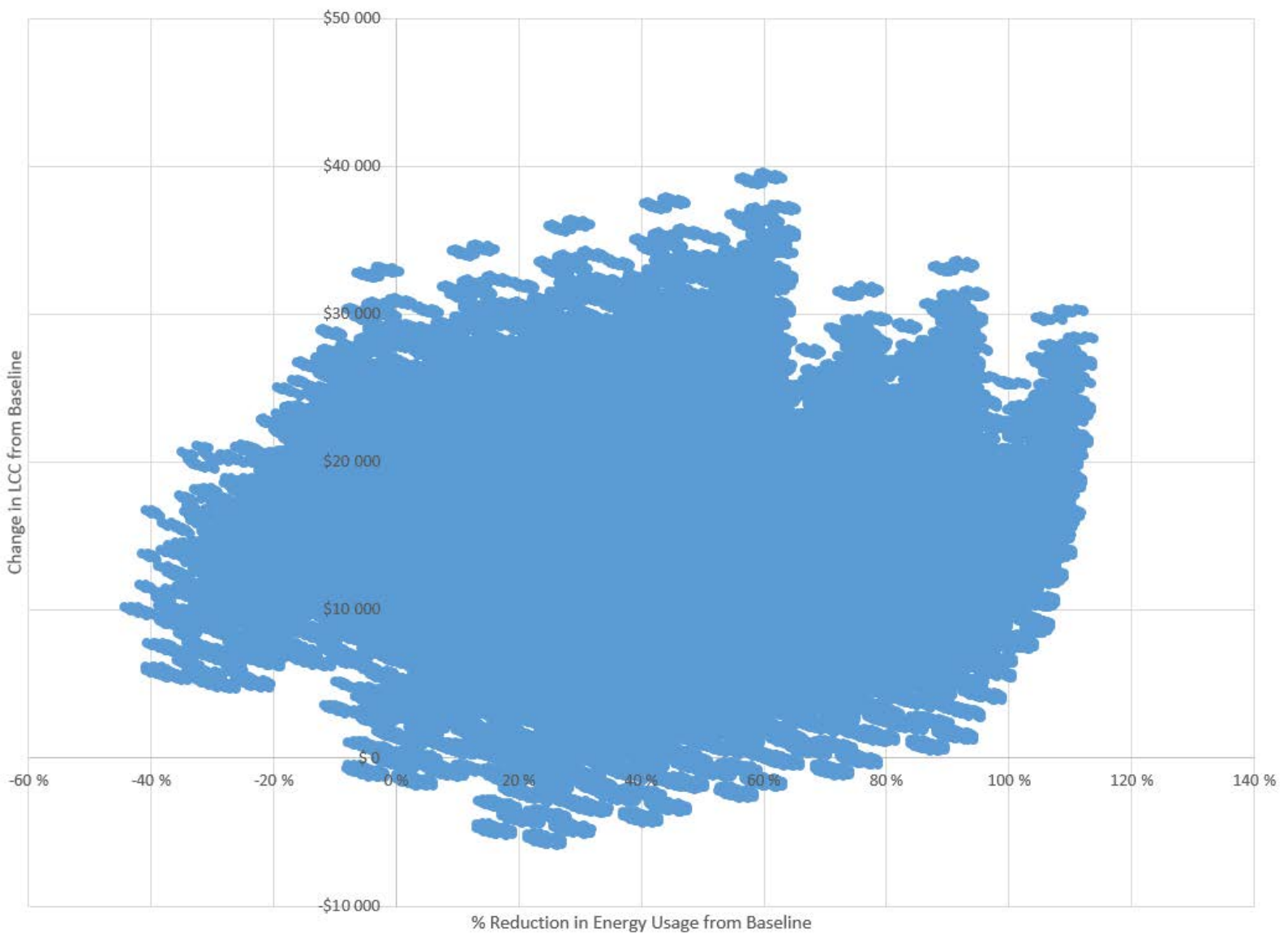

\section{Figure 3-3 Energy Savings and Net Savings - 8 \% Discount Rate, “Average” Construction Quality, and $100 \%$ Cash Financing}

Figure 3-1 and Figure 3-3 include data points for 240000 building designs, many of which are inferior choices because other designs realize (1) significantly lower LCC for the same level of energy savings, (2) greater energy savings for the same LCC, or (3) significantly lower LCC and greater energy savings. A Pareto frontier for the designs can be created by connecting the data points for the building designs that realize the lowest LCC for a given level of energy savings. Figure 3-4 shows the Pareto frontiers generated using this approach for the initial case discussed above (3 \% discount rate, “average” construction quality, and $100 \%$ cash financing) for a 10-, 20-, 30-, and 40-year study period length. These Pareto frontiers can be used to analyze several items: (1) the magnitude of changes in LCCs as energy efficiency increases, (2) the LCC optimal and near-optimal levels of energy efficiency for the NIST NZERTF building design, and (3) how the optimal and near-optimal building designs change as the study period increases in length. 


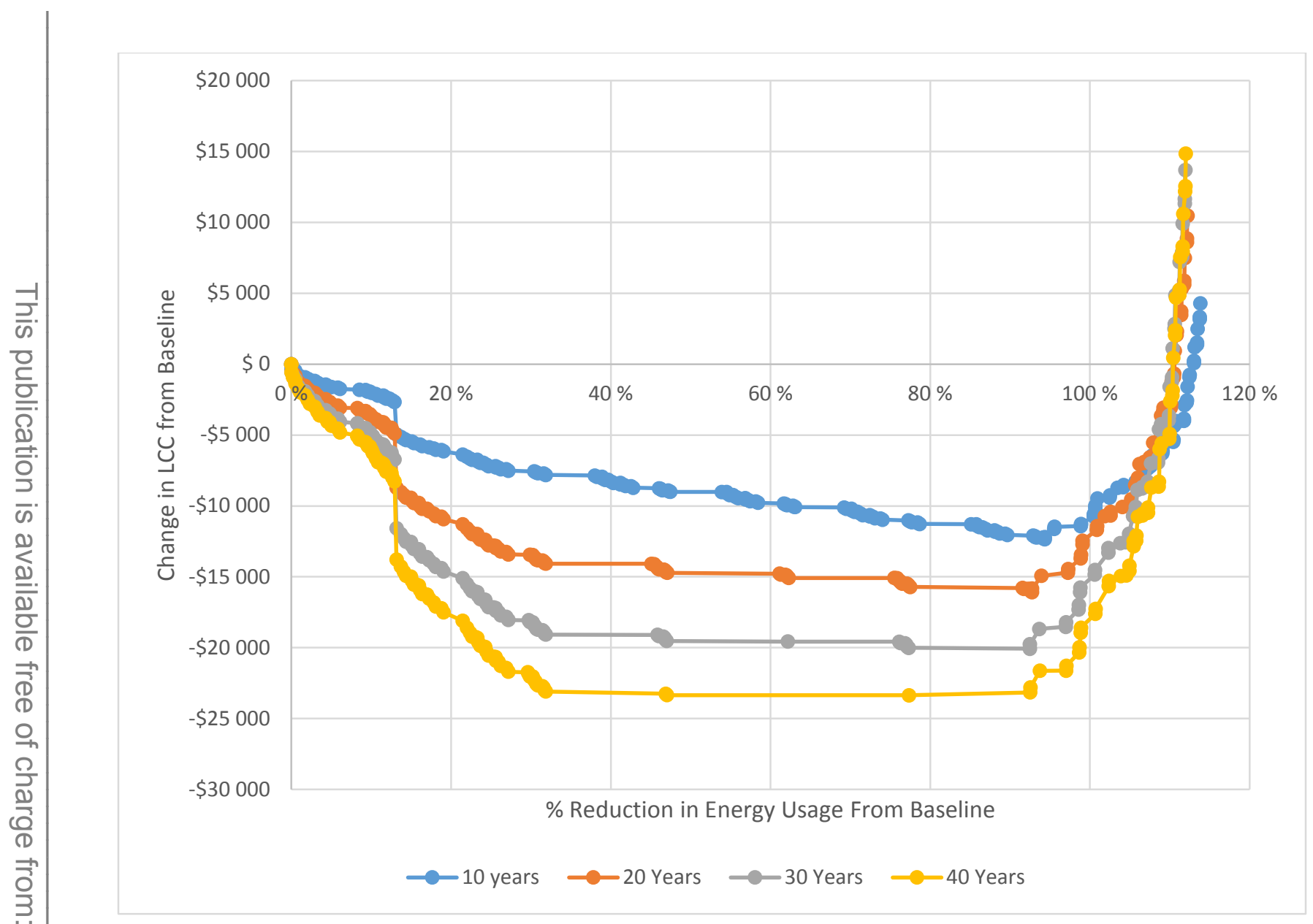

Figure 3-4 Pareto Frontiers for a 3 \% Discount Rate, average Construction Quality, and $100 \%$ Cash Financing

The Pareto frontiers in Figure 3-4 show that an increase in the study period length leads to an increase in the magnitude of the change in LCC. For a 10-year study period, the optimal building design leads to approximately $\$ 12000$ in NS while the increase in LCC to reach $113 \%$ energy savings costs is under $\$ 5000$. For a 40 -year study period, the optimal building design leads to over \$20 000 in NS while the increase in LCC to reach $113 \%$ energy savings increases LCC by over $\$ 15000$.

LCC differences across Pareto frontiers, however, diminish, as energy savings grow larger. Furthermore, the 20-, 30-, and 40-year Pareto frontiers show the same trends and begin to converge as energy savings reaches and surpasses $100 \%$ (net-zero design), suggesting that at higher levels of energy efficiency, extending the study period length will have minimal impacts on the relative LCC performance. The general pattern seen in Figure 3-4 holds under all other combinations of discount rate, construction quality, and financing - however, building design features and associated levels of energy savings for data points on the Pareto frontiers will differ along with the maximum and minimum values along the curve as evident in Figure 3-5. 


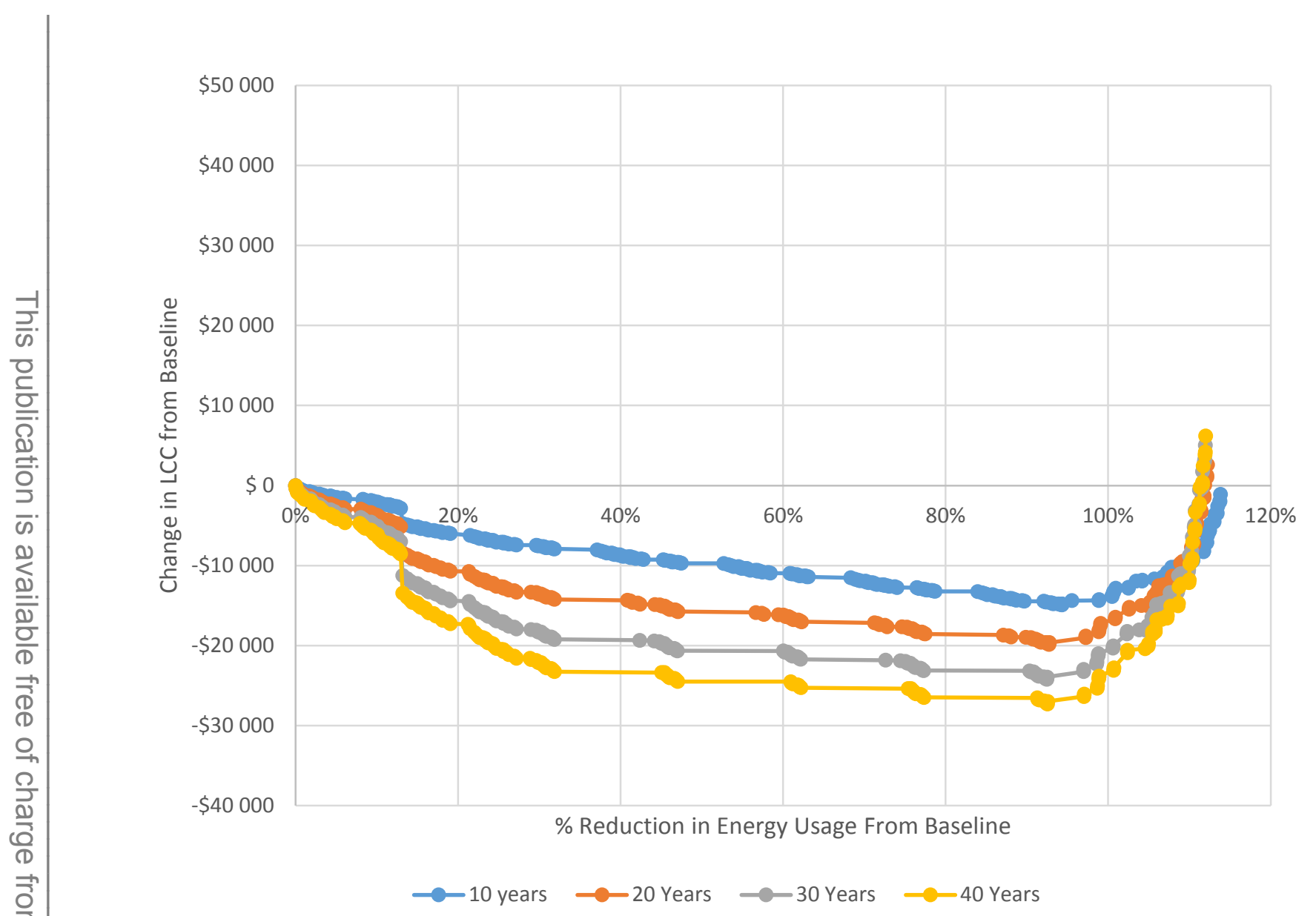

\section{Figure 3-5 Pareto Frontiers for a 3 \% Discount Rate, average Construction Quality, and 20 $\%$ Cash Financing}

Figure 3-6 plots the additional investment costs associated with the Pareto frontier in Figure 3-4 for a 10-year study period including identification of changes in building design features resulting in noticeable impacts on energy efficiency and/or investment costs. Each substantial change tends to be a result of a combination of increasing the energy efficiency of one or more building components while simultaneously selecting less efficient options for one or more other building components.

Most impacts are incremental, but a few EEMs stand out as key drivers of the results: insulation in the ceiling/roof assembly, insulation in the wall assembly, and solar PV. As you move from left to right in Figure 3-6, the first substantial change in energy efficiency occurs at $\mathbf{A}$ as a result of the installation of lower efficiency windows (UsI-0.2/SHGC 0.25 with $U_{S I}-0.35 / S H G C ~ 0.6$ ) while increasing the insulation in the wall assembly and ceiling/roof assembly. Next, the change at $\mathbf{B}$ occurs from a decrease in foundation insulation from $\mathrm{R}_{\mathrm{SI}}-3.9$ (R-22) in the foundation wall assembly and $\mathrm{R}_{\mathrm{SI}}-1.8(\mathrm{R}-10)$ in the foundation floor to $\mathrm{R}_{\mathrm{SI}}-1.41$ (R-8) insulation in the wall assembly and no foundation floor insulation. Windows with a higher U-factor and SHGC ( $\mathrm{U}_{\mathrm{SI}}-0.35 / \mathrm{SHGC} 0.6$ with $\mathrm{USI}_{\mathrm{SI}}-0.45 / \mathrm{SHGC} 0.6$ ) are installed as well. This result shows that there 
are building designs that can increase energy efficiency while decreasing initial construction costs relative to the MCC. The substantial decrease in LCC seen in Figure 3-4 can be directly associated with the decrease in investment costs at $\mathbf{B}$. The next substantial increase in energy efficiency at $\mathbf{C}$ is caused by replacing the electric water heater with a heat pump water heater while decreasing the efficiency of the windows (UsI-0.2/SHGC 0.25 with $\mathrm{U}_{\mathrm{SI}}-0.4 / \mathrm{SHGC} 0.6$ ).

The remaining substantial increases ( $\mathbf{D}$ through $\mathbf{L}$ ) in energy efficiency (and associated investment cost increase) follow a particular pattern. The changes in energy savings and investment costs for $\mathbf{D}, \mathbf{F}, \mathbf{H}, \mathbf{J}$, and $\mathbf{L}$ are from a decrease in the insulation in the ceiling assembly from $\mathrm{R}_{\mathrm{SI}}-8.6$ (R-49) to $\mathrm{RSI}_{\mathrm{SI}}-6.69$ (R-38) and an increase in the insulation in the wall assembly from $\mathrm{RsI}_{\mathrm{II}}-2.3(\mathrm{R}-13)$ to $\mathrm{RSI}_{\mathrm{II}}-2.3+0.9(\mathrm{R}-13+5)$. This result shows that increased thermal performance in the wall assembly has a greater impact on energy efficiency than the additional insulation in the ceiling/roof assembly, which is due to the greater surface area of the walls versus the ceiling/roof. For $\mathbf{E}, \mathbf{G}, \mathbf{I}$, and $\mathbf{K}$, the increase in energy efficiency and investment costs is a result of increasing the size of the solar PV system from $0.0 \mathrm{kWh}$ to $2.5 \mathrm{~kW}$ to $5.1 \mathrm{~kW}$ to 7.6 $\mathrm{kW}$ to $10.2 \mathrm{~kW}$, respectively. These impacts are identical in magnitude because the investment costs and electricity production from solar PV are both relatively linear as the system size increases. 


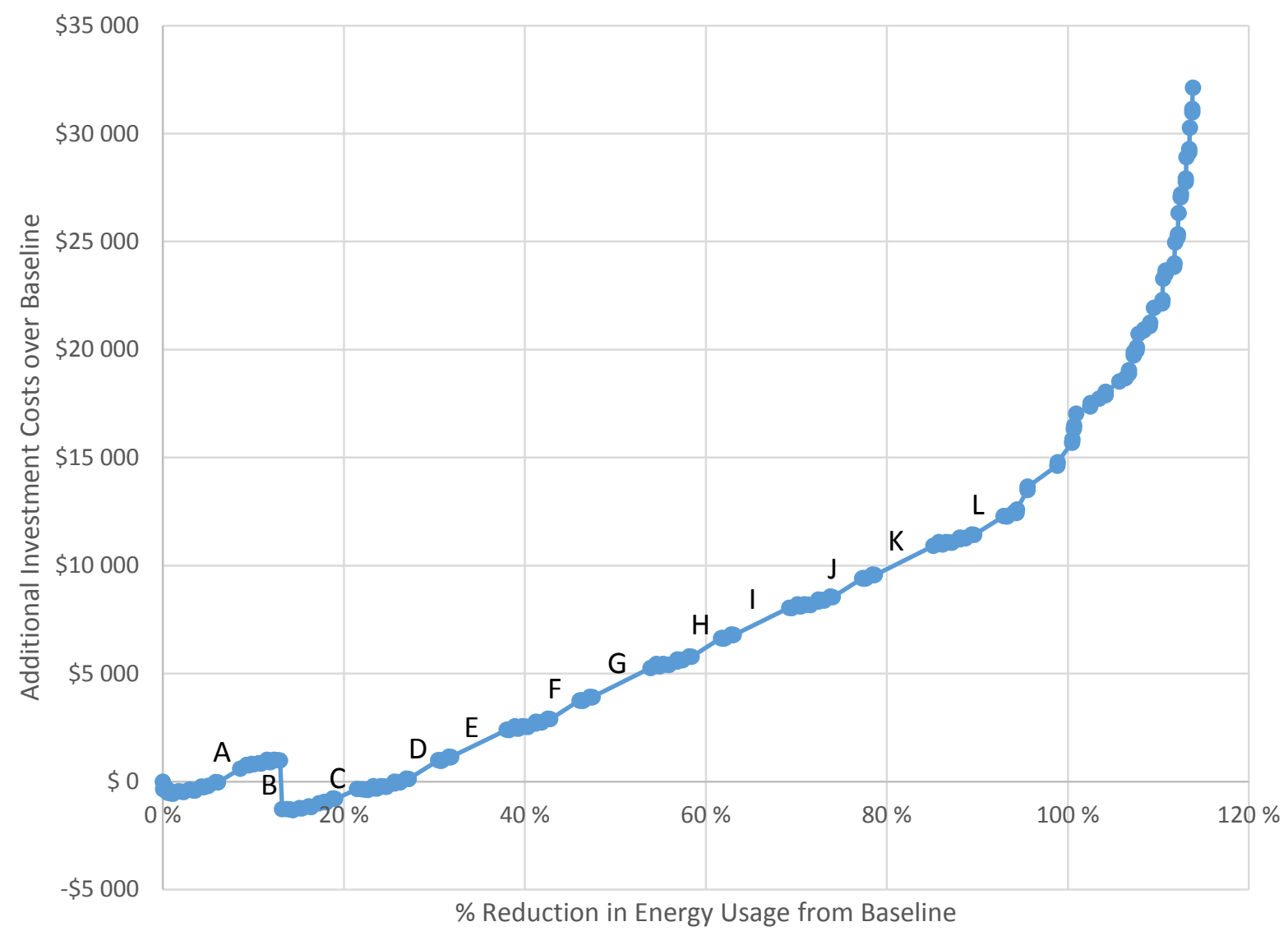

Figure 3-6 Additional Investment Costs relative to the MCC Design for Points along the 10-Year Pareto Frontier with Data Points of Interest (A through L)

Excluding B, Figure 3-6 indicates that progression along the Pareto frontier is generally in the form of small increases in both investment costs and energy efficiency resulting from changes in a combination of different EEMs. In most cases, one or more building components are made less efficient while one or more building components are made more efficient, allowing for a tradeoff that selects the EEM that leads to greater energy savings for minimum additional investment costs. Thus, the design options considered in this analysis often provide gradual increases in energy performance for gradual increases in investments costs. This holds up until the final 10.2 $\mathrm{kW}$ solar PV system configuration is reached at $\mathbf{K}$. At this point there is no overlap between different solar PV system data points, implying that changes only occur along the $10.2 \mathrm{~kW}$ solar PV system portion of the Pareto frontier. Although energy efficiency is increased incrementally investment costs increase at a higher rate due to a lack of alternative combinations of EEMs. Although these specific building design changes are a result of the specific analysis assumptions, the general trends hold true for other assumption combinations as well.

There are number of points located along Pareto frontiers that are of interest. This analysis herein focuses on five specific points along the Pareto frontier: (1) the baseline or MCC design, (2) the 
most energy-efficient design at a LCC level equivalent to the baseline (EE-BaseLCC), (3) the most energy-efficient design overall (EE), (4) the minimum LCC design (Min-LCC), and (5) the design that achieves net-zero energy or better at least cost (LCC-NZE). The five selected designs offer insight into the results of different EEMs when focused on the overall sustainability performance (energy savings, life-cycle costs, and environment impacts). 


\section{Results and Discussion}

Kneifel and O'Rear (2015) analyzed the sustainability performance of different levels of energy efficiency for the NZERTF relative to the Maryland-code compliant (MCC) design based on 2015 IECC with a single set of assumptions. This study expands on the analysis by increasing the number of options for each energy efficiency measure (EEM) to include options in between the Maryland code requirements and design specifications of the NZERTF consider additional incremental energy efficiency improvements. Additionally, the analysis not only uses the same set of assumptions (Case 1), but also 7 additional combinations of those assumptions (Case 2 through Case 8) to determine how the sustainability performance changes based on changes in those assumptions.

\subsection{Energy and Economic Impacts of Incremental Building Design Options}

Prior to focusing on the key building designs listed at the end of Section 3.4, it is useful to examine the net energy consumption savings and life-cycle cost savings associated with incremental changes in each EEM for the baseline design. The MCC design is modified for one building component at a time based on the different design options discussed in Chapter 2 to estimate the additional energy savings or losses for each EEM. Table 4-1 displays the calculated changes in net energy consumption and NS given a 10-year study period, $3 \%$ discount rate, average construction quality, and $100 \%$ cash financing. The additional energy savings or losses realized by each of the design options is independent of the cost-related assumptions and will remain constant across all discount rate, construction quality, and financing combinations.

The results in Table 4-1 can be used to make several assertions related to net energy consumption. First, the EEMs that lead to the greatest energy savings are installation of solar PV systems (up to $62.5 \%$ ), lower air flow rates (20.6 \%), more efficient HVAC equipment (15.2 \%), more efficient DHW system (up to $9.2 \%$ ), and increase in wall assembly insulation (up to $6.8 \%$ ). Second, the EEMs that lead to energy savings of less than $5 \%$ are windows (3\% or less), ceiling/roof assembly insulation ( $2 \%$ or less), lighting $(<1 \%$ ), and foundation insulation $(<0.1 \%)$. Third, the energy savings $(8.0 \%)$ and NS (\$1308) from installing a heat pump water heater are greater than those of installing a solar thermal system (5.9\% and $-\$ 2625$, respectively). 
Table 4-1 Energy Savings (\%) and Net Savings (PV\$) of EEMs on MCC Building Design ${ }^{4}$

\begin{tabular}{|c|c|c|c|c|c|c|c|}
\hline \multirow{2}{*}{$\begin{array}{c}\text { EEM } \\
\text { Windows }\end{array}$} & \multirow{3}{*}{$\begin{array}{l}\quad \text { Option } \\
\text { U Factor: } 1.14 \mathrm{~W} / \mathrm{m}^{2}-\mathrm{K} \\
\text { SHGC: } 0.25\end{array}$} & \multicolumn{2}{|c|}{$\begin{array}{c}\text { Savings relative to MCC } \\
\text { design }\end{array}$} & \multirow{2}{*}{$\begin{array}{c}\text { EEM } \\
\text { DHW }\end{array}$} & Option & \multicolumn{2}{|c|}{$\begin{array}{c}\text { Savings relative to MCC } \\
\text { design }\end{array}$} \\
\hline & & Energy Savings (\%) & $3.0 \%$ & & Electric water heater w/ & Energy Savings (\%) & $5.9 \%$ \\
\hline & & Net Savings (PV\$) & $\$ 620$ & & solar thermal & Net Savings (PV\$) & $-\$ 2625$ \\
\hline & \multirow{2}{*}{$\begin{array}{l}\text { U Factor: } 2.00 \mathrm{~W} / \mathrm{m}^{2}-\mathrm{K} \\
\text { SHGC: } 0.25\end{array}$} & Energy Savings (\%) & $1.2 \%$ & & \multirow{2}{*}{ Heat pump water heater } & Energy Savings (\%) & $8.0 \%$ \\
\hline & & Net Savings (PV\$) & $\$ 347$ & & & Net Savings (PV\$) & $\$ 1308$ \\
\hline & \multirow{2}{*}{$\begin{array}{l}\text { U Factor: } 2.00 \mathrm{~W} / \mathrm{m}^{2}-\mathrm{K} \\
\text { SHGC: } 0.40\end{array}$} & Energy Savings (\%) & $0.1 \%$ & & \multirow{2}{*}{$\begin{array}{l}\text { Heat pump water heater } \\
\text { w/ solar thermal }\end{array}$} & Energy Savings (\%) & $9.2 \%$ \\
\hline & & Net Savings (PV\$) & $\$ 84$ & & & Net Savings (PV\$) & $-\$ 2644$ \\
\hline & \multirow{2}{*}{$\begin{array}{l}\text { U Factor: } 2.28 \mathrm{~W} / \mathrm{m}^{2}-\mathrm{K} \\
\text { SHGC: } 0.40\end{array}$} & Energy Savings (\%) & $-1.1 \%$ & \multirow{8}{*}{$\begin{array}{l}\text { Ceiling / } \\
\text { Roof }\end{array}$} & \multirow{2}{*}{$\begin{array}{l}\text { Roof insulation: } \\
\text { R }_{\mathrm{SI}^{-}}-9.92+5.28\end{array}$} & Energy Savings (\%) & $2.0 \%$ \\
\hline & & Net Savings (PV\$) & $-\$ 169$ & & & Net Savings (PV\$) & $-\$ 3692$ \\
\hline \multirow{4}{*}{$\begin{array}{l}\text { Air Flow } \\
\text { Rate* }\end{array}$} & \multirow{2}{*}{$0.63 \mathrm{ACH}_{50}$ (Outdoor Air) } & Energy Savings (\%) & $20.6 \%$ & & \multirow{2}{*}{$\begin{array}{l}\text { Ceiling insulation: } \\
\mathrm{R}_{\mathrm{SI}}-6.69\end{array}$} & Energy Savings (\%) & $-1.0 \%$ \\
\hline & & Net Savings (PV\$) & $\$ 5617$ & & & Net Savings (PV\$) & $-\$ 128$ \\
\hline & \multirow{2}{*}{$\begin{array}{l}\text { 7.0 } \mathrm{ACH}_{50} \text { (No Outdoor } \\
\text { Air) }\end{array}$} & Energy Savings (\%) & $-31.9 \%$ & & \multirow{2}{*}{$\begin{array}{l}\text { Roof insulation: } \\
\mathrm{R}_{\mathrm{SI}^{-}}-7.92+0.7\end{array}$} & Energy Savings (\%) & $1.2 \%$ \\
\hline & & Net Savings (PV\$) & $-\$ 8745$ & & & Net Savings (PV\$) & $-\$ 704$ \\
\hline \multirow[t]{2}{*}{ HVAC } & \multirow{2}{*}{$\begin{array}{l}\text { Air-to-air heat pump } \\
\text { (SEER 16.5/HSPF 9.1)** }\end{array}$} & Energy Savings (\%) & $15.2 \%$ & & \multirow{2}{*}{$\begin{array}{l}\text { Roof insulation: } \\
\mathrm{R}_{\mathrm{SI}}-7.92+2.64\end{array}$} & Energy Savings (\%) & $1.7 \%$ \\
\hline & & Net Savings (PV\$) & $-\$ 3370$ & & & Net Savings (PV\$) & $-\$ 1943$ \\
\hline \multirow[t]{6}{*}{ Lighting } & \multirow{2}{*}{$\begin{array}{l}34 \% \text { efficient built-in } \\
\text { fixtures }\end{array}$} & Energy Savings (\%) & $-0.9 \%$ & \multirow[t]{8}{*}{ Wall } & \multirow{2}{*}{$\begin{array}{l}\text { Framing: Typical } \\
\text { Insulation: } \mathrm{R}_{\mathrm{SI}}-2.3\end{array}$} & Energy Savings (\%) & $-5.0 \%$ \\
\hline & & Net Savings (PV\$) & $-\$ 275$ & & & Net Savings (PV\$) & $-\$ 408$ \\
\hline & \multirow{2}{*}{$\begin{array}{l}50 \% \text { efficient built-in } \\
\text { fixtures }\end{array}$} & Energy Savings (\%) & $-0.4 \%$ & & \multirow{2}{*}{$\begin{array}{l}\text { Framing: Advanced } \\
\text { Insulation: } \mathrm{R}_{\mathrm{SI}}-3.5\end{array}$} & Energy Savings (\%) & $-0.1 \%$ \\
\hline & & Net Savings (PV\$) & $-\$ 117$ & & & Net Savings (PV\$) & $-\$ 43$ \\
\hline & \multirow{2}{*}{$\begin{array}{l}100 \% \text { efficient built-in } \\
\text { fixtures }\end{array}$} & Energy Savings (\%) & $0.3 \%$ & & \multirow{2}{*}{$\begin{array}{l}\text { Framing: Advanced } \\
\text { Insulation: } \mathrm{R}_{\mathrm{SI}}-3.5+2.1\end{array}$} & Energy Savings (\%) & $4.9 \%$ \\
\hline & & Net Savings (PV\$) & $\$ 91$ & & & Net Savings (PV\$) & $-\$ 821$ \\
\hline \multirow[t]{8}{*}{ Solar PV } & $25 \mathrm{~kW}$ PV sustem & Energy Savings (\%) & $15.6 \%$ & & Framing: Advanced & Energy Savings (\%) & $6.8 \%$ \\
\hline & $2.5 \mathrm{~kW} \mathrm{PV}$ system & Net Savings (PV\$) & $\$ 1197$ & & Insulation: $\mathrm{R}_{\mathrm{SI}}-3$ & Net Savings (PV\$) & $-\$ 1968$ \\
\hline & & Energy Savings (\%) & $31.2 \%$ & Foundation* & Wall: $\mathrm{R}_{\mathrm{SI}}-3.9$ & Energy Savings (\%) & $-3.7 \%$ \\
\hline & 5.1 kW PV system & Net Savings (PV\$) & $\$ 2266$ & & Floor: $\mathrm{R}_{\mathrm{SI}}-1.76$ & Net Savings (PV\$) & $-\$ 3040$ \\
\hline & $76 \mathrm{~kW}$ PV susten & Energy Savings (\%) & $46.8 \%$ & & Wall: $\mathrm{RSI}_{\mathrm{SI}} 3.9$ & Energy Savings (\%) & $0.1 \%$ \\
\hline & 1.6 kW PV system & Net Savings (PV\$) & $\$ 3458$ & & Floor: $\mathrm{R}_{\mathrm{SI}}{ }^{-0}$ & Net Savings (PV\$) & $-\$ 942$ \\
\hline & & Energy Savings (\%) & $62.5 \%$ & & Wall: $\mathrm{R}_{\mathrm{SI}}-1.41$ & Energy Savings (\%) & $-0.1 \%$ \\
\hline & 10 & Net Savings (PV\$) & $\$ 4533$ & & Floor: $\mathrm{R}_{\mathrm{SI}^{-}} 0$ & Net Savings (PV\$) & $\$ 143$ \\
\hline
\end{tabular}

\footnotetext{
${ }^{4}$ For space considerations only SI units are used in Table 4-1. U.S. Customary units for all insulation options can be found in Section 2.1 and Section 2.2.
} 
Table 4-1 also shows the relative life-cycle cost performance of different EEMs. Two of the EEMs that realize the greatest energy savings also lead to the greatest NS: lower air flow rates (\$5617) and solar PV systems (up to \$4533). Meanwhile, increasing the wall assembly insulation and installing a more efficient HVAC system lead to negative NS. The most efficient DHW system (heat pump water heater with solar thermal system) is not the most cost-effective (NS of -\$2644). Installation of the heat pump water heater leads to $87 \%$ of the energy savings as the heat pump water heater with solar thermal system (8.0\% versus $9.2 \%)$, but leads to NS of $\$ 1308$. Although the energy savings is relatively small, more efficient lighting and windows lead to NS of $\$ 91$ and $\$ 620$, respectively. Adding insulation is one of the most common recommendations for increasing energy efficiency in buildings, but in this case the MCC insulation levels in the ceiling/roof assembly and wall assembly appear to be the most cost-effective relative to higher levels of insulation.

The results for different levels of insulation for the basement wall assembly and under the basement slab reveals two interesting outcomes. First, the basement wall assembly in the MCC design is neither the most efficient, nor the most cost-effective option. Increasing the insulation in the basement wall assembly leads to energy savings of $0.1 \%$ while increasing life-cycle costs (NS of -\$942). Furthermore, reducing the insulation in the basement wall assembly leads to NS of $\$ 143$ while increasing energy consumption by $0.1 \%$. Second, incorporating insulation under the basement slab in conjunction with $\mathrm{R}_{\mathrm{SI}}-3.9$ (R-22) in the basement wall actually increases energy consumption by $3.74 \%$ while increasing life-cycle costs with a NS of $-\$ 3040$. This counterintuitive result could potentially be due to the thermal envelope of the building being so tight that the HVAC system occasionally has to run added time to cool/heat air that would normally be cooled/heated through energy transfer through the basement walls and slab, increasing LCC and decreasing energy efficiency of the new design (Kneifel and O'Rear 2015).

Determining the optimal combination of EEMs to incorporate into a building design is not as simple and straightforward as selecting the EEMs that lead to the greatest savings, either in terms of energy or life-cycle costs, because there are interactions between building components. For example, increasing the thermal performance of the building envelope will decrease the heating and cooling loads of the house. Smaller loads decrease the energy consumption of the HVAC system and lead to smaller potential energy savings from increasing the energy efficiency of the HVAC equipment. Additionally, the economics behind each of the incremental design options are largely dependent on assumptions for the discount rate, construction quality, and financing options. Case 1 through Case 8 will explore these energy and economics dependencies by focusing on the energy, economic, and environmental impacts under different combinations of EEMs assuming different combinations of discount rate, construction quality, and financing, and identifying the optimal building designs given different potential objectives. 


\subsection{Case 1: 3 \% Discount Rate, Average Construction Quality, 100 \% Cash Financing}

Case 1 assumes a $3 \%$ discount rate, average construction quality, and full-cash financing. This section will analyze the results under these assumptions and identify the key drivers of energy, economic, and environmental performance.

\subsubsection{Summary of Key Designs - Case 1}

Table 4-2 lists the building design feature combinations for each of the select key designs (except the baseline) defined in the previous section and the percent energy reduction and change in total LCC over the baseline. Several EEMs are consistent across all optimal design goals, with the most efficient alternative for windows, air flow rate, lighting, and solar PV as well as the no insulation alternative for the foundation floor EEMs. These selections are optimal both in terms of energy efficiency and LCC.

\section{Table 4-2 Selected Key Designs for Case 1}

\begin{tabular}{|c|c|c|c|c|}
\hline $\begin{array}{c}\text { Design } \\
\text { Category }\end{array}$ & EE-BaseLCC & $\mathbf{E E}$ & Min-LCC & LCC-NZE \\
\hline Windows & $\begin{array}{c}\text { U Factor: } \\
1.14 \mathrm{~W} / \mathrm{m}^{2}-\mathrm{K} \\
\left(0.2 \mathrm{Btu} / \mathrm{h} \cdot \mathrm{ft}^{2}-\mathrm{F}\right) \\
\text { SHGC: } 0.25\end{array}$ & $\begin{array}{c}\text { U Factor: } \\
1.14 \mathrm{~W} / \mathrm{m}^{2}-\mathrm{K} \\
\left(0.2 \mathrm{Btu} / \mathrm{h} \cdot \mathrm{ft}^{2}-\mathrm{F}\right) \\
\text { SHGC: } 0.25\end{array}$ & $\begin{array}{c}\text { U Factor: } \\
1.14 \mathrm{~W} / \mathrm{m}^{2}-\mathrm{K} \\
\left(0.2 \mathrm{Btu} / \mathrm{h} \cdot \mathrm{ft}^{2}-\mathrm{F}\right) \\
\text { SHGC: } 0.25\end{array}$ & $\begin{array}{c}\text { U Factor: } \\
1.14 \mathrm{~W} / \mathrm{m}^{2}-\mathrm{K} \\
\left(0.2 \mathrm{Btu} / \mathrm{h} \cdot \mathrm{ft}^{2}-\mathrm{F}\right) \\
\text { SHGC: } 0.25\end{array}$ \\
\hline HVAC & $\begin{array}{l}\text { Air-to-air heat pump } \\
\text { (SEER 16.5/ HSPF 9.1) }\end{array}$ & $\begin{array}{c}\text { Air-to-air heat pump } \\
\text { (SEER 16.5/ HSPF 9.1) }\end{array}$ & $\begin{array}{l}\text { Air-to-air heat pump } \\
\text { (SEER 13.0/ HSPF 7.7) }\end{array}$ & $\begin{array}{l}\text { Air-to-air heat pump } \\
\text { (SEER 13.0/ HSPF 7.7) }\end{array}$ \\
\hline Ventilation & Separate HRV system & Separate HRV system & Outdoor air* & Outdoor air* \\
\hline Air Flow Rate & $0.63 \mathrm{ACH}_{50}$ & $0.63 \mathrm{ACH}_{50}$ & $0.63 \mathrm{ACH}_{50}$ & $0.63 \mathrm{ACH}_{50}$ \\
\hline Lighting & $100 \%$ efficient fixtures & 100 \% efficient fixtures & $100 \%$ efficient fixtures & $100 \%$ efficient fixtures \\
\hline Solar PV & $10.2 \mathrm{~kW}$ & $10.2 \mathrm{~kW}$ & $10.2 \mathrm{~kW}$ & $10.2 \mathrm{~kW}$ \\
\hline DHW & $\begin{array}{l}\text { Heat pump water heater } \\
\text { w/ solar thermal system }\end{array}$ & $\begin{array}{l}\text { Heat pump water heater } \\
\text { w/ solar thermal system }\end{array}$ & Heat pump water heater & Heat pump water heater \\
\hline Roof & $\begin{array}{l}\text { Roof insulation: } \\
\text { RsI-7.92 + } 0.7 \\
(\mathrm{R}-45+4)\end{array}$ & $\begin{array}{l}\text { Roof insulation: } \\
\text { R }_{\mathrm{SI}}-7.92+5.28 \\
(\mathrm{R}-45+30)\end{array}$ & $\begin{array}{l}\text { Ceiling Insulation: } \\
\qquad \mathrm{R}_{\mathrm{SI}^{-}}-8.63 \\
(\mathrm{R}-49)\end{array}$ & $\begin{array}{l}\text { Roof insulation: } \\
\text { RSI-7.92 + } 0.7 \\
(\mathrm{R}-45+4)\end{array}$ \\
\hline Wall & $\begin{array}{c}\text { Framing: Advanced } \\
\text { Insulation: } \mathrm{R}_{\mathrm{SI}-3.5+4.2} \\
(\mathrm{R}-20+24)\end{array}$ & $\begin{array}{c}\text { Framing: Advanced } \\
\text { Insulation: } \mathrm{R}_{\mathrm{SI}}-3.5+4.2 \\
(\mathrm{R}-20+24)\end{array}$ & $\begin{array}{l}\text { Framing: Advanced } \\
\text { Insulation: } \mathrm{R}_{\mathrm{SI}}-3.5 \\
(\mathrm{R}-20+0)\end{array}$ & $\begin{array}{c}\text { Framing: Advanced } \\
\text { Insulation: } \mathrm{R}_{\mathrm{SI}}-3.5+2.1 \\
(\mathrm{R}-20+12)\end{array}$ \\
\hline $\begin{array}{c}\text { Foundation } \\
\text { Wall }\end{array}$ & $\begin{array}{c}\mathrm{R}_{\mathrm{SI}^{-}}-1.41 \\
(\mathrm{R}-8)\end{array}$ & $\begin{array}{l}\mathrm{R}_{\mathrm{SI}}-3.9 \\
(\mathrm{R}-22)\end{array}$ & $\begin{array}{c}\mathrm{R}_{\mathrm{SI}^{-}}-1.41 \\
(\mathrm{R}-8)\end{array}$ & $\begin{array}{c}\mathrm{R}_{\mathrm{SI}}-1.41 \\
(\mathrm{R}-8)\end{array}$ \\
\hline $\begin{array}{l}\text { Foundation } \\
\text { Floor }\end{array}$ & $\begin{array}{l}\mathrm{R}_{\mathrm{SI}^{-}}-0 \\
(\mathrm{R}-0)\end{array}$ & $\begin{array}{l}\mathrm{R}_{\mathrm{SI}^{-}}-0 \\
(\mathrm{R}-0)\end{array}$ & $\begin{array}{l}\mathrm{R}_{\mathrm{SI}}-0 \\
(\mathrm{R}-0)\end{array}$ & $\begin{array}{l}\mathrm{R}_{\mathrm{SI}^{-}}-0 \\
(\mathrm{R}-0)\end{array}$ \\
\hline $\begin{array}{c}\text { Energy } \\
\text { Reduction } \\
(\%)\end{array}$ & $113 \%$ & $114 \%$ & $94 \%$ & $101 \%$ \\
\hline $\begin{array}{l}\text { Change in } \\
\text { LCC (10-yr) }\end{array}$ & $\$ 67$ & $\$ 4282$ & $-\$ 12344$ & $-\$ 10749$ \\
\hline
\end{tabular}


Substantial energy efficiency improvements are represented for each design, with varying impacts on the change in LCC over a 10-year study period. When optimizing energy efficiency, the design EE, includes all options that would be considered the "most" efficient EEMs except for the foundation floor. The R-10 foundation floor insulation appears to be less efficient than having no foundation floor insulation. This could potentially be an issue with the nature of heat flow through the house being affected in some unforeseen way due to the additional thermal barrier added to the basement floor. Regardless, the unexpected nature of the result warrants further analysis. When minimizing energy efficiency under the restriction of maintaining the same LCC as the baseline (EE-BaseLCC), energy reduction is close to that in EE, while reducing LCC by over $\$ 4000$. Net zero energy performance can be obtained while reducing LCC by $\$ 10749$ as shown in the net-zero design with the lowest LCC (LCC-NZE). The lowest LCC design leads to a $94 \%$ reduction in energy consumption while reducing LCC by \$12 344 .

These results support a previous analysis that has shown that in the absence of the tax credit the $10.2 \mathrm{~kW}$ system adds a sufficient amount to the cost to make it an uneconomical EEM (Kneifel and O'Rear 2015). By taking advantage of the ITC it is possible for even a large solar PV system to reach cost parity with a no PV option in terms of overall LCC (Kneifel, Webb, and O'Rear 2016).

\subsubsection{First Cost Analysis of Key Designs - Case 1}

Figure 4-1 presents the total first costs for the key designs, including the baseline (MCC design based on 2015 IECC). The MCC design has the lowest first costs of the 5 selected designs at roughly \$344 000, which is to be expected considering the MCC design is the least efficient design considered. EEMs are typically more expensive to implement up front with any expected savings to accrue by reductions in energy costs over the life of the structure. The higher first costs of EEMs is evident for the most efficient design (\$418 382) which costs almost $\$ 75000$ more upfront than the MCC. 


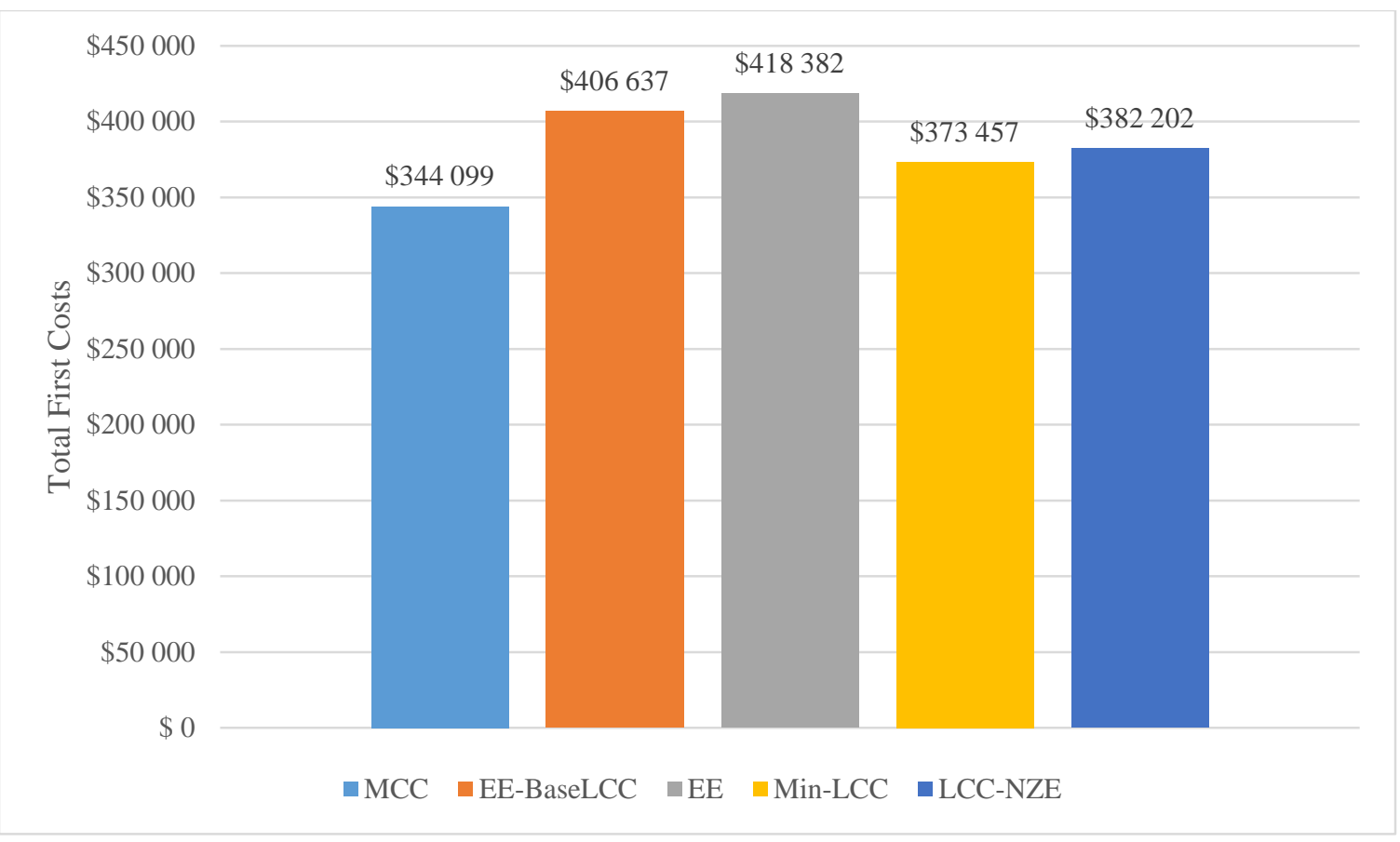

Figure 4-1 Total First Costs for Selected Designs - Case 1

Examining Figure 4-1 and incorporating the energy reductions from Table 4-2 further reveals that it is possible to achieve better than net-zero performance (113\% reduction) for the same LCC as the MCC design, but it requires an additional \$62 538 in costs upfront. The lowest LCC design that still achieves net-zero energy performance requires additional first costs of \$38 103, or $11.1 \%$ mark-up. The lowest LCC over the 10 -year study period reaches near net-zero energy performance at a $94 \%$ reduction while requiring an additional \$29 358 in costs upfront, or an $8.5 \%$ mark-up relative to the MCC design.

Figure 4-2 breaks down the additional first costs, relative to the MCC design, into the portions contributed by each EEM. As expected the inclusion of the solar PV system adds the most to the first costs. As all four designs utilize the $10.2 \mathrm{~kW}$ solar PV system, which adds \$27 864 to the first costs. In the case of the Min-LCC design and the LCC-NZE design, the solar PV accounts for $94 \%$ and $73 \%$ of the additional first costs. For the remaining designs the contribution of the solar PV system does not get above $50 \%$. Note that the $30 \%$ tax credit is considered in the first costs although it is claimed at the end of the year. 


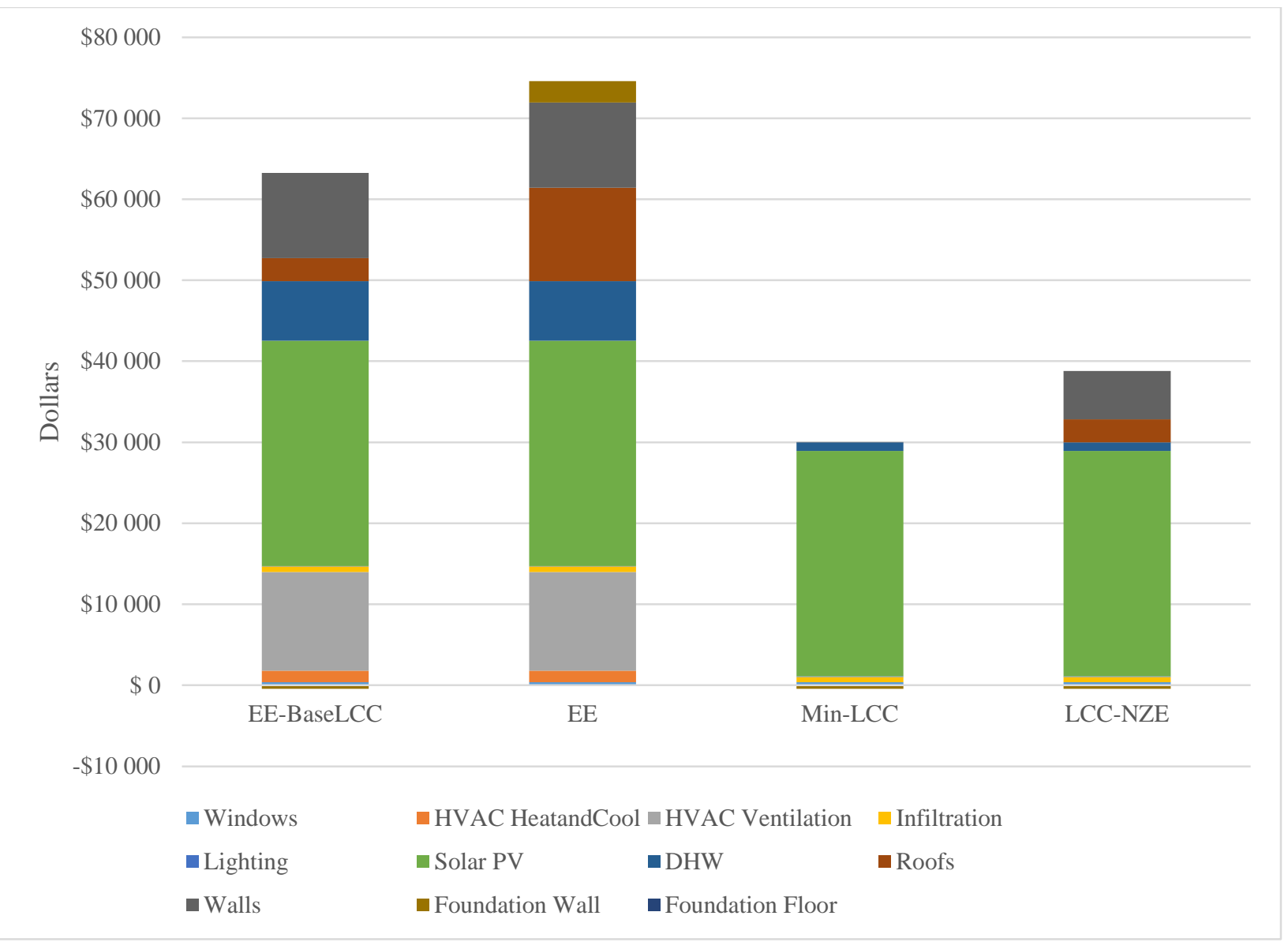

Figure 4-2 Incremental First Costs for Selected Designs relative to Baseline - Case 1

Incorporation of a separate HRV system accounts for $19 \%$ and $16 \%$ of the increase in first costs for the most efficient at baseline LCCs (EE-BaseLCC) and the most energy efficient (EE) design. Changing from the standard electric water heater to the heat pump water heater with a solar thermal system adds an additional $\$ 7334$ to the first costs while adding just the heat pump water heater adds \$1057. The additional costs for the roof range from \$2844 to \$11 531 depending on the specific design, while wall related EEMs add an additional \$34 for a minor upgrade in energy efficiency to \$10 507 for the most efficient option. Both the selection of the more efficient heat pump and lowest air flow rate option has a relatively minor impact (maximum of \$1420 and \$667 respectively). Foundation wall insulation related EEMs can actually decrease first costs relative to the MCC design, $-\$ 425$, because less insulation leads to marginally less energy consumption while lowering costs, and the most expensive and efficient foundation wall option increases the costs by $\$ 2645$.

\subsubsection{Future Cost Analysis of Key Designs - Case 1}

Figure 4-3 shows the present value of energy costs for each design for each year in a 40-year time period. In this and all subsequent sections, any analysis using data over all 40 years 
generated in the BIRDS low-energy residential database will focus on the $40^{\text {th }}$ year for specific comparisons. Year 40 generally has the most pronounced differences in impact between designs. EEMs, even for the least efficient of the selected key designs, have the potential to greatly reduce the energy costs for a home. This reduction is achieved through multiple means. First, the EEMs related to the air flow rate and windows as well as the wall, roof, and foundation insulation reduce heat transfer through the building envelope, reducing the thermal load on the HVAC system and decreasing the amount of operation needed to maintain thermostat set points. Second, the EEMs related to the DHW, HVAC, and lighting systems reduce the power consumed when those systems are in operation. Lastly the solar PV system generates electricity that offsets some or all the electricity pulled from the grid. All of these EEMs work in tandem to reduce the actual energy drawn from the grid, drastically bringing down annual electricity costs. The most energy efficient design (EE) and the most efficient design at the baseline LCC (EE-BaseLCC) actually produce more energy than they consume, resulting in a negative cost of electricity.

By year 40 the most efficient design has led to $\$ 3669$ in net present value electricity sales from self-generated electricity, as opposed to the MCC design, which accrues $\$ 84152$ in net present value electricity costs. Even the more modest improvements of the minimum LCC design manage to reduce the total present value energy costs over 40 years to $\$ 8296$, a reduction of $\$ 75856$. 


\section{$\$ 60000$}

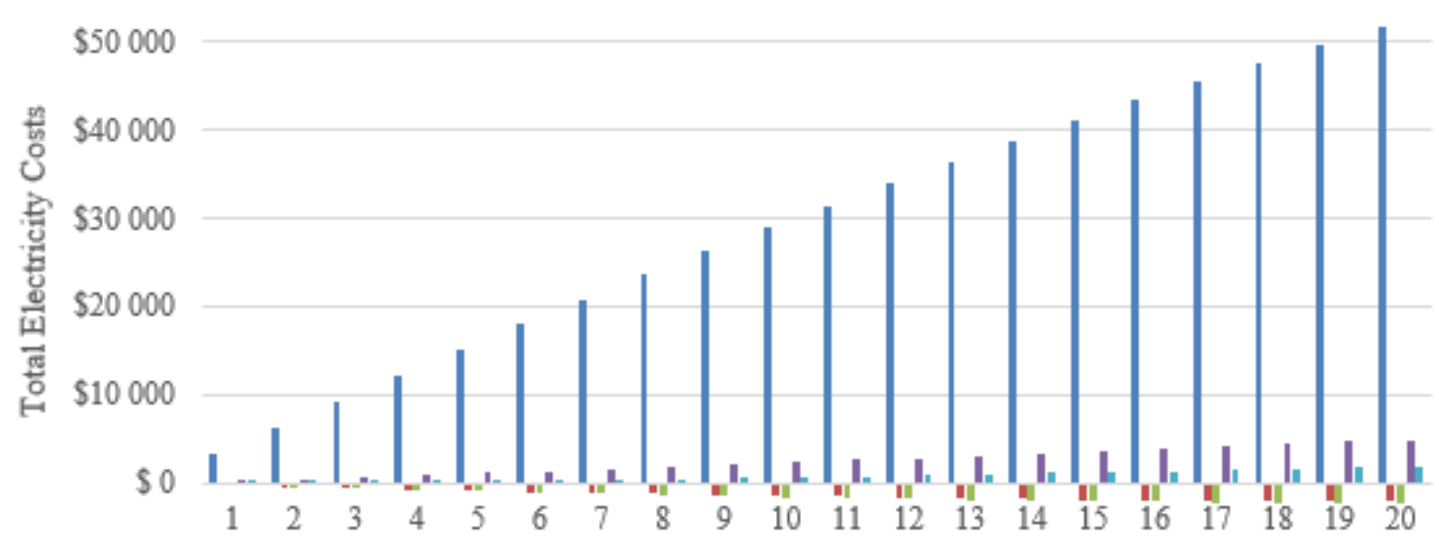

$-\$ 10000$

\section{Year}

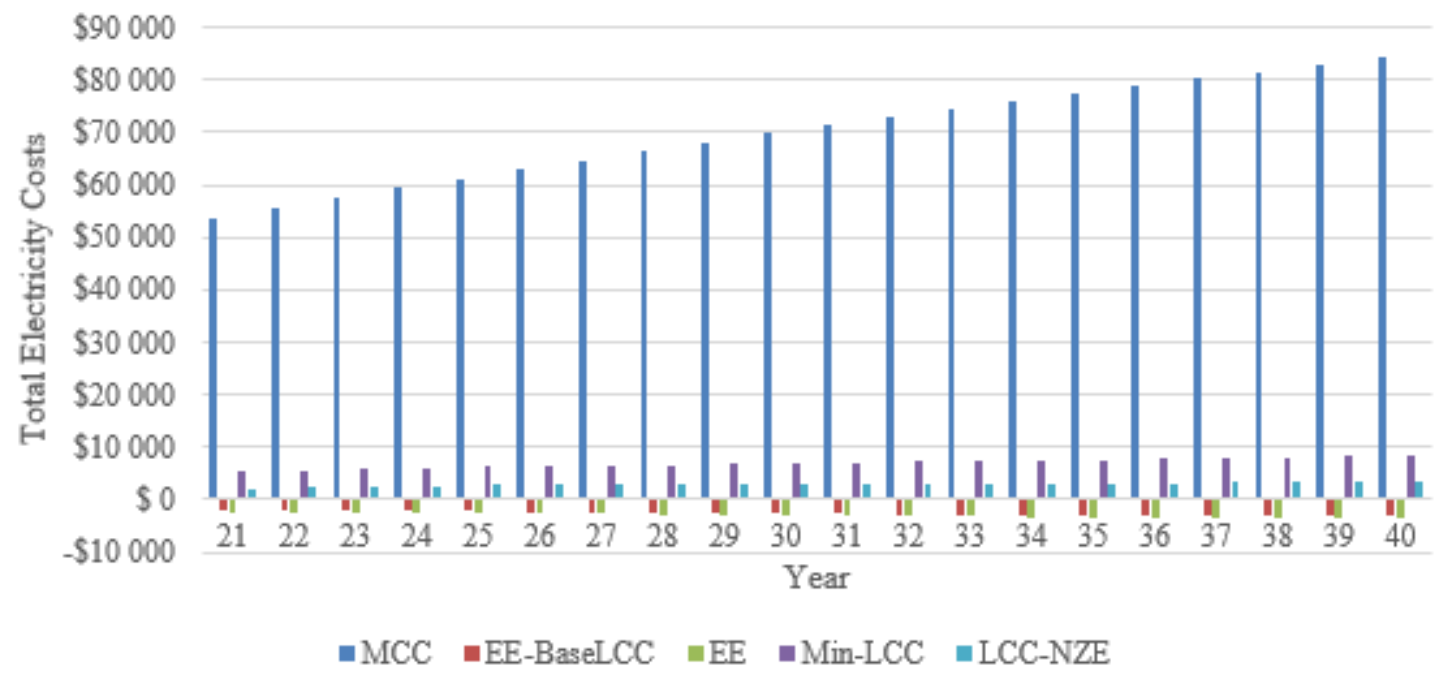

Figure 4-3 Present Value of Total Electricity Costs for Selected Designs - Case 1

Although the more efficient designs save electricity, some of those savings are offset by higher MRR costs. The present value of total MRR costs over a 40-year period in Figure 4-4 illustrate that the MCC design has consistently lower total MRR costs, \$36 615 at 40 years, than any of the other designs, driven primarily by the inclusion of the solar PV system. The PV system requires a solar inverter replacement at the beginning of years 11,21 , and 31 , as well as a full system replacement at the start of year 26. There is also the maintenance for the system, an additional \$204 annually. Inclusion of the solar thermal system adds further maintenance and repair costs, resulting in the total MRR costs for the most efficient design (EE) and most efficient design at the baseline LCC (EE-BaseLCC) being larger than the other designs. 


\section{$\$ 30000$}
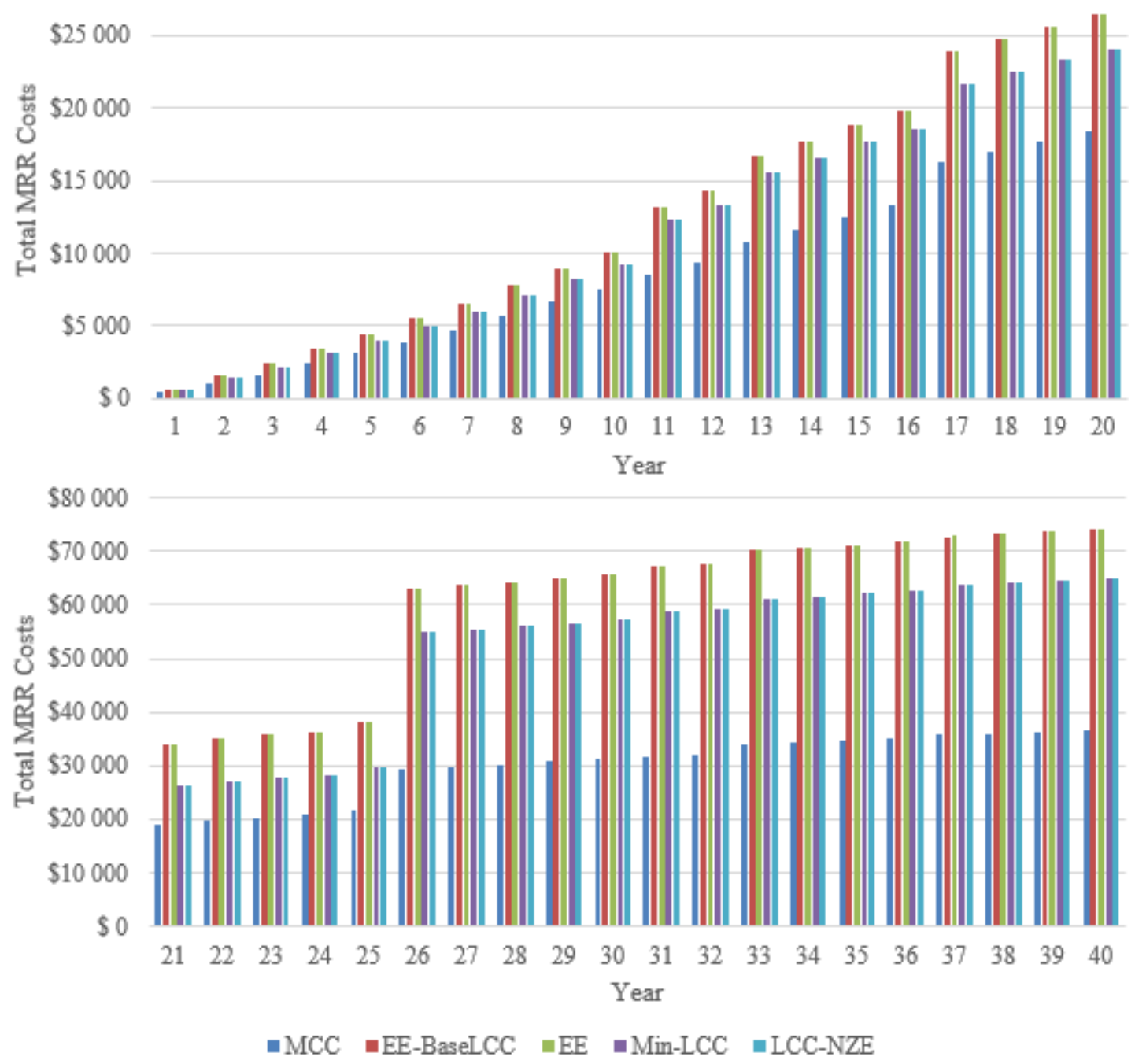

Figure 4-4 Present Value of Total MRR Costs for Selected Designs - Case 1

The present value of residual value of each design for a 40-year time period is presented in Figure 4-5. As previously noted, it is assumed that the full residual value is captured at resale. The MCC design has the lowest residual value, which is not surprising considering the salvage value of an item is a linear depreciation of its initial value over its useful life. As the MCC has the lowest total costs, it should also have the lowest residual value. There is a steady decrease in residual value as the resale value is prorated over the assumed lifetime of the EEM. The large increase in residual value in year 26 in all designs except for the MCC design is due to the replacement of the solar PV system, which essentially renews its useful life. 

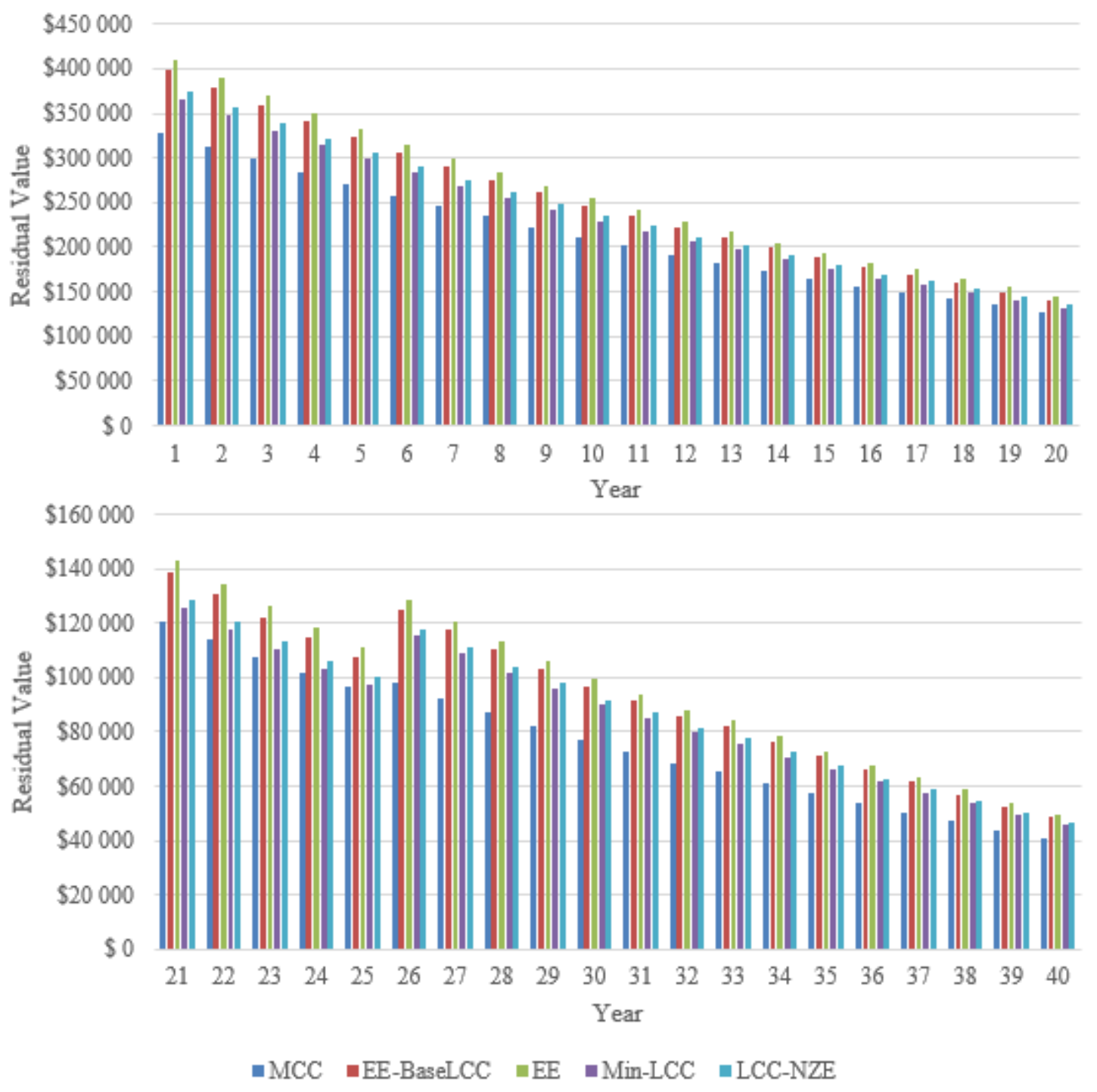

Figure 4-5 Present Value of Residual Value for Selected Designs - Case 1

\subsubsection{LCC Analysis and Payback Period of Key Designs - Case 1}

The previous two subsections represent major elements in the total LCC of the design: first costs and future costs. Figure 4-6 plots the present value of the lifecycle cost for a 40-year period while Figure 4-7 plots the difference between the selected designs and the MCC over the same 40 years. 

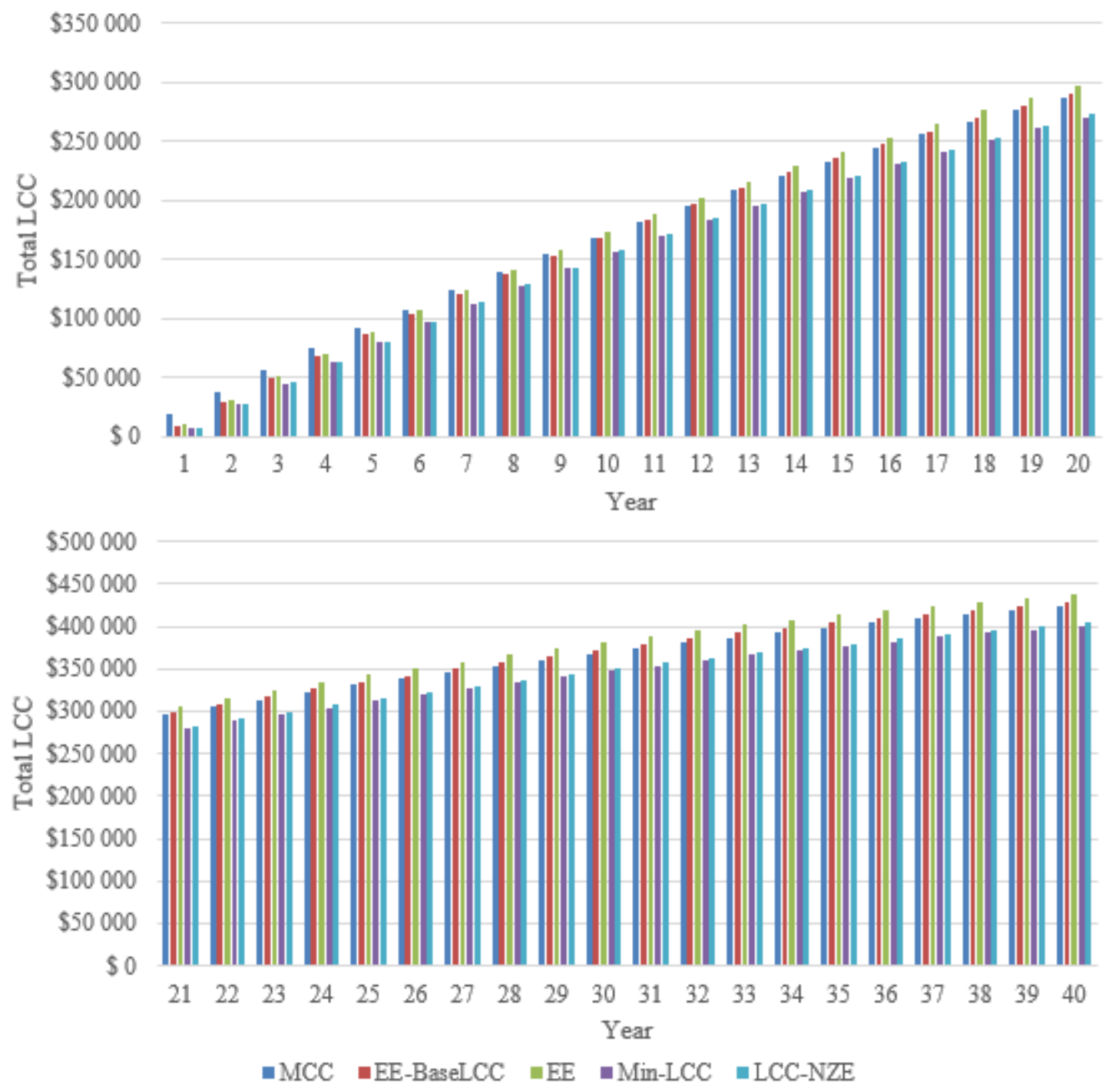

Figure 4-6 Present Value of Total LCC for Selected Designs - Case 1

By definition, the most efficient design at the baseline LCC for the assumed 10-year study period (EE-BaseLCC) has the same LCC as the baseline in year 10 (+/- \$100 tolerance). For shorter study periods, EE-BaseLCC has a lower LCC than the baseline due to the upfront federal tax credit for the solar PV system while becoming more expensive than the baseline design for all study periods greater than 10 years. It is out of the scope of this report to identify and analyze the EE-BaseLCC for each of the 40 study periods. For these reasons, EE-BaseLCC will be excluded from further analysis that considers results outside the 10-year study period.

A similar trend seen for EE-BaseLCC is observed for the most efficient overall design (EE) with its LCC being greater than the baseline design for all study periods greater than 6 years because the additional EEMs included in the design are not cost-effective. Regardless of the study period, the most efficient design never has additional LCC greater than $\$ 15000$, which is 
$4.4 \%$ of the baseline design's first costs. Both the minimum LCC design (Min-LCC) and minimum LCC net-zero design (LCC-NZE) realize lower LCCs than the baseline design for all 40 study periods. Net savings generally increase as the study period increases in length, though at an inconsistent rate due to component replacements and solar PV degradation.
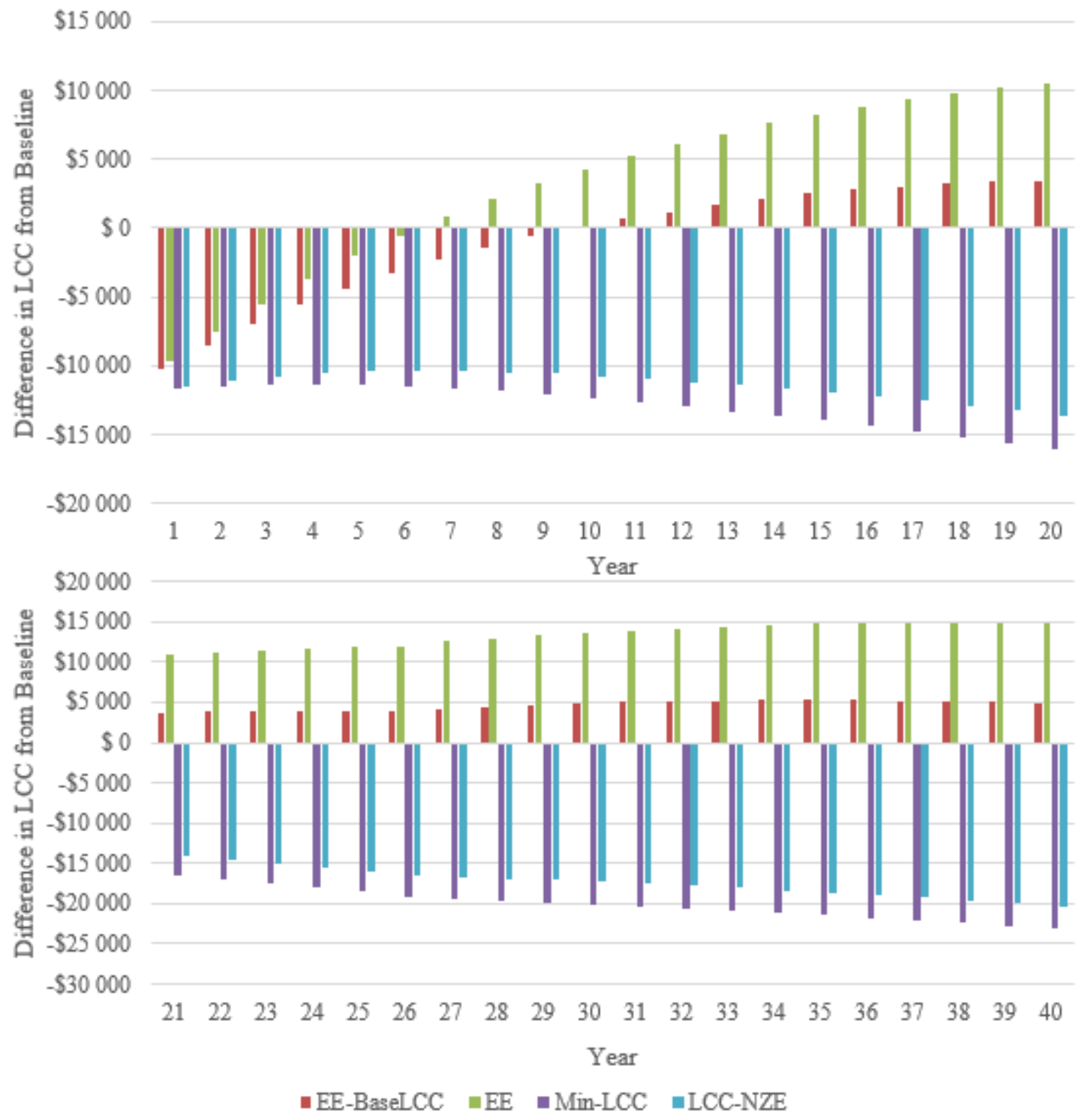

Figure 4-7 Present Value of the Difference in LCC relative to Baseline for Selected Designs- Case 1

An alternative to LCC analysis that is commonly implemented in considering energy efficiency investment decisions is modified payback period. For the purposes of this report the modified payback period refers to the length of time required to pay off the additional first costs of any EEM(s) relative to the baseline through future cost savings (all in present value terms). See 
Equation (4) in Section 3.2 for the details on how the modified payback period is calculated. Table 4-3 summarizes the modified payback period for the selected designs.

Table 4-3 Modified Payback Period for Selected Key Designs - Case 1

\begin{tabular}{|c|c|}
\hline Design & Payback Period* \\
\hline EE-BaseLCC & N/A \\
\hline EE & N/A \\
\hline Min-LCC & 14 years** \\
\hline LCC-NZE & \\
\hline $\begin{array}{l}* \text { N/A indicates that the option has a payback } \\
\text { period of longer than } 40 \text { years, if one exists at all } \\
* * \text { Obtained using linear interpolation; rounded } \\
\text { up to the next year }\end{array}$ \\
\hline
\end{tabular}

The most efficient design (EE) and the most efficient design for the same LCC as the baseline (EE-BaseLCC) have payback periods of greater than 40 years. Meanwhile, the minimum LCC design (Min-LCC) and the design with the lowest LCC while reaching net-zero energy performance (LCC-NZE) have payback periods of 14 years and 17 years, respectively. The use of the payback period provides much less information for the decision-maker and can lead to different outcomes. For example, EE-BaseLCC has the same LCC as the baseline (+/- \$100) over a 10-year study period, but according to the payback period approach it takes at least 40 years to recover the initial investment costs because the residual value of the building is not considered in payback period calculations. Also, if other factors beyond the economics have a role in the decision, such as the desire to decrease energy consumption or the environmental impacts, then the magnitude of the relative costs becomes important. For example, a homeowner may be willing to pay an additional \$40 000 upfront and have an increase of \$5 000 in total LCC over 30 years (in present value terms) as is the case for the $\mathbf{E E}$ design in order to have the social status of living in a "net-zero energy home." In this case, the payback period does not inform the decision-maker in a way to allow for such a trade-off consideration without the monetization of the additional benefits. Considering that non-monetary benefits may be monetized differently based on the individual home owner, no attempt is made in the analysis to incorporate them.

\subsubsection{Environmental Impact Analysis of Key Designs - Case 1}

Up to this point, the focus has been on the economic and energy performance of the key designs while ignoring the environmental impacts of increasing energy efficiency of a home to net-zero performance. Making comparisons among our five selected building designs based on environmental performance is done using twelve environmental impact categories and an 
environmental impact score (EIS) based on a weighted average of those twelve impact categories. Calculation of the EIS takes into account the environmental impacts from energy consumption and the environmental flows embodied in the building materials, both of which change across designs due to the different EEMs incorporated into each building design.

The environmental performance of the MCC design relative to the four alternative designs is likely to vary based on the impact category being considered; hence, an evaluation of environmental performance must consider all twelve environmental impact categories. As stated in Section 3.3, the twelve impact categories are: GWP, Primary Energy Consumption, Human Health - Cancer Effects, Human Health - Non-cancer Effects, Water Consumption, Ecological Toxicity, Eutrophication Potential, Land Use, Smog Formation, Acidification Potential, and Ozone Depletion.

The spider plot below (Figure 4-8) displays the results from measuring the impacts of the four alternative designs across all 12 impact categories relative to the MCC design (in percentage terms) given a 10-year study period. Each of the four energy-efficient design alternatives performs worse than the MCC design in at least half of the impact categories. The most significant difference in performance is seen with ecotoxicity, where the contributions of each alternative to this impact category are more than four times greater (a percentage point difference of more than 300) than that of the baseline. Drivers behind these relative differences in performance across the twelve impact categories are explained later in this section. 


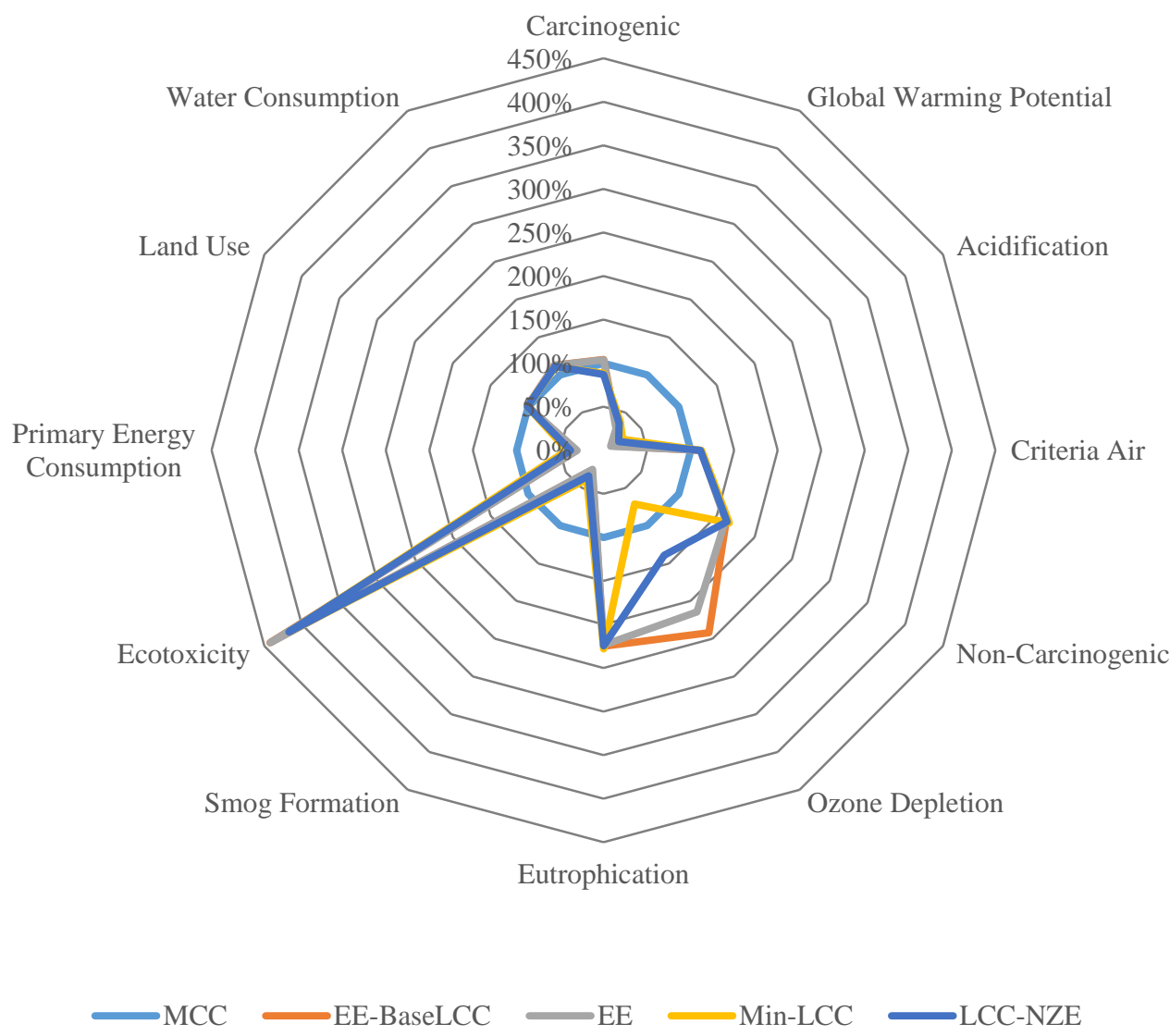

\section{Figure 4-8 Comparative Differences in Environmental Impacts relative to Baseline for Selected Designs- Case 1}

The above figure reveals that none of the energy-efficient alternatives perform better than the MCC design in all twelve of the environmental impact categories, making it difficult to draw a conclusion on which building design is the most environmentally-friendly. This is where a single metric that combines the performance across all 12 impact categories in a single score is beneficial in guiding decisions. The EIS is computed by first normalizing the resulting flows for each of the 12 impact categories since each category is expressed and measured in different units. The normalization process uses fixed scale references based on the relative annual contributions of total U.S. economic activity to each of the 12 impact categories. Table 4-4 lists the annual normalization reference values used in EIS calculations (Lippiatt, Kneifel et al. 2013). 
Table 4-4 Normalization References: Annual U.S. Contributions

\begin{tabular}{|c|c|c|}
\hline Impact Category & Units & Normalization Reference \\
\hline Global Warming Potential & $\mathrm{kg} \mathrm{CO} 2 \mathrm{e}$ & $7.16 \mathrm{E}+12$ \\
\hline HH - Criteria Air & kg PM10 eq. & $2.24 \mathrm{E}+10$ \\
\hline $\mathrm{HH}$ - Carcinogenic & CTUh & $1.05 \mathrm{E}+04$ \\
\hline HH - Non-carcinogenic & CTUh & $5.03 \mathrm{E}+05$ \\
\hline Water Consumption & $\mathrm{L}$ & $1.69 \mathrm{E}+14$ \\
\hline Ecotoxicity & CTUe & $3.82 E+13$ \\
\hline Eutrophication & kg $\mathrm{N}$ eq. & $1.01 \mathrm{E}+10$ \\
\hline Land Use & hectare (acre) & 7.32E+08 (1.81E+09) \\
\hline Smog Formation & $\mathrm{kg} \mathrm{O}_{3} \mathrm{eq}$ & $4.64 \mathrm{E}+11$ \\
\hline Acidification & mol H+ eq. & $1.66 \mathrm{E}+12$ \\
\hline Ozone Depletion & kg CFC-11-eq. & $5.10 \mathrm{E}+07$ \\
\hline Primary Energy Consumption & kWh (BTU) & $3.52 \mathrm{E}+13(1.20 \mathrm{E}+14)$ \\
\hline
\end{tabular}

The normalized impact assessment scores for the MCC, EE-BaseLCC, EE, Min-LCC, and LCC-NZE designs for a 10-year study period are displayed in Table 4-5. They were computed by dividing the initial impact category flows by the total U.S. contribution corresponding to that category. ${ }^{5}$

Normalized flows can be used to compare environmental performance across building designs and impact category, revealing potential areas of improvement. According to Table 4-5, the EE-BaseLCC and EE designs perform better than the MCC design in the areas of GWP, smog formation, acidification, and primary energy consumption. The Min-LCC design also outperforms the baseline in these four areas, in addition to improved performance in both the carcinogenic and ozone depletion impact categories. The LCC-NZE outperforms the baseline in all of these except ozone depletion. The reduced impacts on GWP, smog formation, ozone depletion, acidification, and primary energy consumption achieved by the four design

\footnotetext{
${ }^{5}$ The impact of a single building is small relative to the impacts of the total U.S. economy, resulting in normalized flows that are small fractions of a percent. BIRDS v3.0 adjusts these normalized values by multiplying them by the U.S. population ( $\sim 309$ million), creating normalized values reflecting the impacts per capita for each of the twelve impact categories.
} 
alternatives are primarily linked to the improved energy efficiency of these buildings over the baseline, which coincide with reductions in operating energy use. Further reductions in ozone depletion and carcinogenic impacts realized by the Min-LCC design are attributed to fewer embodied emissions due to the use of advanced framing and less installed insulation in both the basement and the walls of the first and second floor wall assemblies. Similarly, the additional reduction in ozone depletion impacts attained by the LCC-NZE design is associated with fewer embodied emissions attributed to the use of advanced framing and less wall insulation.

Table 4-5 Normalization Flows

\begin{tabular}{lccccc}
\hline Impact Category & MCC & Min-LCC & LCC-NZE & EE-BaseLCC & EE \\
\hline Global Warming Potential & 8.40 & 3.22 & 3.02 & 2.41 & 2.39 \\
HH - Criteria Air & 1.05 & 1.18 & 1.17 & 1.17 & 1.17 \\
HH - Carcinogenic & 5.46 & 4.82 & 4.74 & 5.67 & 5.67 \\
HH - Non-carcinogenic & 2.81 & 4.69 & 4.60 & 4.55 & 4.55 \\
Water Consumption & 2.67 & 2.96 & 2.98 & 3.00 & 3.01 \\
Ecotoxicity & 0.10 & 0.40 & 0.40 & 0.42 & 0.42 \\
Eutrophication & 0.94 & 2.15 & 2.12 & 2.10 & 2.12 \\
\hline Land Use & 2.68 & 2.70 & 2.70 & 2.70 & 2.70 \\
\hline Smog Formation & 9.40 & 3.62 & 3.21 & 2.42 & 2.38 \\
Acidification & 14.62 & 3.66 & 2.91 & 1.42 & 1.36 \\
\hline Ozone Depletion & 0.42 & 0.30 & 0.59 & 0.87 & 0.90 \\
\hline Primary Energy Consumption & 4.99 & 2.10 & 1.90 & 1.51 & 1.51 \\
\hline
\end{tabular}

After flows have been normalized, an EIS is calculated by taking a weighted average of the normalized flows. The EIS in this analysis serves as an indicator of the overall environmental performance of a single building design, where a higher score suggests that the building will have a greater environmental impact over its lifetime. The chosen weights used for EIS computation greatly affect the relative environmental performance. The BIRDS software offers its users five options for weighting the environmental impact categories. The first two options are based on weights developed by the EPA Science Advisory Board (SAB) and the NIST Building Environmental and Economic Sustainability (BEES) stakeholder panel. The third option assumes an equal weighting approach, assigning a weight of $8.3 \%$ to each of the twelve impact categories, while the fourth is the "Carbon-Only" option that assigns $100 \%$ of the weight 
to the GWP category. The fifth and final option allows BIRDS users to assign their own weighting to each category. Refer to Lippiatt et al. (2013) for further details on the aforementioned weighting approaches.

Distinct differences in the weighting values associated with each approach reveal differences in the importance of each environmental impact to an individual user. For example, a user of the SAB weights believes that GWP and Land Use impacts are of greatest importance. On the other hand, a user of the BEES Stakeholder Panel weights considers GWP and Primary Energy Consumption to be the "highest-risk" problems. Table 4-6 lists the weights for the first two weighting options.

Table 4-6 EIS Weighting Approaches

\begin{tabular}{lccc}
\hline Impact Category & $\begin{array}{c}\text { Equal } \\
\text { Weighting }\end{array}$ & SAB & $\begin{array}{c}\text { BEES Stakeholder } \\
\text { Panel }\end{array}$ \\
\hline Global Warming Potential & 8.3 & 18 & 29.9 \\
HH - Criteria Air & 8.3 & 7 & 10.3 \\
\hline HH - Carcinogenic & 8.3 & 7 & 9.3 \\
\hline HH - Non-carcinogenic & 8.3 & 8 & 8.2 \\
\hline Water Consumption & 8.3 & 3 & 8.2 \\
\hline Ecotoxicity & 8.3 & 12 & 7.2 \\
\hline Eutrophication & 8.3 & 5 & 6.2 \\
\hline Land Use & 8.3 & 18 & 6.2 \\
\hline Smog Formation & 8.3 & 5 & 5.2 \\
\hline Acidification & 8.3 & 7 & 4.1 \\
\hline Ozone Depletion & 8.3 & 5 & 3.1 \\
\hline Primary Energy Consumption & 8.3 & 5 & 2.1 \\
\hline
\end{tabular}

Graphical illustrations of the computed EISs and the individual contributions of the normalized flows to the EIS are captured in Figure 4-9, Figure 4-10, Figure 4-11, and Figure 4-12. The normalized flows in Figure 4-9 have been weighted using the Equal Weighting approach. According the graph, the MCC design is the least environmentally friendly design, with an EIS of 4.46. Over the course of its life cycle it contributes significantly to acidification, GWP, and 
smog formation. The EE design proves to have the least impact on the environment with an EIS of approximately 2.35. The EE-BaseLCC design follows closely behind with an EIS of roughly 2.36. Regardless of the alternative design, all lead to significantly lower environmental impacts once the individual impact categories are normalized and weighted to account for equal importance across categories.

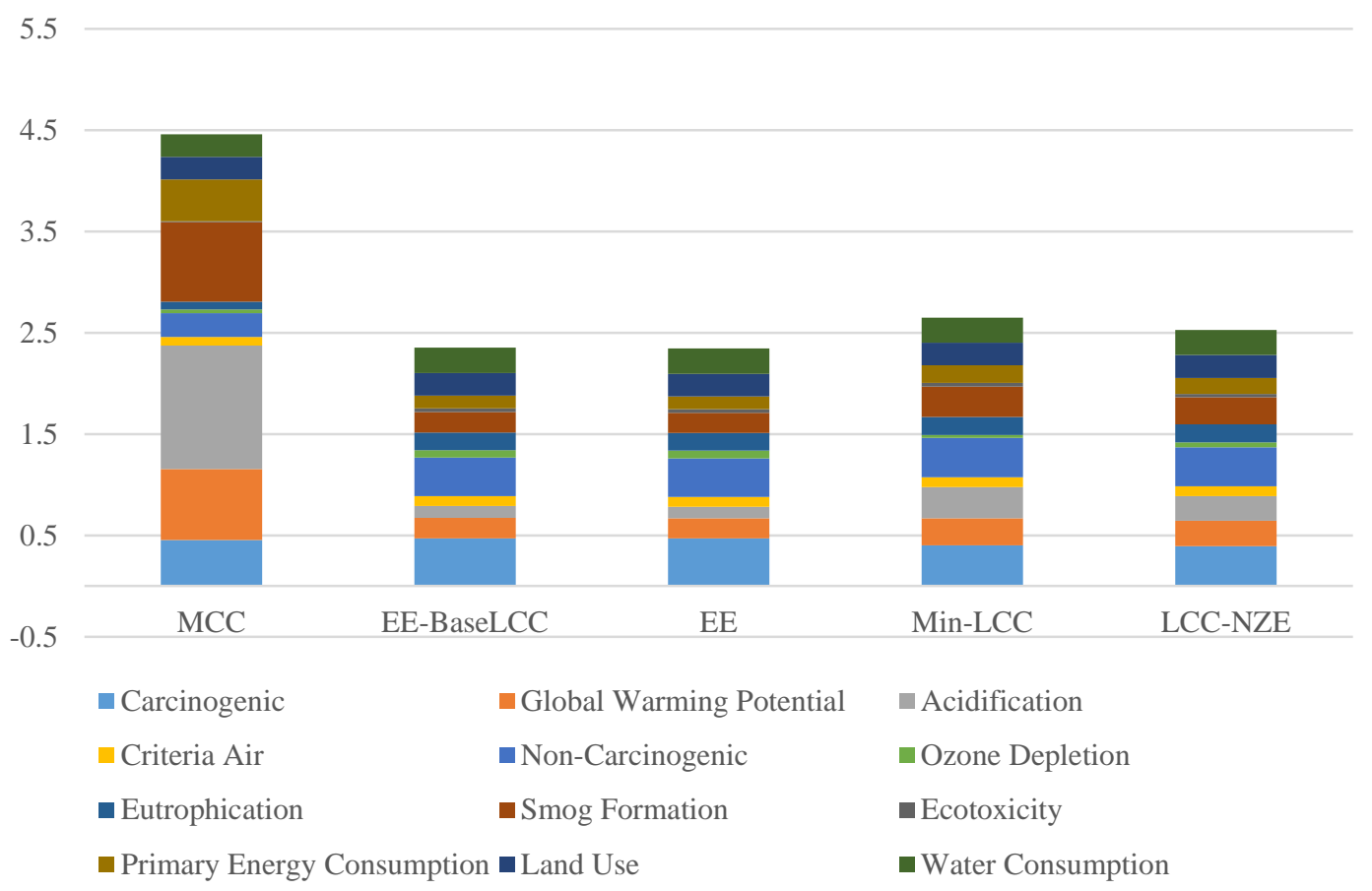

Figure 4-9 EIS for Selected Designs using Equal Weighting Approach - Case 1

The EISs displayed in Figure 4-10 are based on environmental preferences matching those of the BEES Stakeholder Panel weights. All of the design alternatives continue to outperform the MCC design, with EISs well below 3.00. Figure 4-3 reveals the effects switching to a series of unequal weights can have on EIS computations. For example, all of the design alternatives perform worse than the baseline in categories such as eutrophication and ecotoxicity. Their contributions to the overall EIS are minimal partly because they are not weighted heavily. However, the contributions of GWP, criteria air, and non-carcinogenics - categories where the alternatives perform better than the baseline - are significant given that close to $50 \%$ of the BEES weights are assigned to these impact categories. 


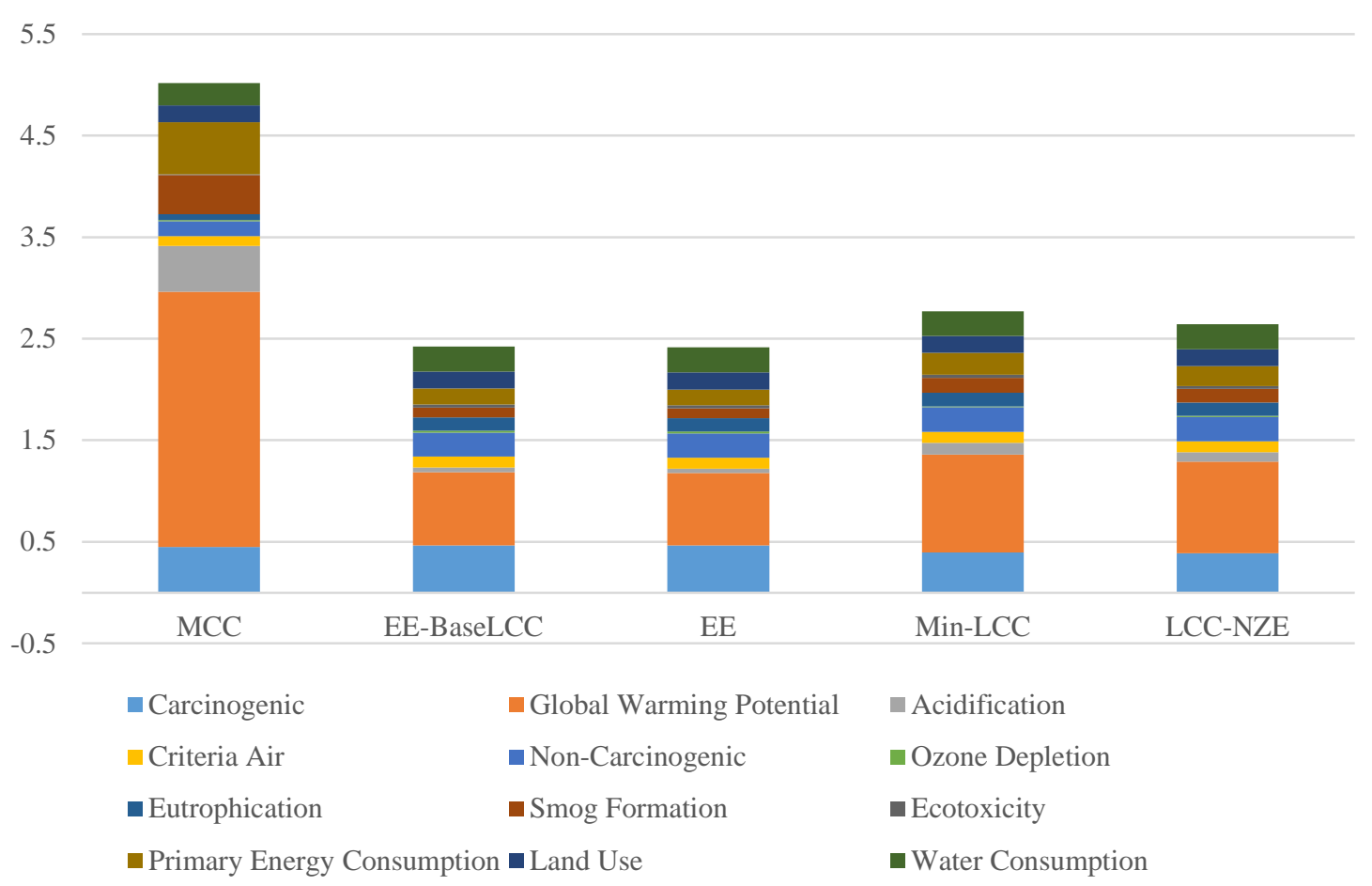

Figure 4-10 EIS for Selected Designs using BEES Weighting Approach - Case 1

A similar pattern is revealed by Figure 4-11, which applies the SAB series of weights to derive the EISs. Impact category flows more negatively affected by all of the energy-efficient design alternatives are weighted less than category flows positively impacted, leading to smaller contributions to the overall EIS. The adopted EEMs captured in the four design alternatives reduce the baseline EIS by almost half. Regardless of the alternative design, all lead to significantly lower environmental impacts once the individual impact categories are normalized and weighted to account for their relative importance across categories. 


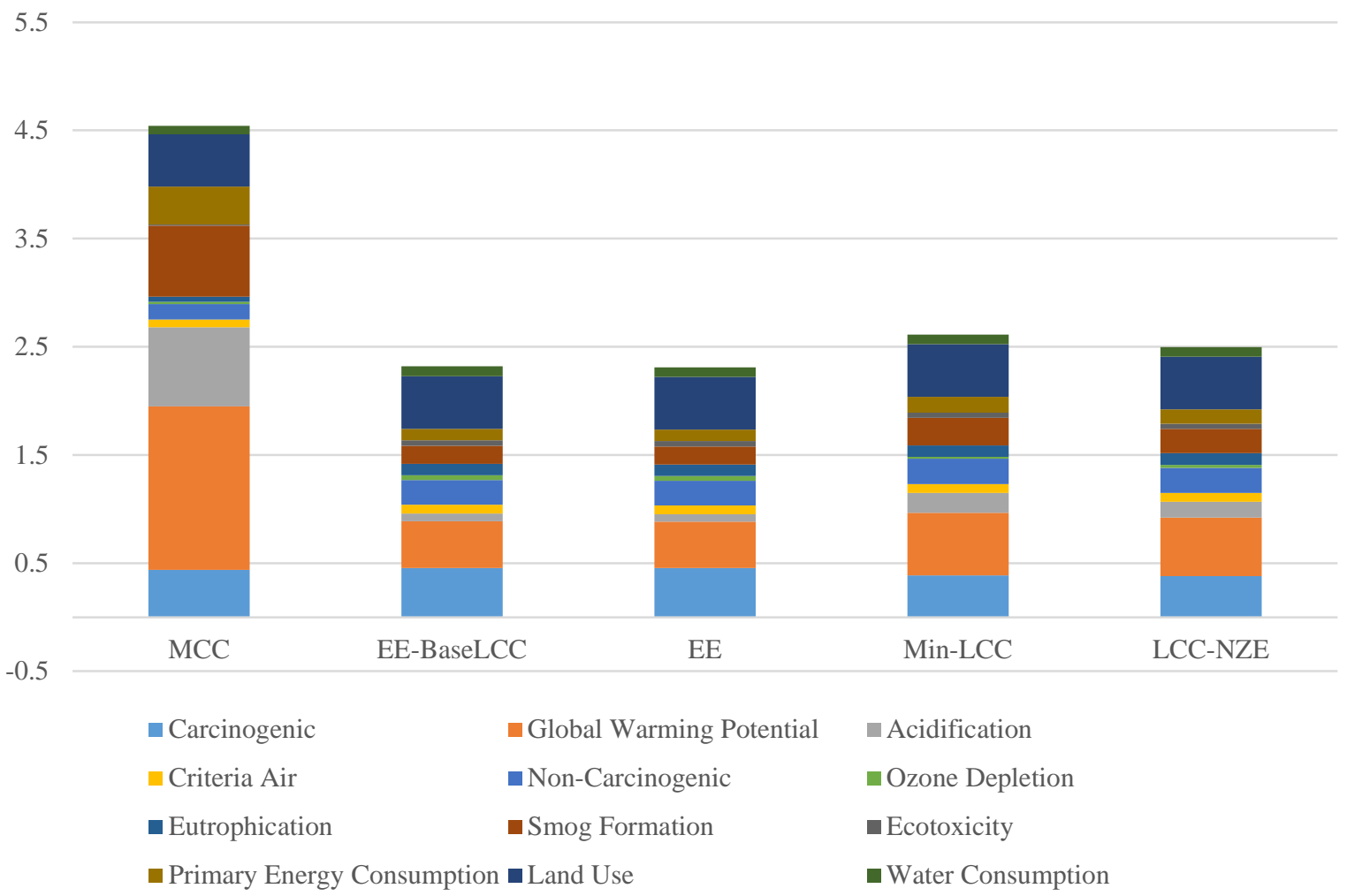

Figure 4-11 EIS for Selected Designs using SAB Weighting Approach - Case 1

Emphasizing the importance of a building's carbon footprint through use of the Carbon Footprint Only weights shown in Figure 4-12 again suggests that there is a vast improvement in the environmental performance of the four alternatives relative to the baseline, with the $\mathbf{E E}$ and $\mathbf{E E}$ BaseLCC designs showing the most improvement. Regardless of the alternative design, all lead to significantly lower environmental impacts once the individual impact categories are normalized and weighted to account for their relative importance across categories. 


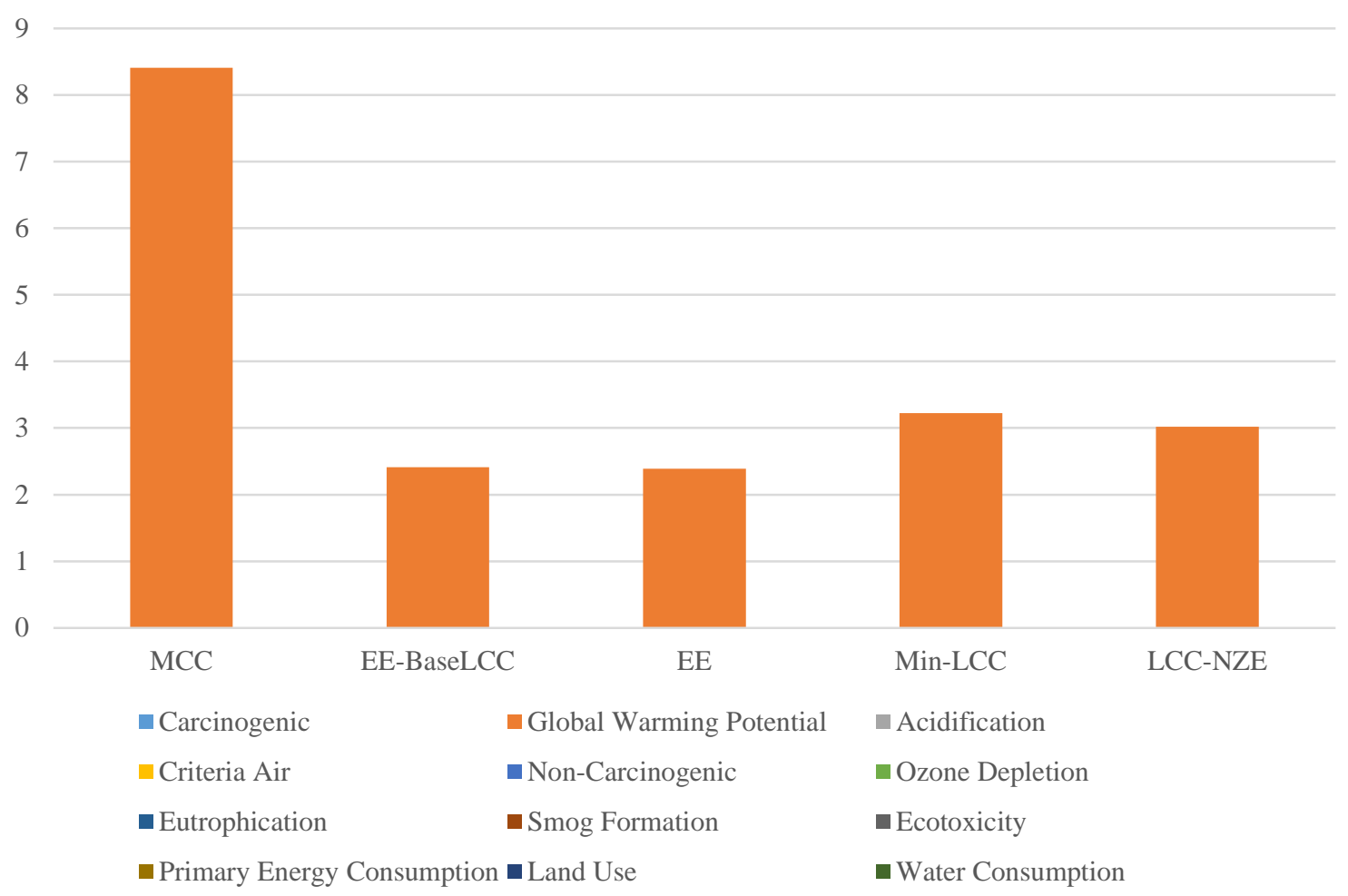

Figure 4-12 EIS for Selected Designs using Carbon Only Weighting Approach - Case 1

Under the assumption that the BIRDS user is primarily interested in the effects of improving the energy efficiency of a building on the building's environmental footprint, Figure 4-12 suggests that the EE design leads to the greatest improvement in GWP relative to the MCC design, followed closely behind by the EE-BaseLCC design. Regardless of the alternative design, all lead to significantly lower carbon footprints.

Table 4-7, Table 4-8, and Table 4-9, tabulations of the data in Figure 4-9, Figure 4-10, and Figure 4-11, contain the total EISs and the weighted impact category components for each design based on the Equal Weighting, BEES Stakeholder Panel Weighting, and SAB Weighting approaches, respectively. The EISs once again indicate that all of the design alternatives considered are overall more environmentally friendly over their lifetime than the baseline MCC design. It is clear that the weights chosen by the user to reflect their own individual environmental preferences affect the magnitude of the differences in the measured environmental performance based on the EIS. For example, use of the Equal Weighting convention leads to differences in EISs (measured in \% change) between the baseline design and the others ranging from $41 \%$ to $47 \%$. However, percent differences in EISs based on the BEES Stakeholder Panel and SAB weights, range from $45 \%$ to $52 \%$ and from $43 \%$ to $49 \%$, respectively. Much of the divergence in EISs between the Equal Weighting approach and the others is largely attributed to significant reductions in GWP achieved with energy efficiency improvements along with the BEES and SAB approaches weighting GWP heavily. 
Table 4-7 Normalized Impact by Category and EIS - Equal Weighting

\begin{tabular}{lccccc}
\hline Impact Category & MCC & Min-LCC & LCC-NZE & EE-BaseLCC & EE \\
\hline GWP & 0.70 & 0.27 & 0.25 & 0.20 & 0.20 \\
HH - Criteria Air & 0.09 & 0.10 & 0.10 & 0.10 & 0.10 \\
HH - Carcinogenic & 0.46 & 0.40 & 0.40 & 0.47 & 0.47 \\
\hline HH - Non-carcinogenic & 0.23 & 0.39 & 0.38 & 0.38 & 0.38 \\
Water Consumption & 0.22 & 0.25 & 0.25 & 0.25 & 0.25 \\
\hline Ecotoxicity & 0.01 & 0.03 & 0.03 & 0.04 & 0.04 \\
\hline Eutrophication & 0.08 & 0.18 & 0.18 & 0.18 & 0.18 \\
Land Use & 0.22 & 0.22 & 0.22 & 0.23 & 0.23 \\
\hline Smog Formation & 0.78 & 0.30 & 0.27 & 0.20 & 0.20 \\
\hline Acidification & 1.22 & 0.31 & 0.24 & 0.12 & 0.11 \\
\hline Ozone Depletion & 0.04 & 0.02 & 0.05 & 0.07 & 0.08 \\
\hline Primary Energy Consumption & 0.42 & 0.18 & 0.16 & 0.13 & 0.13 \\
\hline Total & 4.46 & 2.65 & 2.53 & 2.36 & 2.35 \\
\hline \% Difference & - & $-41 \%$ & $-43 \%$ & $-47 \%$ & $-47 \%$ \\
\hline
\end{tabular}


Table 4-8 Normalized Impact by Category and EIS - BEES Weighting

\begin{tabular}{lccccc}
\hline Impact Category & MCC & Min-LCC & LCC-NZE & EE-BaseLCC & EE \\
\hline GWP & 2.51 & 0.96 & 0.90 & 0.72 & 0.71 \\
HH - Criteria Air & 0.10 & 0.11 & 0.11 & 0.11 & 0.11 \\
HH - Carcinogenic & 0.45 & 0.40 & 0.39 & 0.46 & 0.46 \\
\hline HH - Non-carcinogenic & 0.15 & 0.24 & 0.24 & 0.24 & 0.24 \\
Water Consumption & 0.22 & 0.24 & 0.24 & 0.25 & 0.25 \\
\hline Ecotoxicity & 0.01 & 0.03 & 0.03 & 0.03 & 0.03 \\
Eutrophication & 0.06 & 0.13 & 0.13 & 0.13 & 0.13 \\
\hline Land Use & 0.17 & 0.17 & 0.17 & 0.17 & 0.17 \\
\hline Smog Formation & 0.39 & 0.15 & 0.13 & 0.10 & 0.10 \\
\hline Acidification & 0.45 & 0.11 & 0.09 & 0.04 & 0.04 \\
\hline Ozone Depletion & 0.01 & 0.01 & 0.01 & 0.02 & 0.02 \\
\hline Primary Energy Consumption & 0.51 & 0.22 & 0.20 & 0.16 & 0.16 \\
\hline Total & 5.02 & 2.77 & 2.64 & 2.42 & 2.41 \\
\hline \% Difference & - & $-45 \%$ & $-47 \%$ & $-52 \%$ & $-52 \%$ \\
\hline
\end{tabular}


Table 4-9 Normalized Impact by Category and EIS - SAB Weighting

\begin{tabular}{lccccc}
\hline Impact Category & MCC & Min-LCC & LCC-NZE & EE-BaseLCC & EE \\
\hline GWP & 1.51 & 0.58 & 0.54 & 0.43 & 0.43 \\
HH - Criteria Air & 0.07 & 0.08 & 0.08 & 0.08 & 0.08 \\
HH - Carcinogenic & 0.44 & 0.39 & 0.38 & 0.45 & 0.45 \\
HH - Non-carcinogenic & 0.14 & 0.23 & 0.23 & 0.23 & 0.23 \\
Water Consumption & 0.08 & 0.09 & 0.09 & 0.09 & 0.09 \\
Ecotoxicity & 0.01 & 0.05 & 0.05 & 0.05 & 0.05 \\
Eutrophication & 0.05 & 0.11 & 0.11 & 0.11 & 0.11 \\
Land Use & 0.48 & 0.49 & 0.49 & 0.49 & 0.49 \\
Smog Formation & 0.66 & 0.25 & 0.22 & 0.17 & 0.17 \\
Acidification & 0.73 & 0.18 & 0.15 & 0.07 & 0.07 \\
Ozone Depletion & 0.02 & 0.01 & 0.03 & 0.04 & 0.05 \\
\hline Primary Energy Consumption & 0.35 & 0.15 & 0.13 & 0.11 & 0.11 \\
\hline Total & 4.54 & 2.61 & 2.50 & 2.32 & 2.31 \\
\hline \% Difference & - & $-43 \%$ & $-45 \%$ & $-49 \%$ & $-49 \%$ \\
\hline
\end{tabular}

The results listed in the tables above are derived using only three series of weighting, so they should be considered with caution. Alternative assumptions of environmental preferences may lead to significantly different results. Also, the measured environmental flows associated with a building and its components have been annualized, which means the environmental performance of the building is likely to vary with increased study period lengths as the total flows associated with operating energy consumption increases. 


\subsection{Case 2: 3 \% Discount Rate, Average Construction Quality, 20 \% Down / 80 \% Loan Financing}

Case 2 is identical to Case 1 ( $3 \%$ discount rate and average construction quality) except the financing option is a 30-year loan financing with $20 \%$ down payment. This section will analyze the results under these assumptions and identify the key drivers of energy, economic, and environmental performance.

\subsubsection{Summary of Key Designs - Case 2}

Financing of a home purchase lowers upfront costs (down payment) while increasing future costs (mortgage payments). The selected designs under the new financing option are given in Table 4-10 with the EEMs that are different than Case 1 in gray.

Table 4-10 Selected Key Designs - Case 2

\begin{tabular}{|c|c|c|c|c|}
\hline $\begin{array}{l}\text { Design } \\
\text { Category }\end{array}$ & EE-BaseLCC & EE** & Min-LCC** & LCC-NZE** \\
\hline Windows & $\begin{array}{c}\text { U Factor: } \\
1.14 \mathrm{~W} / \mathrm{m}^{2}-\mathrm{K} \\
\left(0.2 \mathrm{Btu} / \mathrm{h} \cdot \mathrm{ft}^{2}-\mathrm{F}\right) \\
\text { SHGC: } 0.25\end{array}$ & $\begin{array}{c}\text { U Factor: } \\
1.14 \mathrm{~W} / \mathrm{m}^{2}-\mathrm{K} \\
\left(0.2 \mathrm{Btu} / \mathrm{h} \cdot \mathrm{ft}^{2}-\mathrm{F}\right) \\
\text { SHGC: } 0.25\end{array}$ & $\begin{array}{c}\text { U Factor: } \\
1.14 \mathrm{~W} / \mathrm{m}^{2}-\mathrm{K} \\
\left(0.2 \mathrm{Btu} / \mathrm{h} \cdot \mathrm{ft}^{2}-\mathrm{F}\right) \\
\text { SHGC: } 0.25\end{array}$ & $\begin{array}{c}\text { U Factor: } \\
1.14 \mathrm{~W} / \mathrm{m}^{2}-\mathrm{K} \\
\left(0.2 \mathrm{Btu} / \mathrm{h} \cdot \mathrm{ft}^{2}-\mathrm{F}\right) \\
\text { SHGC: } 0.25\end{array}$ \\
\hline HVAC & $\begin{array}{c}\text { Air-to-air heat pump } \\
\text { (SEER 16.5/ HSPF 9.1) }\end{array}$ & $\begin{array}{c}\text { Air-to-air heat pump } \\
\text { (SEER 16.5/ HSPF 9.1) }\end{array}$ & $\begin{array}{c}\text { Air-to-air heat pump } \\
\text { (SEER 13.0/ HSPF 7.7) }\end{array}$ & $\begin{array}{c}\text { Air-to-air heat pump } \\
\text { (SEER 13.0/ HSPF 7.7) }\end{array}$ \\
\hline Ventilation & Separate HRV system & Separate HRV system & Outdoor air* & Outdoor air* \\
\hline Air Flow Rate & $0.63 \mathrm{ACH}_{50}$ & $0.63 \mathrm{ACH}_{50}$ & $0.63 \mathrm{ACH}_{50}$ & $0.63 \mathrm{ACH}_{50}$ \\
\hline Lighting & $100 \%$ efficient fixtures & $100 \%$ efficient fixtures & $100 \%$ efficient fixtures & $100 \%$ efficient fixtures \\
\hline Solar PV & $10.2 \mathrm{~kW}$ & $10.2 \mathrm{~kW}$ & $10.2 \mathrm{~kW}$ & $10.2 \mathrm{~kW}$ \\
\hline DHW & $\begin{array}{l}\text { Heat pump water heater } \\
\text { w/ solar thermal system }\end{array}$ & $\begin{array}{l}\text { Heat pump water heater } \\
\text { w/ solar thermal system }\end{array}$ & Heat pump water heater & Heat pump water heater \\
\hline Roof & $\begin{array}{c}\text { Roof insulation: } \\
\text { RsI-7.92 + 5.28 } \\
(\text { R-45 + 30) } \\
\end{array}$ & $\begin{array}{l}\text { Roof insulation: } \\
\text { R }_{\text {SI-7.92 + } 5.28} \\
(\mathrm{R}-45+30) \\
\end{array}$ & $\begin{array}{c}\text { Ceiling Insulation: } \\
\mathrm{R}_{\mathrm{SI}}-8.63 \\
(\mathrm{R}-49)\end{array}$ & $\begin{array}{l}\text { Roof insulation: } \\
\mathrm{R}_{\mathrm{SI}}-7.92+0.7 \\
(\mathrm{R}-45+4)\end{array}$ \\
\hline Wall & $\begin{array}{c}\text { Framing: Advanced } \\
\text { Insulation: } \mathrm{R}_{\mathrm{SI}}-3.5+4.2 \\
(\mathrm{R}-20+24)\end{array}$ & $\begin{array}{c}\text { Framing: Advanced } \\
\text { Insulation: } \mathrm{R}_{\mathrm{SI}}-3.5+4.2 \\
(\mathrm{R}-20+24)\end{array}$ & $\begin{array}{l}\text { Framing: Advanced } \\
\text { Insulation: } \mathrm{R}_{\mathrm{SI}}-3.5 \\
(\mathrm{R}-20+0)\end{array}$ & $\begin{array}{c}\text { Framing: Advanced } \\
\text { Insulation: } \mathrm{R}_{\mathrm{SI}}-3.5+2.1 \\
(\mathrm{R}-20+12)\end{array}$ \\
\hline $\begin{array}{l}\text { Foundation } \\
\text { Wall }\end{array}$ & $\begin{array}{l}\mathrm{R}_{\mathrm{SI}}-3.9 \\
(\mathrm{R}-22)\end{array}$ & $\begin{array}{l}\mathrm{R}_{\mathrm{SI}}-3.9 \\
(\mathrm{R}-22)\end{array}$ & $\begin{array}{c}\mathrm{R}_{\mathrm{SI}}-1.41 \\
(\mathrm{R}-8)\end{array}$ & $\begin{array}{c}\mathrm{R}_{\mathrm{SI}}-1.41 \\
(\mathrm{R}-8)\end{array}$ \\
\hline $\begin{array}{l}\text { Foundation } \\
\text { Floor }\end{array}$ & $\begin{array}{c}\mathrm{R}_{\mathrm{SI}}-1.76 \\
(\mathrm{R}-10)\end{array}$ & $\begin{array}{l}\mathrm{R}_{\mathrm{Sl}^{-}}-0 \\
(\mathrm{R}-0)\end{array}$ & $\begin{array}{l}\mathrm{R}_{\mathrm{Sl}^{-}}-0 \\
(\mathrm{R}-0)\end{array}$ & $\begin{array}{l}\mathrm{R}_{\mathrm{SI}^{-}}-0 \\
(\mathrm{R}-0)\end{array}$ \\
\hline $\begin{array}{c}\text { Energy } \\
\text { Reduction } \\
(\%) \\
\end{array}$ & $112 \%$ & $114 \%$ & $94 \%$ & $101 \%$ \\
\hline $\begin{array}{c}\text { Change in } \\
\text { LCC (10-yr) }\end{array}$ & $-\$ 8$ & $-\$ 1097$ & $-\$ 14919$ & $-\$ 13870$ \\
\hline
\end{tabular}


For Case 2, the EE, Min-LCC and LCC-NZE designs are identical to those designs identified in Case 1. The EE design will be the same across all cases considered because changing the financing option does not change the energy performance of a building design. The most costeffective design overall (Min-LCC) and the most cost-effective net-zero energy design (LCCNZE) remain the same as in Case 1, which implies that the optimal designs are robust to the method of home purchase. Financing of a home purchase makes it more economically viable to increase energy efficiency. For Case 2, Min-LCC and LCC-NZE both lead to more than \$2500 in additional net savings than in Case 1 (\$14 919 versus \$12 344 and \$13 870 versus \$10 749, respectively). The only design that changes for Case 2 relative to Case 1 is EE-BaseLCC, which increases levels of insulation in the roof assembly and foundation wall and floor assemblies leading to the EE-BaseLCC design being identical to the design of the NZERTF during Phase I of its demonstration phase. These differences lead to approximately the same energy savings (112 \% versus 113 \%) and change in LCC (-\$8 versus \$67) relative to EE-BaseLCC for Case 1.

\subsubsection{First Cost Analysis of Key Designs - Case 2}

Figure 4-13 shows that financing the home purchase with an 80/20 loan instead of $100 \%$ cash leads to lower initial costs for all five designs because only $20 \%$ of the costs are paid at the date of purchase. The most efficient design now only has an \$86 061 down payment instead of the $\$ 418382$ payment in Case $1 .^{6}$ The other designs are reduced in the same manner, with the baseline MCC design remaining the least expensive upfront (\$68 820) while the most expensive design is now the most efficient at the baseline LCC (\$86 606). Interestingly, the most efficient design (EE) has lower first costs than the most energy efficient design at the same cost as the baseline (EE-BaseLCC), which shows that additional energy efficiency that can be obtained while reducing first costs.

\footnotetext{
${ }^{6}$ This value is slightly off from the exact value of $20 \%$ of $\$ 418382$ due to minor rounding errors that accumulate through the process of building the database of LCC results.
} 


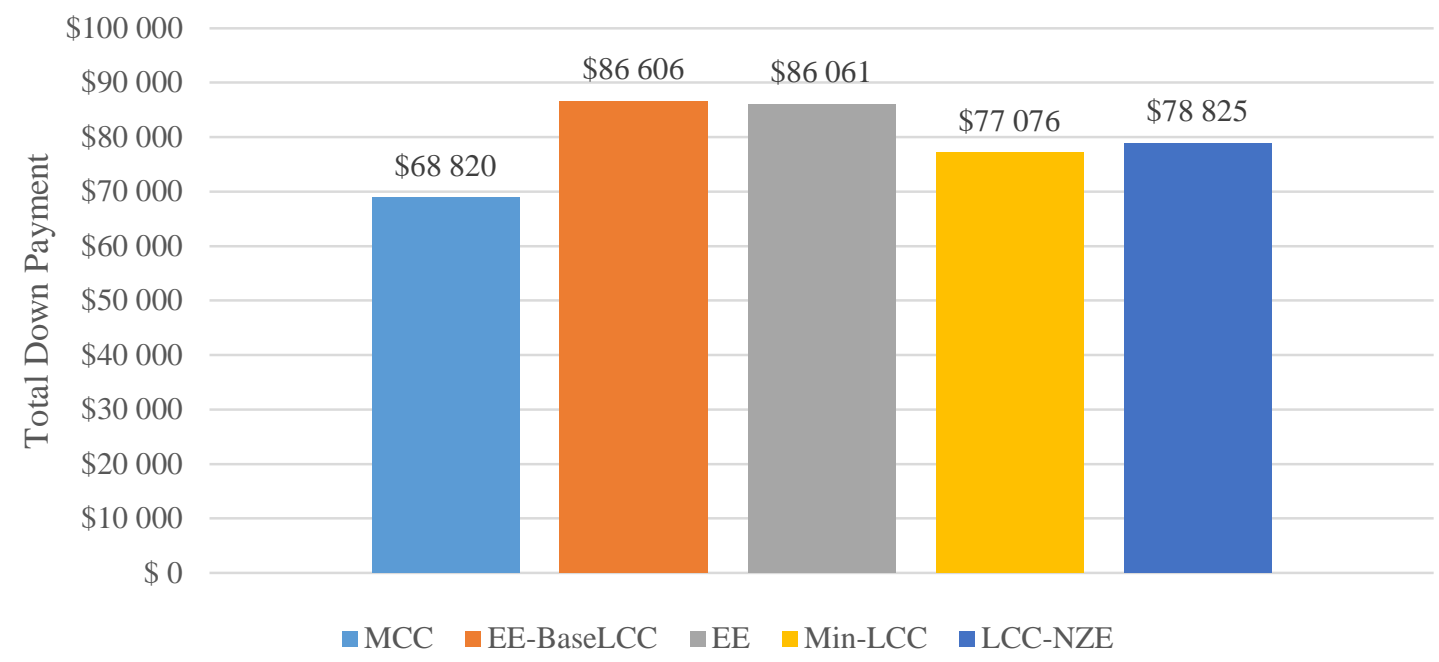

Figure 4-13 Total First Costs for Selected Designs - Case 2

Figure 4-14 shows the incremental first costs for each of the key alternative designs. The lowest LCC design that still achieves net-zero energy performance (LCC-NZE) requires additional first costs of $\$ 10$ 005. The lowest LCC over the 10-year study period reaches near net zero energy performance at a $94 \%$ reduction while requiring an additional \$8256 in costs upfront. As in Case 1, the $10.2 \mathrm{~kW}$ solar PV system comprises the majority of the first costs for each alternative design. The remaining trends observed for Case 1 also hold here as well.

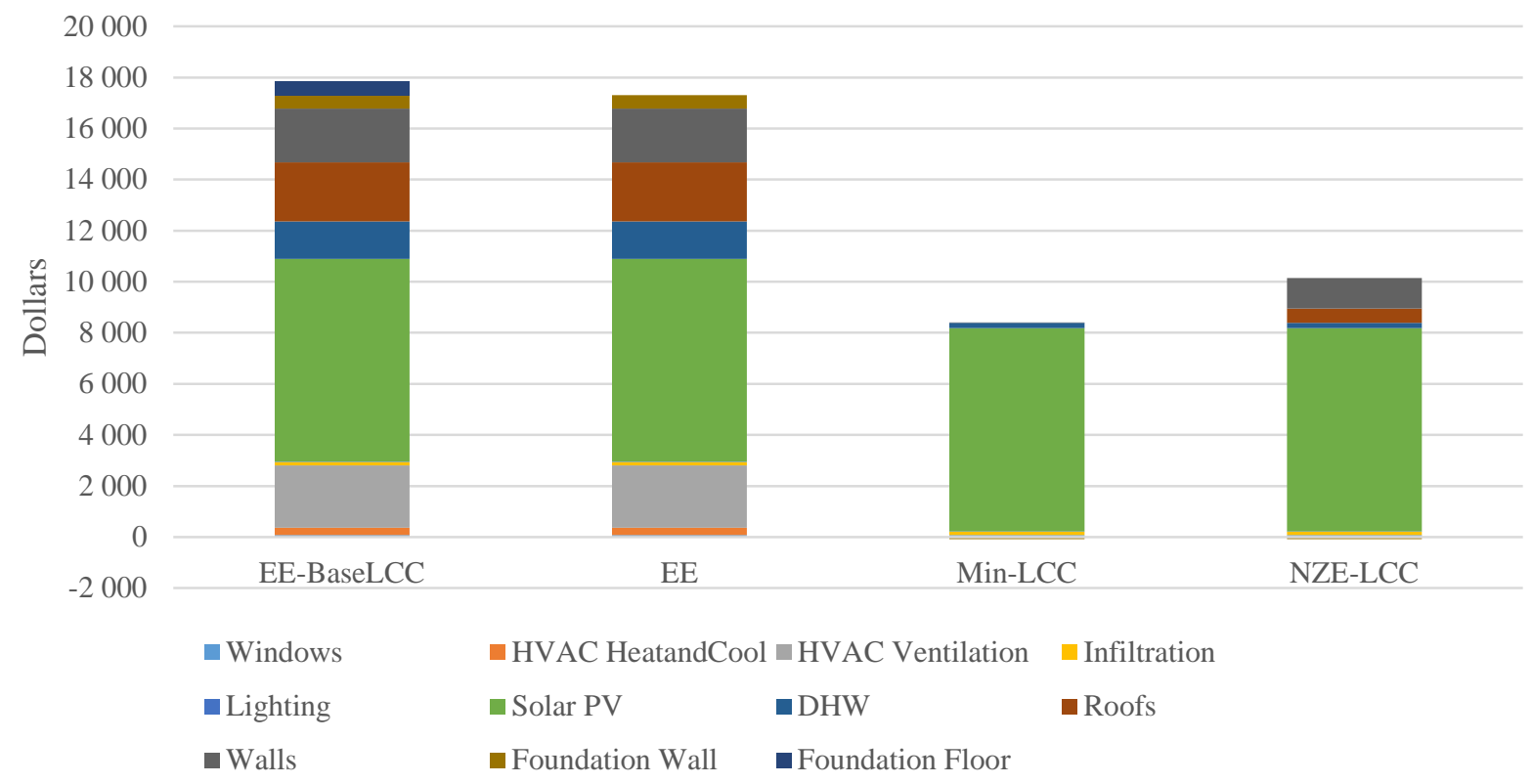

Figure 4-14 Incremental First Costs Relative to Baseline for Selected Designs - Case 2 


\subsubsection{Future Cost Analysis of Key Designs - Case 2}

The energy costs and total MRR costs are independent of the financing option as any costs incurred under them occur after the initial payment. Residual value is unaffected as well since the actual value of any components of the buildings are used for the residual value calculation, and not the amount paid at construction under the $20 \%$ down financing option. The only changes occur for the most efficient design at the baseline LCC (EE-BaseLCC), which includes different EEMs. EE-BaseLCC for Case 1 leads to slightly lower net payments for excess energy production relative to Case 2 due to a $1 \%$ decrease in annual energy savings. MRR costs for EE-BaseLCC are identical to those from Case 1 because the EEMs that changed were not building components that lead to MRR costs. The residual value for Case 2 follows the same trend with slightly higher values than those for Case 1 because the EEMs for EE-BaseLCC for Case 2 require additional insulation, and therefore additional construction costs and building resale value.

An additional future cost that is not considered in Case 1, but must be considered in Case 2, is mortgage loan payments. Nominal loan payments are the same across the 30-year loan while the discounted present value of those yearly loan payments, plotted in Figure 4-15, show a decreasing trend. Selecting to finance a home purchase with a loan provides LCC savings over a $100 \%$ cash purchase if the discounted present value of the loan payments plus the down payment is less than the total cost of the construction. For the minimum LCC design (Min-LCC), the down payment (\$77 076) plus the total discounted loan payments (\$269 670) equals \$346 746, or \$26 711 less than the total construction costs (\$373 457). In this case, it is more cost-effective to select the 80/20 loan. Note that not all loans will result in a reduced LCC, however, as the combination of loan interest rate, percent down payment, and homebuyer's discount rate impact this comparison. 

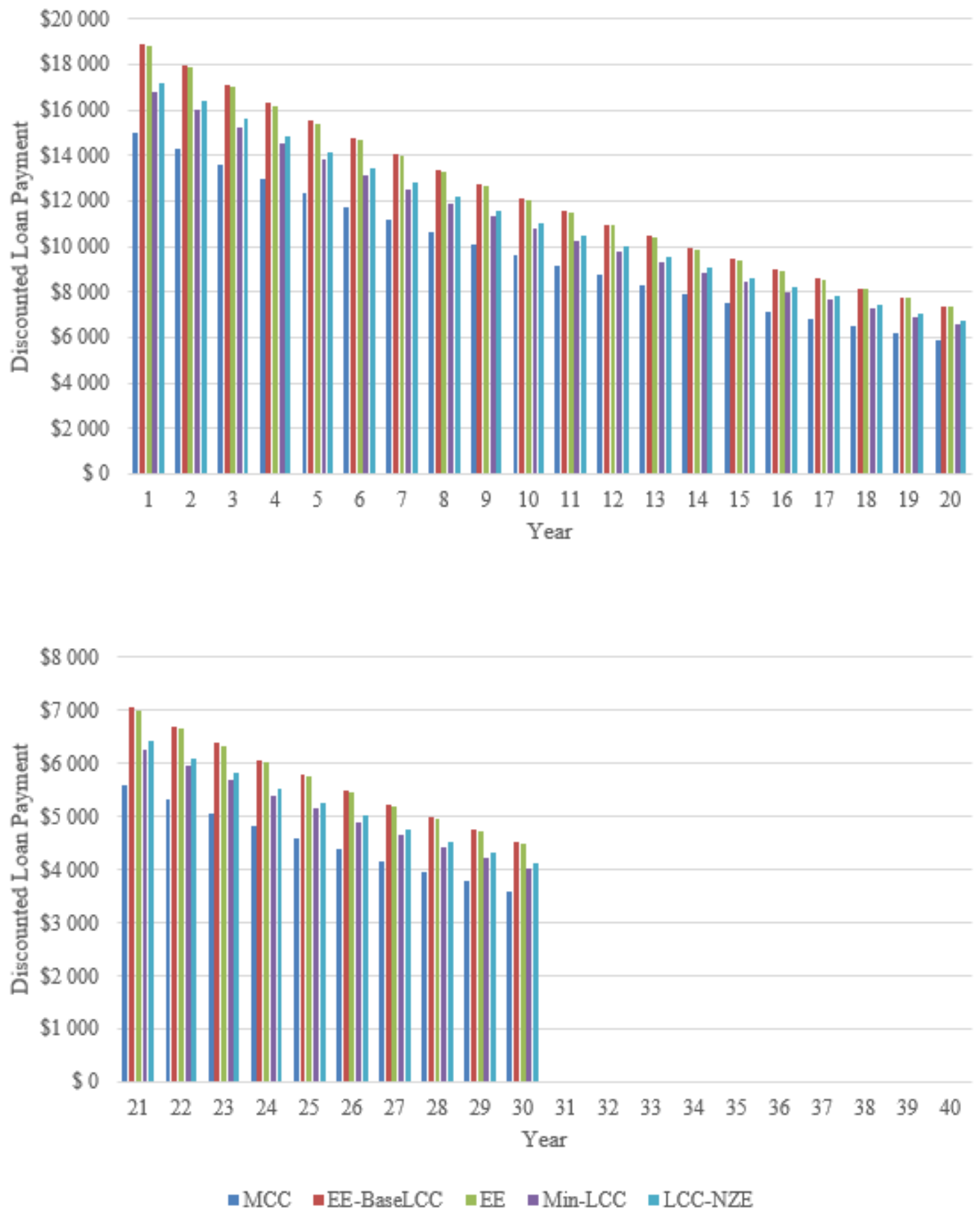

Figure 4-15 Present Value of Mortgage Loan Payments for Selected Designs - Case 2

\subsubsection{LCC Analysis and Payback Period of Key Designs - Case 2}

LCC are lower for all designs for all study periods for Case 2 (shown in Figure 4-16) relative to Case 1 because financing the home purchase delays costs to future years of the study period, which leads to those costs being discounted and lowers their net present value. Note that it is not 
necessarily the case that a loan will achieve the goal of lowering LCC, as the loan terms, interest rate, and length can vary. Also the individual's discount rate plays a role in how future payments are viewed.
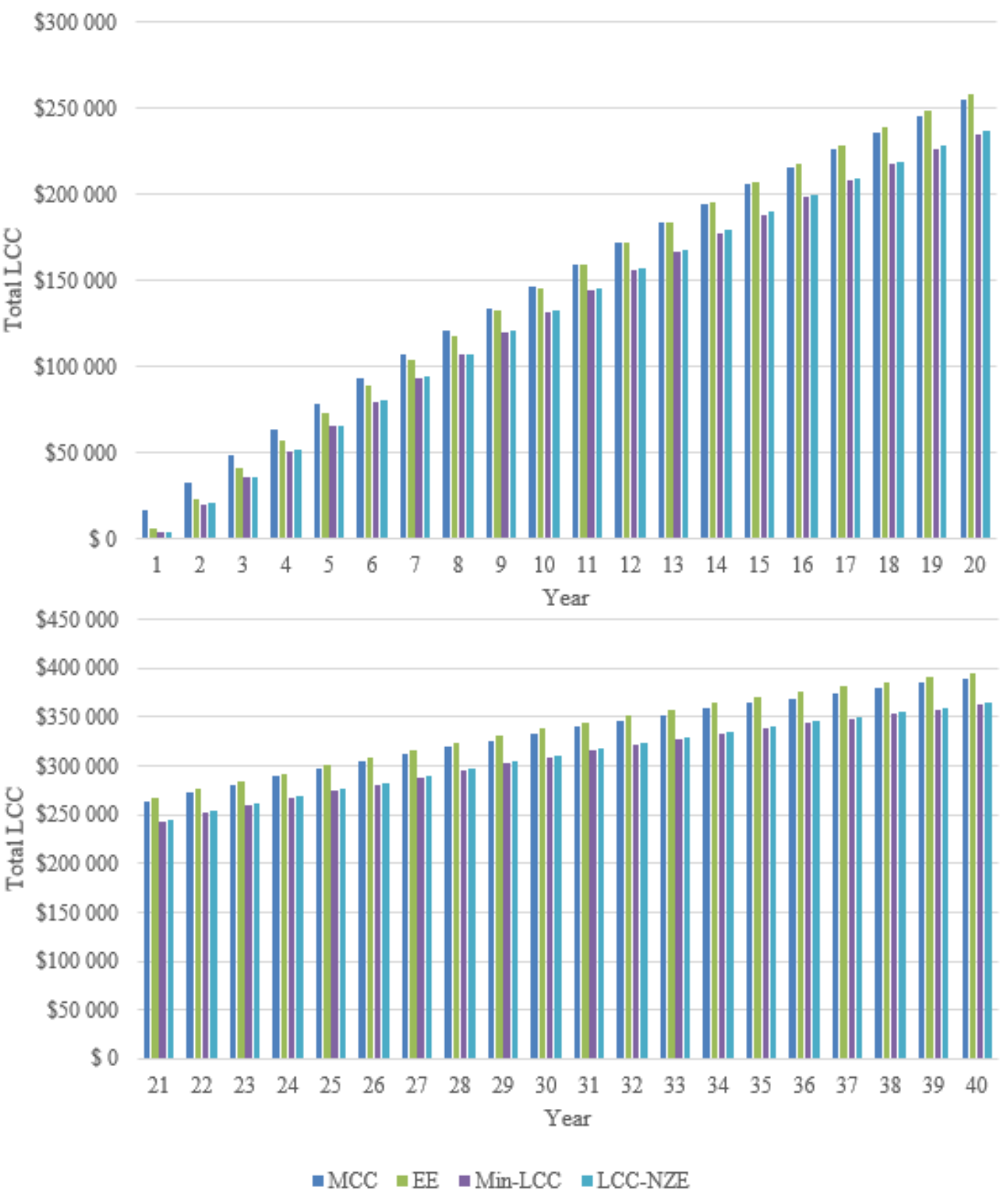

Figure 4-16 Present Value of Total LCC for Selected Designs - Case 2

The differences in LCCs from the baseline shown in Figure 4-17 are "shifted" down relative to Case 1, resulting in smaller positive differences (increasing LCC) and larger negative differences (decreasing LCC). Similar to Case 1, the most energy efficient design (EE) initially has lower LCC than the baseline due to the upfront federal tax credit for the solar PV system; however, it is 
not cost-effective for all study periods greater than 12 years, which is twice the length of the maximum study period length for Case 1 . Regardless of the study period, the most efficient design (EE) never has additional LCC greater than \$10 000.

$\$ 5000$
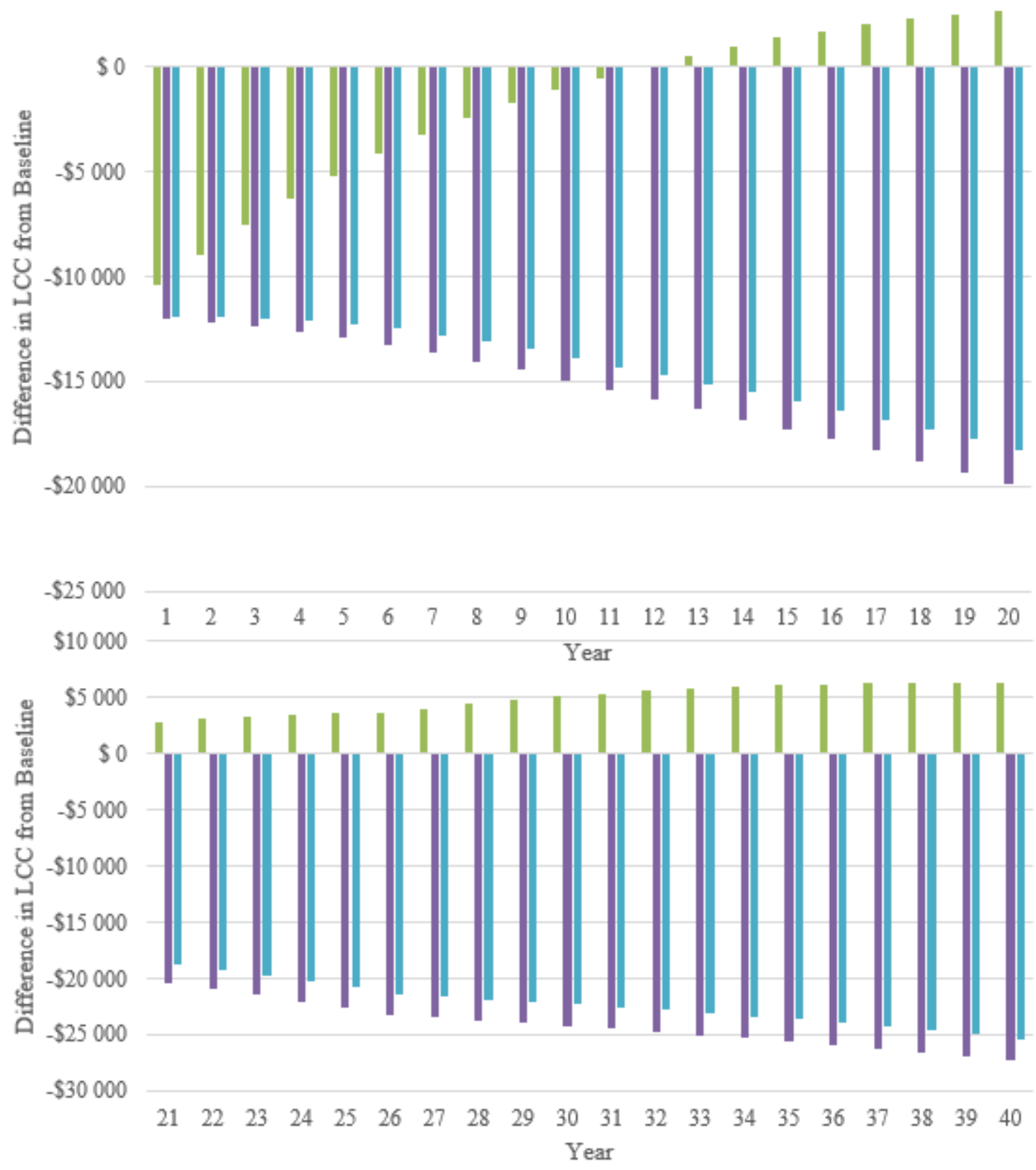

$\because \mathrm{EE} \quad \mathrm{Min}-\mathrm{LCC} \quad \mathrm{LCC}-\mathrm{NZE}$

Figure 4-17 Difference in LCC Relative to Baseline for Selected Designs - Case 2 
As in Case 1, both the minimum LCC design (Min-LCC) and minimum LCC net-zero design (LCC-NZE) realize lower LCCs than the baseline design for all 40 study periods for Case 2. Net savings generally increase as the study period increases in length, though at an inconsistent rate due to component replacements and solar PV degradation.

Table 4-11 summarizes the modified payback period for the selected designs. Similar interpretations can be made for Case 2 as for Case 1 except that the payback period for the Min-LCC and LCC-NZE designs are reduced by 2 years because of the reduced upfront costs from lowering the down payment. As with Case 1, the use of the payback period method does not inform the home purchaser to the same extent that the LCC methodology is capable.

Table 4-11 Modified Payback Period for Selected Designs - Case 2

\begin{tabular}{|c|c|}
\hline Design & Payback Period* \\
\hline EE-BaseLCC & N/A \\
\hline EE & N/A \\
\hline Min-LCC & 12 years** \\
\hline LCC-NZE & 15 years** \\
\hline $\begin{array}{l}\text { * N/A indicates that the option has a payback } \\
\text { period of longer than } 40 \text { years, if one exists at all } \\
\text { ** Obtained using linear interpolation; rounded } \\
\text { up to the next year }\end{array}$ \\
\hline
\end{tabular}

\subsubsection{Environmental Impact Analysis of Key Designs - Case 2}

The environmental impacts are unchanged for EE, Min-LCC, and LCC-NZE relative to Case 1 because the building designs and associate energy performance are identical. The change in the EE-BaseLCC design leads to slightly higher environmental impacts because there are additional embodied emissions in the building from the additional roof and foundation insulation. Additionally, the energy performance is reduced from a $113 \%$ reduction relative to the baseline to $112 \%$. This single percentage point difference may not seem significant, but the extra emissions associated with the additional energy use have a considerable impact on GWP, smog formation, ozone depletion, and primary energy use.

\subsection{Case 3: 3 \% Discount Rate, Luxury Construction Quality, 100 \% Cash Financing}

Case 3 changes the construction quality from "average” to "luxury," which only impacts the total construction costs with all designs increasing by the same amount because it impacts interior finishes such as high-end cabinets and countertops focused on aesthetic appeal. The energy 
performance of the building designs remains the same. As a result, the selected key designs are identical to those in Table 4-2 for Case 1.

The change from "average" to "luxury" construction quality will only impact initial construction costs, residual value, total LCC, and total environmental impacts. These factors will be the focus for the remainder of this section. Since all building designs increase by the same value, there is no impact on the other costs or the relative energy, cost, or environmental performance.

Figure 4-18 presents the total first costs for the selected designs, which are each \$118 638 more expensive than those in Case 1. Therefore, the relative differences between the key designs and the baseline are the same as in Case 1 (with consideration of rounding errors in the calculations).

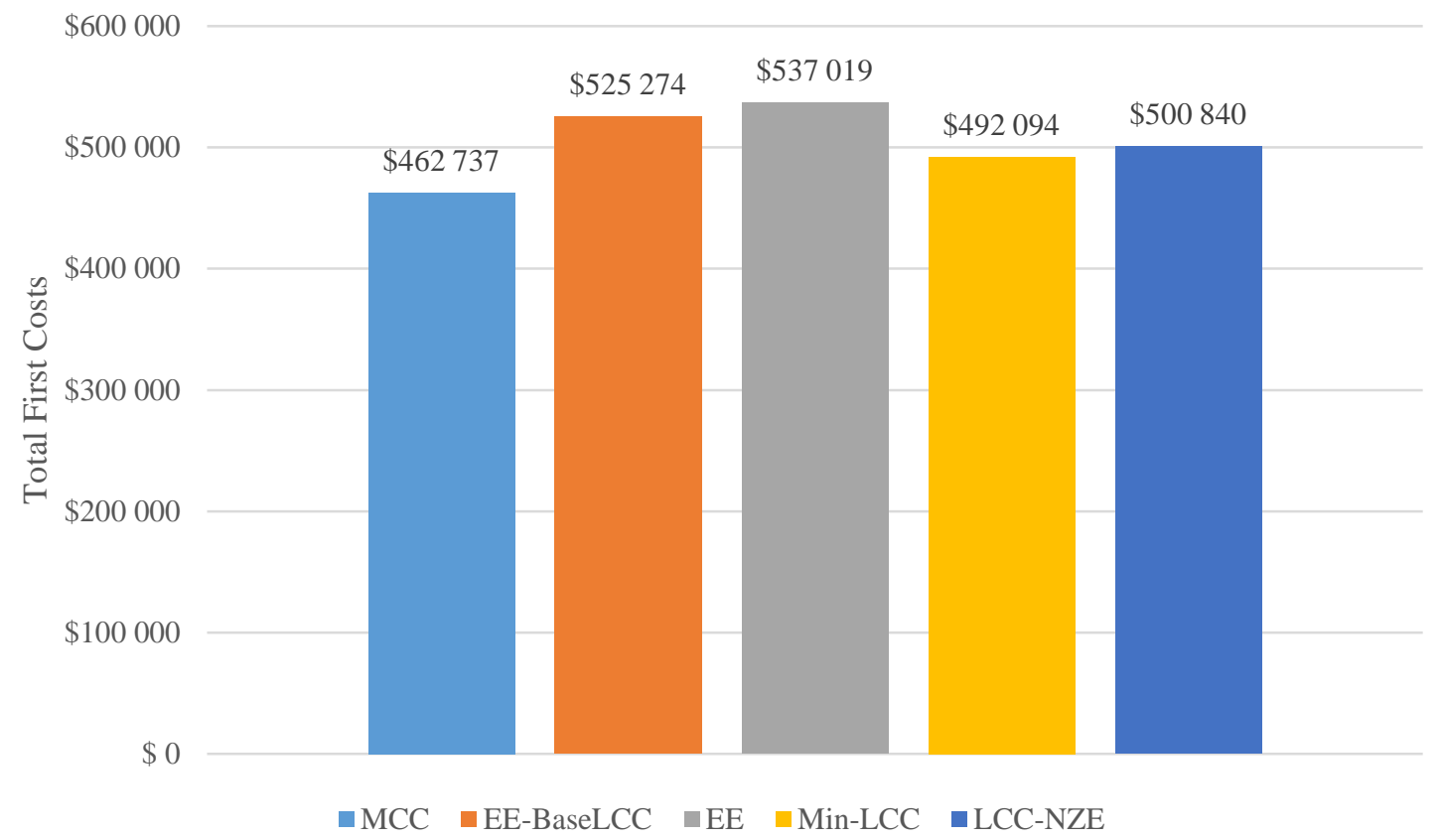

Figure 4-18 Total First Costs for Selected Designs - Case 3

Figure 4-19 presents the present value of the residual value for each key design over 40 years. Because the EEMs are unaffected by the construction quality, their contribution to the residual value remains the same as in Case 1 . As such the increase in residual value is directly attributable to the increase in construction quality and the associated increase in total construction costs. Consider the residual value for the baseline (MCC) design for a 1-year study period. The residual value for Case 1 is \$328 313 and the residual value from Figure 4-19 is \$441 723. Therefore, the additional residual value due to the increased construction quality for the MCC 2015 design for a 1-year study period is $\$ 113410$ in present value terms. 

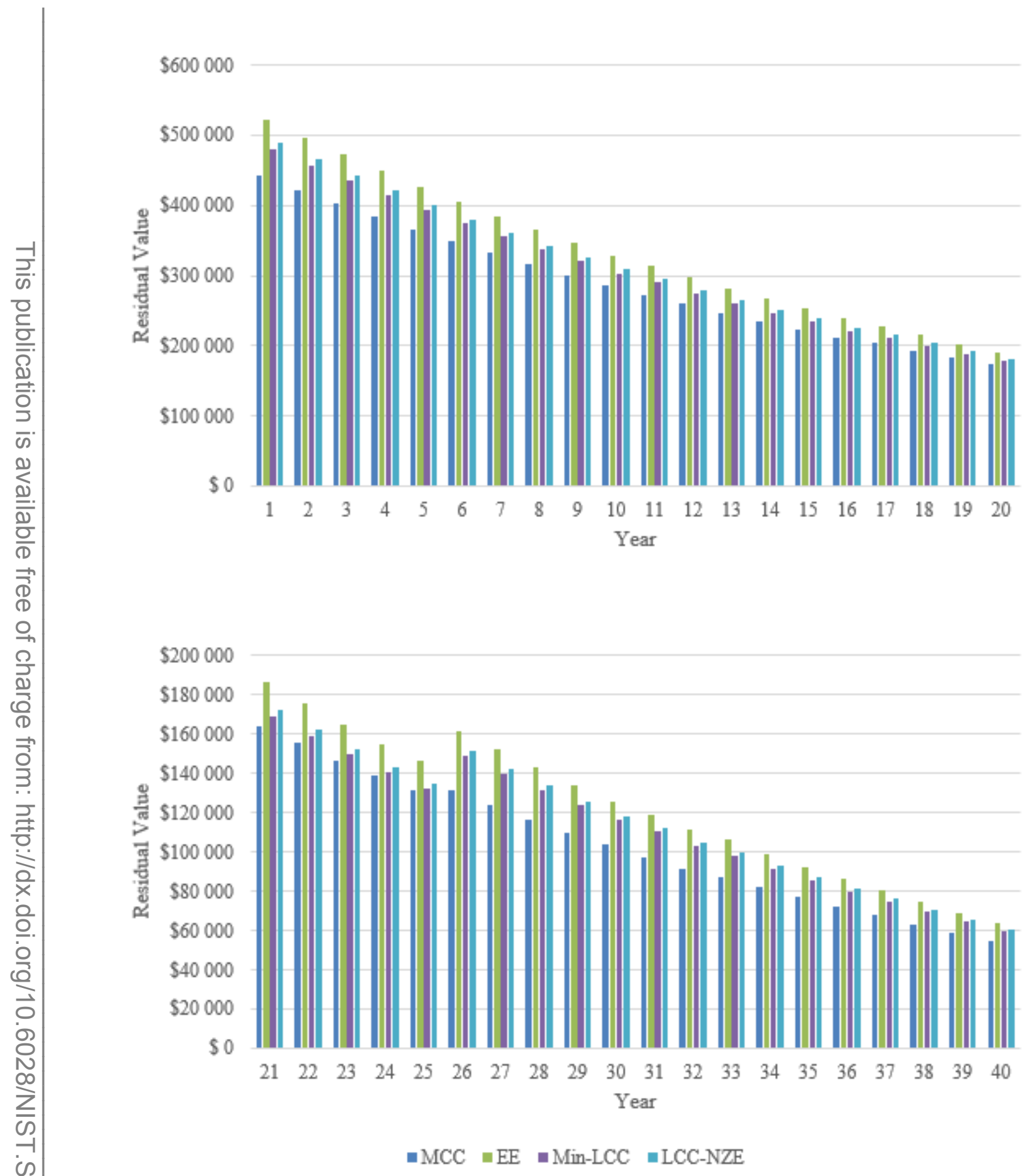

Figure 4-19 Present Value of Residual Value for Selected Designs - Case 3

The total present value of LCCs is given in Figure 4-20. As was the case with first costs, the total LCC values increase by the same amount for all designs, and the relative difference between designs is the same as in Case 1. For a 40-year study period, the "luxury" premium results in an increase of \$104 605 in present value terms for all considered designs. 

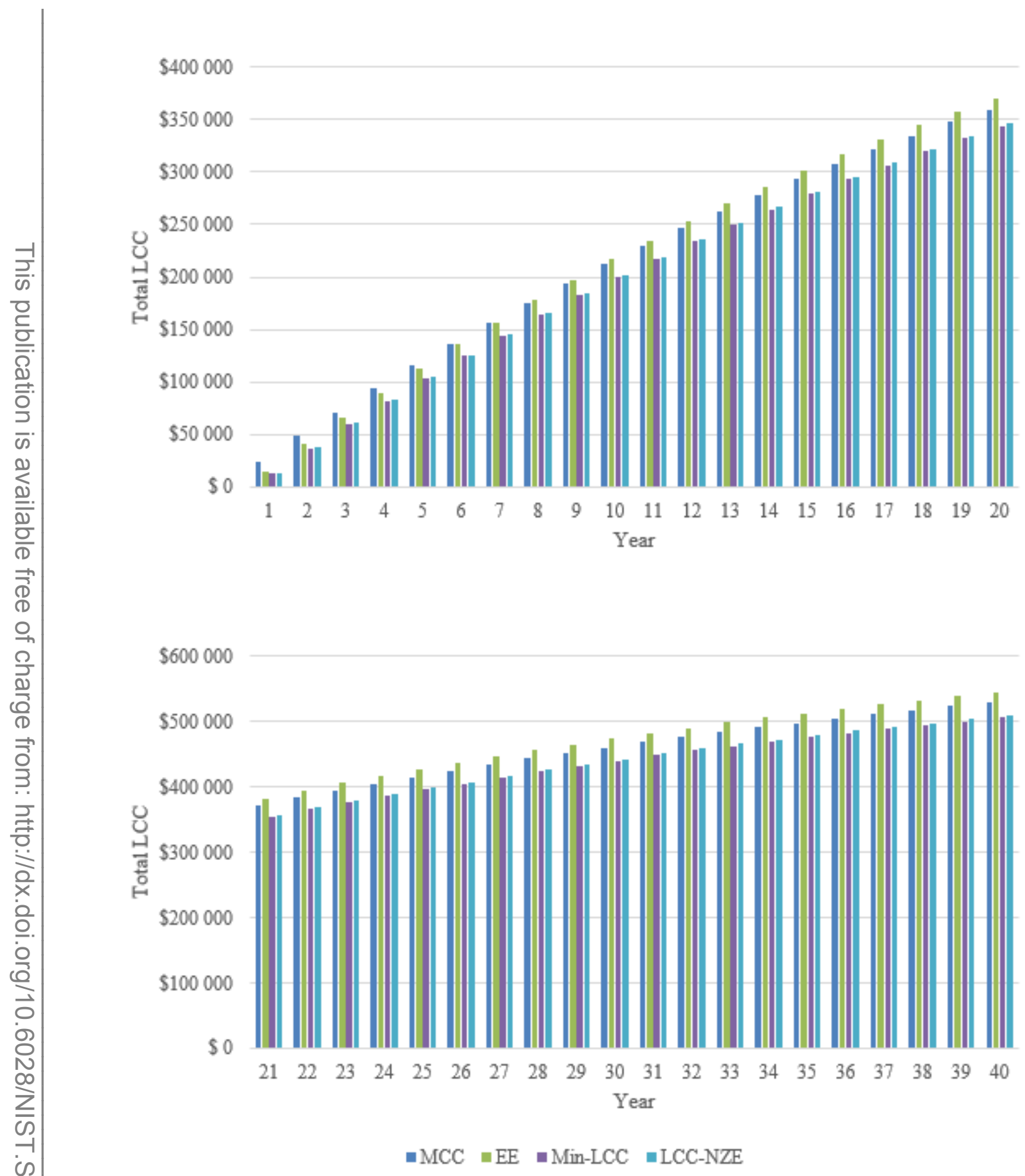

Figure 4-20 Present Value of Total LCC for Selected Designs - Case 3

As discussed in Section 2.6, homes of "luxury" construction quality offer more amenities than those of "average" construction quality. As discussed in Section 3.3, the BIRDS low-energy residential database assumes the additional costs of the luxury quality construction are associated with additional embodied flows based on the industry average flows per dollar of expenditure, which is applied to all designs. Therefore, the total flows for each impact category increase by 
the same amount for each design. These changes are minimized in the normalization and weighting process and leads to no change in the EIS value. Therefore, the same interpretations hold for Case 3 as for those discussed for Case 1 in Section 4.2.5.

\subsection{Case 4: 3 \% Discount Rate, Luxury Construction Quality, 20 \% Down/80 \% Loan Financing}

Case 4 maintains the $3 \%$ discount rate as is used in Case 1, Case 2, and Case 3 while assuming luxury construction quality and a 30-year loan financing with $20 \%$ down payment. The selected designs under the loan financing option combined with luxury construction quality are given in Table 4-12. These designs are the same as those in Case 2, with the EE-BaseLCC design including EEMs that are different than Case 1 (shown in gray) while the other three key designs remain the same.

Table 4-12 Selected Key Designs - Case 4

\begin{tabular}{|c|c|c|c|c|}
\hline $\begin{array}{c}\text { Design } \\
\text { Category }\end{array}$ & EE-BaseLCC & $\mathbf{E E}^{* *}$ & Min-LCC** & LCC-NZE** \\
\hline Windows & $\begin{array}{c}\text { U Factor: } \\
1.14 \mathrm{~W} / \mathrm{m}^{2}-\mathrm{K} \\
\left(0.2 \mathrm{Btu} / \mathrm{h} \cdot \mathrm{ft}^{2}-\mathrm{F}\right) \\
\text { SHGC: } 0.25\end{array}$ & $\begin{array}{c}\text { U Factor: } \\
1.14 \mathrm{~W} / \mathrm{m}^{2}-\mathrm{K} \\
\left(0.2 \mathrm{Btu} / \mathrm{h} \cdot \mathrm{ft}^{2}-\mathrm{F}\right) \\
\text { SHGC: } 0.25\end{array}$ & $\begin{array}{c}\text { U Factor: } \\
1.14 \mathrm{~W} / \mathrm{m}^{2}-\mathrm{K} \\
\left(0.2 \mathrm{Btu} / \mathrm{h} \cdot \mathrm{ft}^{2}-\mathrm{F}\right) \\
\text { SHGC: } 0.25\end{array}$ & $\begin{array}{c}\text { U Factor: } \\
1.14 \mathrm{~W} / \mathrm{m}^{2}-\mathrm{K} \\
\left(0.2 \mathrm{Btu} / \mathrm{h} \cdot \mathrm{ft}^{2}-\mathrm{F}\right) \\
\text { SHGC: } 0.25\end{array}$ \\
\hline HVAC & $\begin{array}{c}\text { Air-to-air heat pump } \\
\text { (SEER 16.5/ HSPF 9.1) }\end{array}$ & $\begin{array}{c}\text { Air-to-air heat pump } \\
\text { (SEER 16.5/ HSPF 9.1) }\end{array}$ & $\begin{array}{c}\text { Air-to-air heat pump } \\
\text { (SEER 13.0/ HSPF 7.7) }\end{array}$ & $\begin{array}{c}\text { Air-to-air heat pump } \\
\text { (SEER 13.0/ HSPF 7.7) }\end{array}$ \\
\hline Ventilation & Separate HRV system & Separate HRV system & Outdoor air* & Outdoor air* \\
\hline Air Flow Rate & $0.63 \mathrm{ACH}_{50}$ & $0.63 \mathrm{ACH}_{50}$ & $0.63 \mathrm{ACH}_{50}$ & $0.63 \mathrm{ACH}_{50}$ \\
\hline Lighting & $100 \%$ efficient fixtures & $100 \%$ efficient fixtures & $100 \%$ efficient fixtures & $100 \%$ efficient fixtures \\
\hline Solar PV & $10.2 \mathrm{~kW}$ & $10.2 \mathrm{~kW}$ & $10.2 \mathrm{~kW}$ & $10.2 \mathrm{~kW}$ \\
\hline DHW & $\begin{array}{l}\text { Heat pump water heater } \\
\text { w/ solar thermal system }\end{array}$ & $\begin{array}{l}\text { Heat pump water heater } \\
\text { w/ solar thermal system }\end{array}$ & Heat pump water heater & Heat pump water heater \\
\hline Roof & $\begin{array}{c}\text { Roof insulation: } \\
\text { Rsi-7.92 + 5.28 } \\
(\text { R-45 + 30) } \\
\end{array}$ & 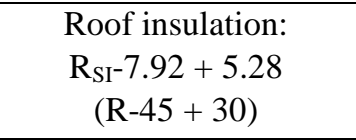 & $\begin{array}{c}\text { Ceiling Insulation: } \\
\mathrm{R}_{\mathrm{SI}}-8.63 \\
(\mathrm{R}-49)\end{array}$ & $\begin{array}{c}\text { Roof insulation: } \\
\text { R }_{\mathrm{SI}^{-}-7.92+0.7} \\
(\mathrm{R}-45+4) \\
\end{array}$ \\
\hline Wall & $\begin{array}{c}\text { Framing: Advanced } \\
\text { Insulation: } \mathrm{R}_{\mathrm{SI}}-3.5+4.2 \\
(\mathrm{R}-20+24)\end{array}$ & $\begin{array}{c}\text { Framing: Advanced } \\
\text { Insulation: } \mathrm{R}_{\mathrm{SI}}-3.5+4.2 \\
(\mathrm{R}-20+24)\end{array}$ & $\begin{array}{l}\text { Framing: Advanced } \\
\text { Insulation: } \mathrm{R}_{\mathrm{SI}}-3.5 \\
(\mathrm{R}-20+0)\end{array}$ & $\begin{array}{c}\text { Framing: Advanced } \\
\text { Insulation: } \mathrm{R}_{\mathrm{SI}}-3.5+2.1 \\
(\mathrm{R}-20+12)\end{array}$ \\
\hline $\begin{array}{l}\text { Foundation } \\
\text { Wall }\end{array}$ & $\begin{array}{l}\mathrm{R}_{\mathrm{S}^{-}}-3.9 \\
(\mathrm{R}-22)\end{array}$ & $\begin{array}{l}\mathrm{R}_{\mathrm{S}^{-}}-3.9 \\
(\mathrm{R}-22)\end{array}$ & $\begin{array}{c}\mathrm{R}_{\mathrm{SI}}-1.41 \\
\text { (R-8) }\end{array}$ & $\begin{array}{l}\mathrm{R}_{\mathrm{SI}}-1.41 \\
(\mathrm{R}-8)\end{array}$ \\
\hline $\begin{array}{l}\text { Foundation } \\
\text { Floor }\end{array}$ & $\begin{array}{c}\mathrm{R}_{\mathrm{SI}}-1.76 \\
(\mathrm{R}-10)\end{array}$ & $\begin{array}{l}\mathrm{R}_{\mathrm{SI}^{-}}-0 \\
(\mathrm{R}-0)\end{array}$ & $\begin{array}{l}\mathrm{R}_{\mathrm{SI}}{ }^{-0} \\
(\mathrm{R}-0)\end{array}$ & $\begin{array}{l}\mathrm{R}_{\mathrm{SI}}-0 \\
(\mathrm{R}-0)\end{array}$ \\
\hline $\begin{array}{c}\text { Energy } \\
\text { Reduction } \\
(\%) \\
\end{array}$ & $112 \%$ & $114 \%$ & $94 \%$ & $101 \%$ \\
\hline $\begin{array}{c}\text { Change in } \\
\text { LCC (10-yr) }\end{array}$ & $-\$ 8$ & $-\$ 1097$ & $-\$ 14919$ & $-\$ 13870$ \\
\hline
\end{tabular}


The analysis will proceed in a similar manner to that of Case 3, focusing only on those results that are different than the previous analysis in Case 2. The total down payment (first cost) for each of the key designs are presented in Figure 4-21. The differences in down payments relative to the baseline (MCC) remain the same as those for Case 2, however, total first costs include a \$23 727 premium due to the higher construction quality, which is approximately $20 \%$ of the premium found in Case 3 for the total down payment (\$118 638).

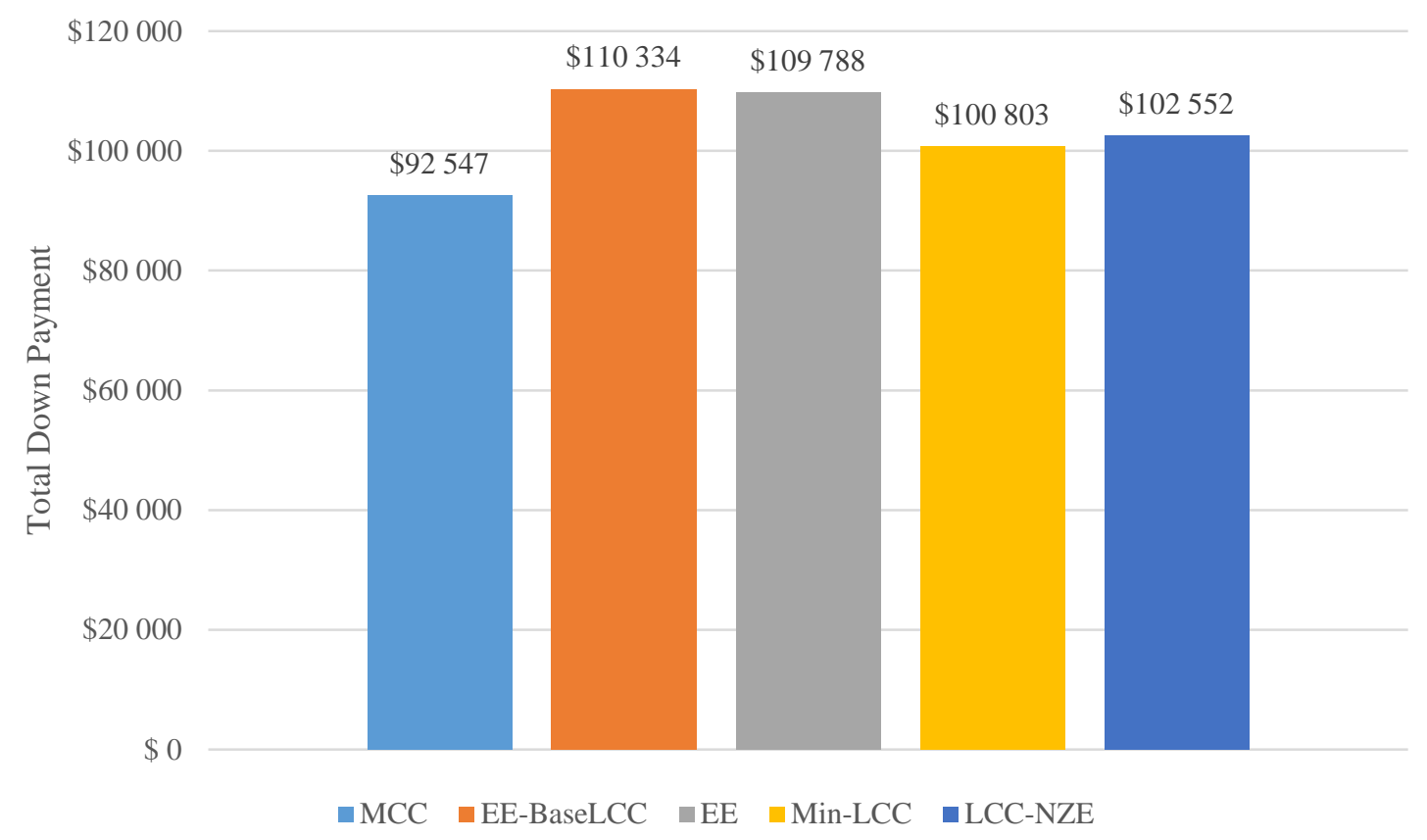

Figure 4-21 Present Value of Total First Costs for Selected Designs - Case 4

Residual value over a 40-year period, see Figure 4-22, maintains the relative differences across building designs. However, residual values are greater than those in Case 2 due to the total construction cost premium of $\$ 113411$, which is equal (within rounding error), to the premium added to the residual value for Case 3. 
$\$ 600000$
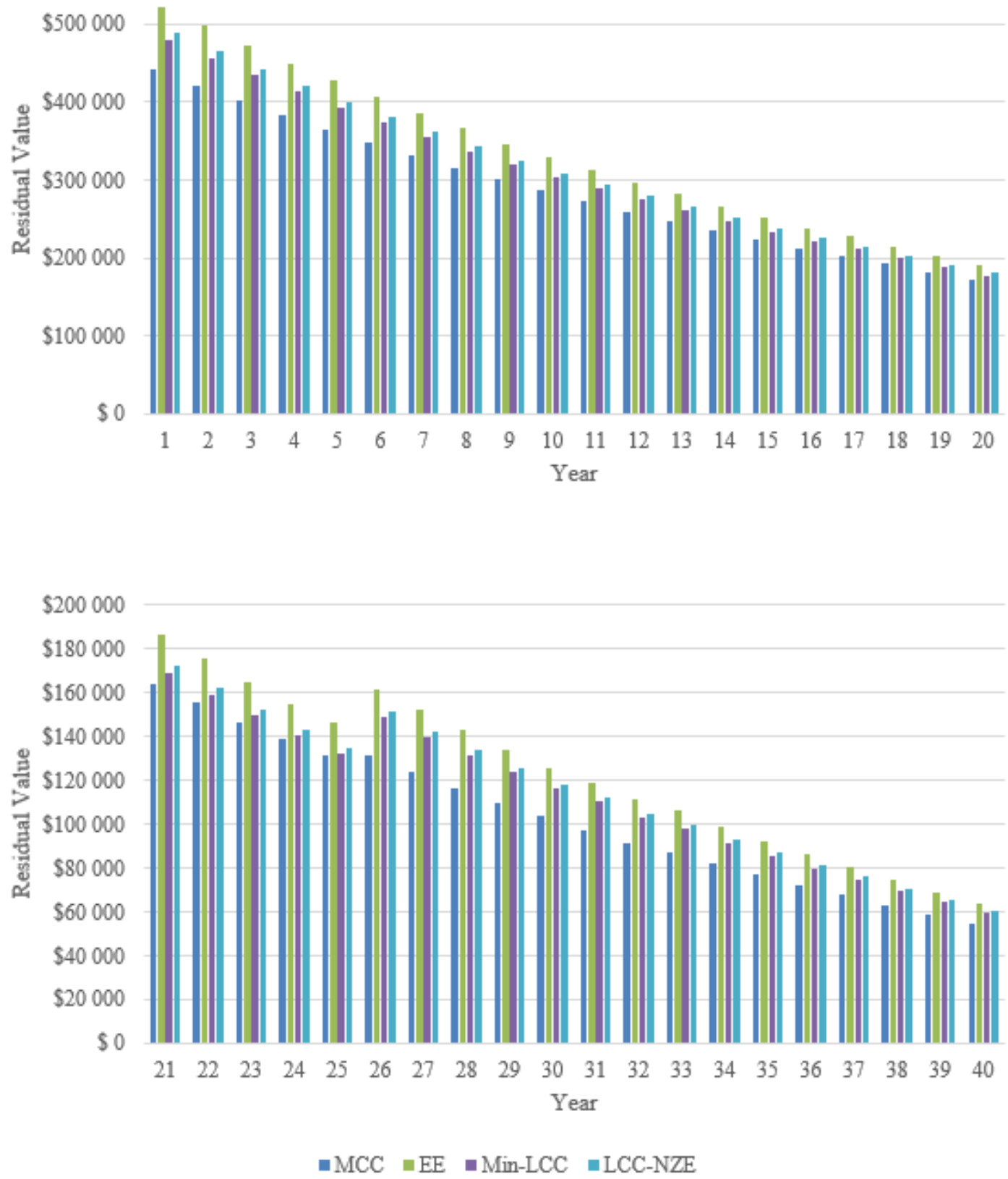

Figure 4-22 Present Value of Residual Value for Selected Designs - Case 4

The total LCC for each design, plotted in Figure 4-23, reveals the effects of the luxury construction quality. For a 40-year study period, the LCC for each design is \$92 757 greater than those in Case 2. The differences between the key designs and the baseline (MCC) are the same as in Case 2. 

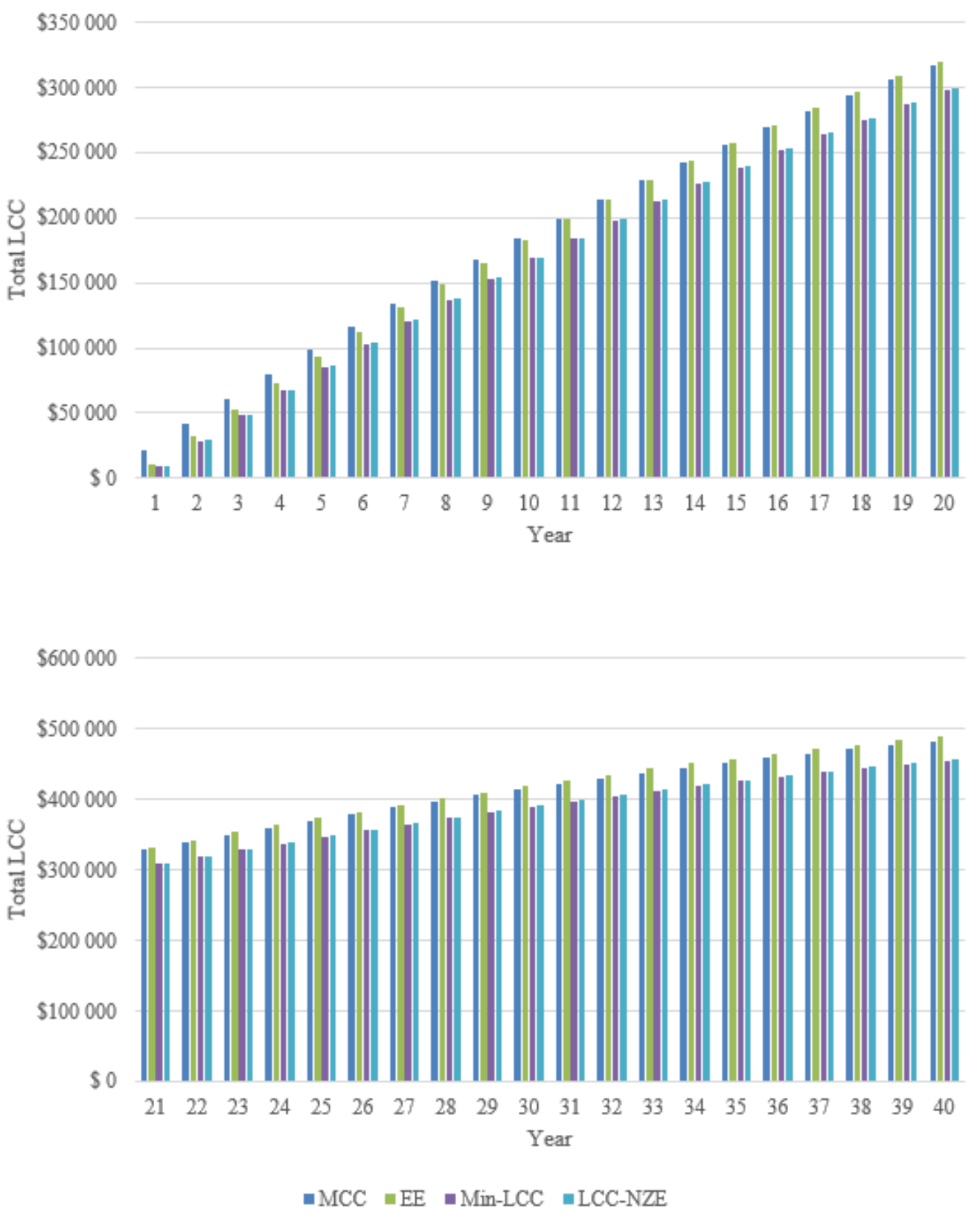

Figure 4-23 Present Value of Total LCC for Selected Designs - Case 4

As discussed in Section 2.6, homes of "luxury" construction quality offer more amenities than those of "average" construction quality. As discussed in Section 3.3, the BIRDS low-energy residential database assumes the additional costs of the luxury quality construction are associated with additional embodied flows based on the industry average flows per dollar of expenditure, which is applied to all designs. Therefore, the total flows for each impact category increase by the same amount for each design. These changes are minimized in the normalization and weighting process and leads to no change in the EIS value. Therefore, the same interpretations hold for Case 4 as for those discussed for Case 2 in Section 4.3.5. 


\subsection{Case 5: 8 \% Discount Rate, Average Construction Quality, 100 \% Cash Financing}

Case 5 is identical to Case 1 except using an $8 \%$ discount rate instead of $3 \%$. Therefore, analysis for Case 5 will focus on results comparisons to Case 1.

\subsubsection{Summary of Key Designs - Case 5}

Changing the discount rate from $3 \%$ to $8 \%$ decreases the importance of cash flows in later years of a study period because a higher discount rate decreases the present value of future expenditures. Table 4-13 shows that the discount rate has an impact on the characteristics of two designs: most efficient design at the baseline LCC (EE-BaseLCC) and lowest LCC design (Min-LCC). Differences from Case 1 are noted by shaded entries in Table 4-13.

Table 4-13 Selected Key Designs for Case 5

\begin{tabular}{|c|c|c|c|c|}
\hline $\begin{array}{l}\text { Design } \\
\text { Category }\end{array}$ & EE-BaseLCC & $\mathbf{E E}^{* *}$ & Min-LCC & LCC-NZE** \\
\hline Windows & $\begin{array}{c}\text { U Factor: } \\
1.14 \mathrm{~W} / \mathrm{m}^{2}-\mathrm{K} \\
\left(0.2 \mathrm{Btu} / \mathrm{h} \cdot \mathrm{ft}^{2}-\mathrm{F}\right) \\
\text { SHGC: } 0.25\end{array}$ & $\begin{array}{c}\text { U Factor: } \\
1.14 \mathrm{~W} / \mathrm{m}^{2}-\mathrm{K} \\
\left(0.2 \mathrm{Btu} / \mathrm{h} \cdot \mathrm{ft}^{2}-\mathrm{F}\right) \\
\text { SHGC: } 0.25\end{array}$ & $\begin{array}{c}\text { U Factor: } \\
1.14 \mathrm{~W} / \mathrm{m}^{2}-\mathrm{K} \\
\left(0.2 \mathrm{Btu} / \mathrm{h} \cdot \mathrm{ft}^{2}-\mathrm{F}\right) \\
\text { SHGC: } 0.25\end{array}$ & $\begin{array}{c}\text { U Factor: } \\
1.14 \mathrm{~W} / \mathrm{m}^{2}-\mathrm{K} \\
\left(0.2 \mathrm{Btu} / \mathrm{h} \cdot \mathrm{ft}^{2}-\mathrm{F}\right) \\
\text { SHGC: } 0.25\end{array}$ \\
\hline HVAC & $\begin{array}{c}\text { Air-to-air heat pump } \\
\text { (SEER 13.0/ HSPF 7.7) }\end{array}$ & $\begin{array}{c}\text { Air-to-air heat pump } \\
\text { (SEER 16.5/ HSPF 9.1) }\end{array}$ & $\begin{array}{c}\text { Air-to-air heat pump } \\
\text { (SEER 13.0/ HSPF 7.7) }\end{array}$ & $\begin{array}{c}\text { Air-to-air heat pump } \\
\text { (SEER 13.0/ HSPF 7.7) }\end{array}$ \\
\hline Ventilation & Outdoor air* & Separate HRV system & Outdoor air* & Outdoor air* \\
\hline $\begin{array}{l}\text { Air Flow } \\
\text { Rate }\end{array}$ & $0.63 \mathrm{ACH}_{50}$ & $0.63 \mathrm{ACH}_{50}$ & $0.63 \mathrm{ACH}_{50}$ & $0.63 \mathrm{ACH}_{50}$ \\
\hline Lighting & $50 \%$ efficient fixtures & $100 \%$ efficient fixtures & $100 \%$ efficient fixtures & $100 \%$ efficient fixtures \\
\hline Solar PV & $7.6 \mathrm{~kW}$ & $10.2 \mathrm{~kW}$ & $0.0 \mathrm{~kW}$ & $10.2 \mathrm{~kW}$ \\
\hline DHW & Heat pump water heater & $\begin{array}{l}\text { Heat pump water heater } \\
\text { w/ solar thermal system }\end{array}$ & Heat pump water heater & Heat pump water heater \\
\hline Roof & $\begin{array}{c}\text { Ceiling insulation: } \\
\mathrm{R}_{\mathrm{SI}}-8.63 \\
(\mathrm{R}-49) \\
\end{array}$ & $\begin{array}{l}\text { Roof insulation: } \\
\text { RII-7.92 + 5.28 } \text { (R-45 + 30) } \\
\end{array}$ & $\begin{array}{l}\text { Ceiling Insulation: } \\
\mathrm{R}_{\mathrm{SI}}-6.69 \\
(\mathrm{R}-38)\end{array}$ & $\begin{array}{l}\text { Roof insulation: } \\
\text { RSI-7.92 + 0.7 }^{(\mathrm{R}-45+4)}\end{array}$ \\
\hline Wall & $\begin{array}{l}\text { Framing: Advanced } \\
\text { Insulation: } \mathrm{R}_{\mathrm{SI}}-3.5 \\
(\mathrm{R}-20+0)\end{array}$ & $\begin{array}{c}\text { Framing: Advanced } \\
\text { Insulation: } \mathrm{R}_{\mathrm{SI}}-3.5+4.2 \\
(\mathrm{R}-20+24)\end{array}$ & $\begin{array}{l}\text { Framing: Typical } \\
\text { Insulation: } \mathrm{R}_{\mathrm{SI}}-2.3 \\
(\mathrm{R}-13+0)\end{array}$ & $\begin{array}{c}\text { Framing: Advanced } \\
\text { Insulation: } \mathrm{R}_{\mathrm{SI}}-3.5+2.1 \\
(\mathrm{R}-20+12)\end{array}$ \\
\hline $\begin{array}{c}\text { Foundation } \\
\text { Wall }\end{array}$ & $\begin{array}{l}\mathrm{R}_{\mathrm{SI}}-1.76 \\
(\mathrm{R}-10)\end{array}$ & $\begin{array}{l}\mathrm{R}_{\mathrm{SI}}-3.9 \\
(\mathrm{R}-22)\end{array}$ & $\begin{array}{l}\mathrm{R}_{\mathrm{SI}}-1.41 \\
(\mathrm{R}-8)\end{array}$ & $\begin{array}{l}\mathrm{R}_{\mathrm{SI}}-1.41 \\
(\mathrm{R}-8)\end{array}$ \\
\hline $\begin{array}{c}\text { Foundation } \\
\text { Floor }\end{array}$ & $\begin{array}{l}\mathrm{R}_{\mathrm{SI}}{ }^{-0} \\
(\mathrm{R}-0)\end{array}$ & $\begin{array}{l}\mathrm{R}_{\mathrm{SI}^{-}}-0 \\
(\mathrm{R}-0)\end{array}$ & $\begin{array}{l}\mathrm{R}_{\mathrm{SI}^{-}}-0 \\
(\mathrm{R}-0)\end{array}$ & $\begin{array}{l}\mathrm{R}_{\mathrm{SI}^{-}}-0 \\
(\mathrm{R}-0)\end{array}$ \\
\hline $\begin{array}{c}\text { Energy } \\
\text { Reduction } \\
(\%) \\
\end{array}$ & $78 \%$ & $114 \%$ & $26 \%$ & $101 \%$ \\
\hline $\begin{array}{l}\text { Change in } \\
\text { LCC (10-yr) }\end{array}$ & $-\$ 47$ & $\$ 28337$ & $-\$ 5904$ & $\$ 5394$ \\
\hline
\end{tabular}


EE-BaseLCC has eight characteristics that change relative to Case 1, including all system-related components (HVAC, lighting, DHW, and solar PV) while Min-LCC has three characteristics than change (solar PV system and roof/ceiling and wall assemblies). EE-

BaseLCC uses the less efficient HVAC system, decreases the size of the solar PV system, excludes the solar thermal system, decreases the fraction of efficient lighting, and decreases the insulation installed in the exterior wall and foundation wall assemblies. Additionally, the insulation in the roof assembly is shifted from the insulation within the rafters and the exterior rigid insulation to blown-in insulation on the attic floor ( $2^{\text {nd }}$ floor ceiling). Each of these EEM changes decreases energy savings while lowering construction costs and MRR costs associated with these building components. A higher discount rate leads to future energy cost savings having smaller present values, which leads to fewer incremental EEMs being cost-effective relative to the baseline design. As a result, the energy savings that can be obtained for the same LCC as the baseline design (EE-BaseLCC) decreases significantly from $113 \%$ to 78 \% (35 percentage points) relative to Case 1 .

Similarly, Min-LCC does not include a solar PV system and decreases insulation levels in the roof/ceiling and wall assemblies. Also, the insulation in the roof assembly is shifted from the insulation within the rafters and the exterior rigid insulation to blown-in insulation on the attic floor ( $2^{\text {nd }}$ floor ceiling). As a result, the energy savings realized at minimum LCC (Min-LCC) decrease significantly from $94 \%$ to $26 \%$ (68 percentage points) relative to Case 1 . Additionally, the net savings in LCC decreases from \$12 344 to \$5904 relative to Case 1, further showing that the discount rate is a key assumption for the analysis.

The most energy efficient design (EE) is unchanged from Case 1. Since energy efficiency is independent of LCC and therefore changes in discount rates, the most efficient design (EE) remains the same as Case 1 . However, the higher discount rate leads to the change in LCC increasing from \$4282 in Case 1 to \$28 337 in Case 5, a difference of \$24 055, for obtaining the $114 \%$ reduction in energy savings.

The minimum LCC design that reaches net-zero energy performance (LCC-NZE) for Case 5 has the same characteristics as in Case 1, but realizes an increase in LCC of \$5394 while a decrease in LCC of $\$ 10749$ is realized in Case 1. The LCC-NZE remains the same due to where the netzero thresholds occur on the Pareto frontiers for Case 1 and Case 5. Figure 3-1 and Figure 3-3 show the change in LCC at the optimal building design for a given level of energy savings at $3 \%$ (Case 1) and $8 \%$ discount rate (Case 5), respectively. Figure 3-3 shows that LCCs trend upward as energy efficiency increases beyond the $20 \%$ reduction mark while Figure 3-1 shows a downward trend that continues until you approach $95 \%$ energy savings. The decrease in the energy savings associated with the Min-LCC design for an $8 \%$ discount rate is consistent with this result. However, both Figure 3-1 and Figure 3-3 show the same increasing trend as energy savings approaches the net-zero thresholds (100 \% energy reduction). In order to reach net-zero performance, it is necessary to install the largest $(10.2 \mathrm{~kW})$ solar PV system. Thus the lowest LCC design is not based on a comparison between all EEMs, but only EEM combinations 
constrained to a $10.2 \mathrm{~kW}$ solar PV system. Although the discount rate has a tremendous impact on the specific designs that make up the Pareto frontier based on the solar PV system, there is less of an impact on other EEM combinations. Thus the Pareto frontier in regions with the same solar PV system are less sensitive to changes in the discount rate.

\subsubsection{First Cost Analysis of Key Designs - Case 5}

First costs are not affected by the assumed discount rate because the costs occur in Year 0 and are already in present value terms. However, the EE-BaseLCC and Min-LCC designs changes relative to Case 1, leading to different first costs for those designs as shown in Figure 4-24. EEBaseLCC realizes first costs of \$366 698, which is \$39 939 less than in Case 1, which is a result of the lower level of energy efficiency. Min-LCC not only realizes first costs (\$342 463) that are lower than that in Case 1 (\$373 457), but it is actually less than the first cost of the baseline (MCC) design.

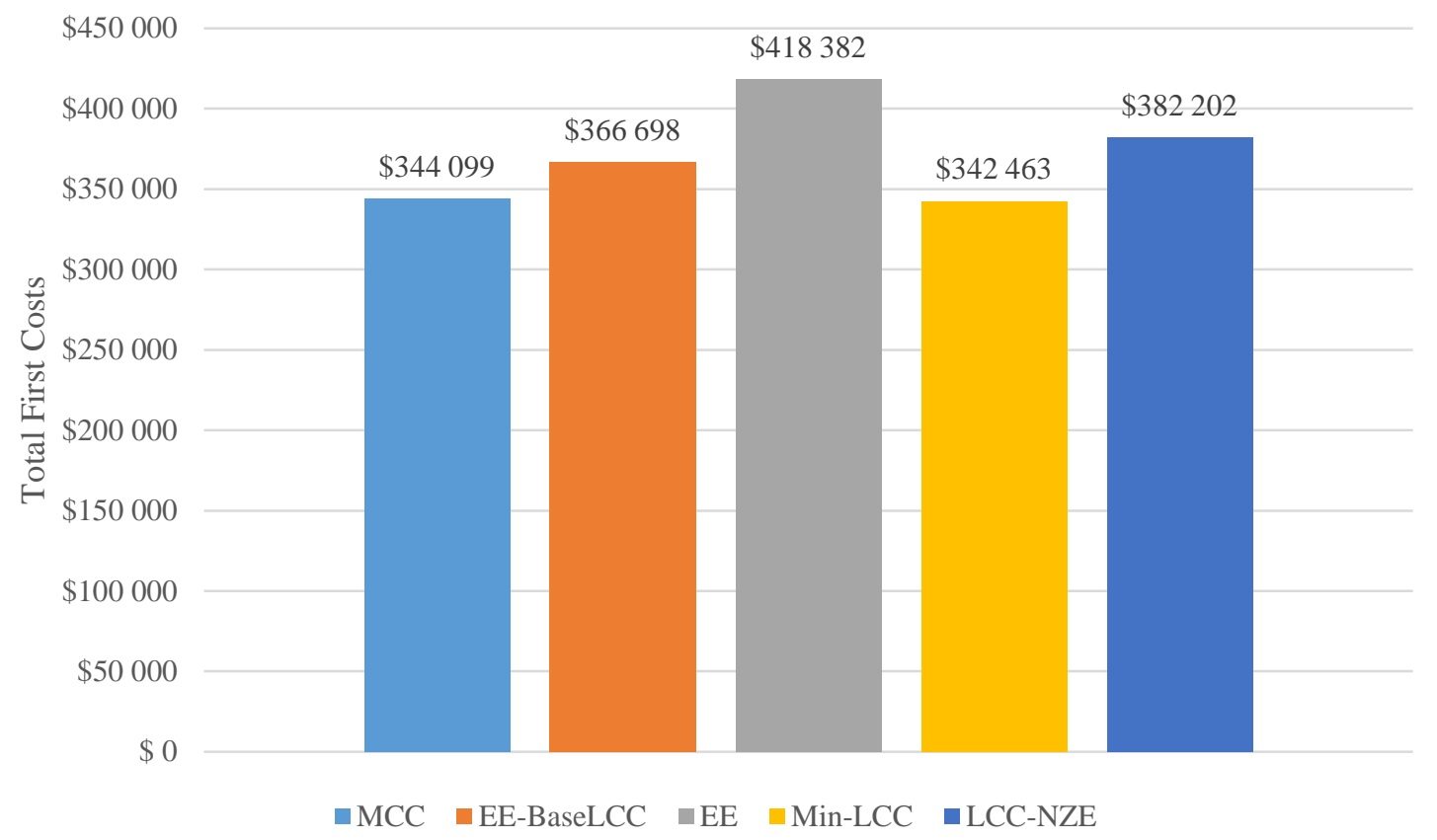

Figure 4-24 Present Value of Total First Costs for Selected Designs - Case 5

Incremental first costs for the key designs relative to the baseline are shown in Figure 4-25. For the most efficient design at the baseline LCC (EE-BaseLCC), the solar PV system adds $91 \%$ of the additional first costs (\$20 748). Min-LCC achieves a decrease in LCC relative to the baseline through adopting the most cost-effective EEMs (decreasing air leakage rate, heat pump water heater, and lighting) while removing less cost-effective EEMs (insulation in roof/ceiling, exterior wall, and foundation wall assemblies) and excluding a solar PV system. Although some of the building components do not meet Maryland code prescriptive requirements, it leads to additional energy savings relative to the baseline design (26\%). 


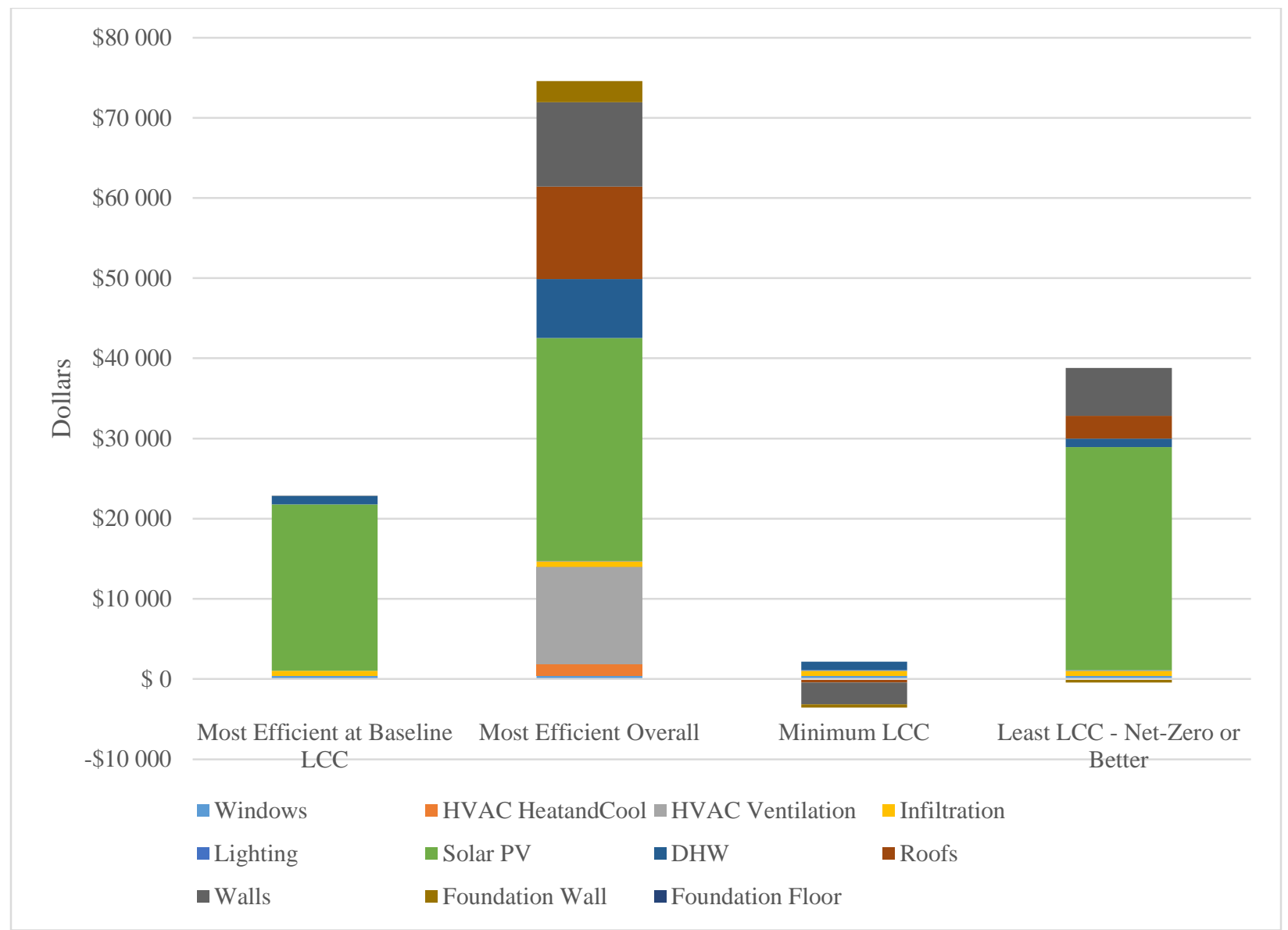

Figure 4-25 Present Value of Incremental First Costs relative to Baseline for Selected Designs - Case 5

\subsubsection{Future Cost Analysis of Key Designs - Case 5}

Figure 4-26 presents the total electricity costs over study periods up to 40 years for Case 5 . The effect of the increased discount rate is apparent when comparing these results to Figure 4-3 for Case 1 . The higher discount rate decreases the present value of the future electricity costs, leading to a decrease in the value associated with energy reductions from increased levels of energy efficiency. As a result, building designs that increase energy efficiency are less cost competitive. For a 40-year study period, the loss in electricity cost savings value relative to the baseline (MCC) design for the most energy efficient (EE) design is $\$ 47479$, which is just over half of the savings achieved under Case 1 (\$87 428). The other major difference is that the minimum LCC (Min-LCC) design has significant positive electricity costs when compared to their Case 1 counterparts with a difference of $\$ 20$ 187, respectively. 

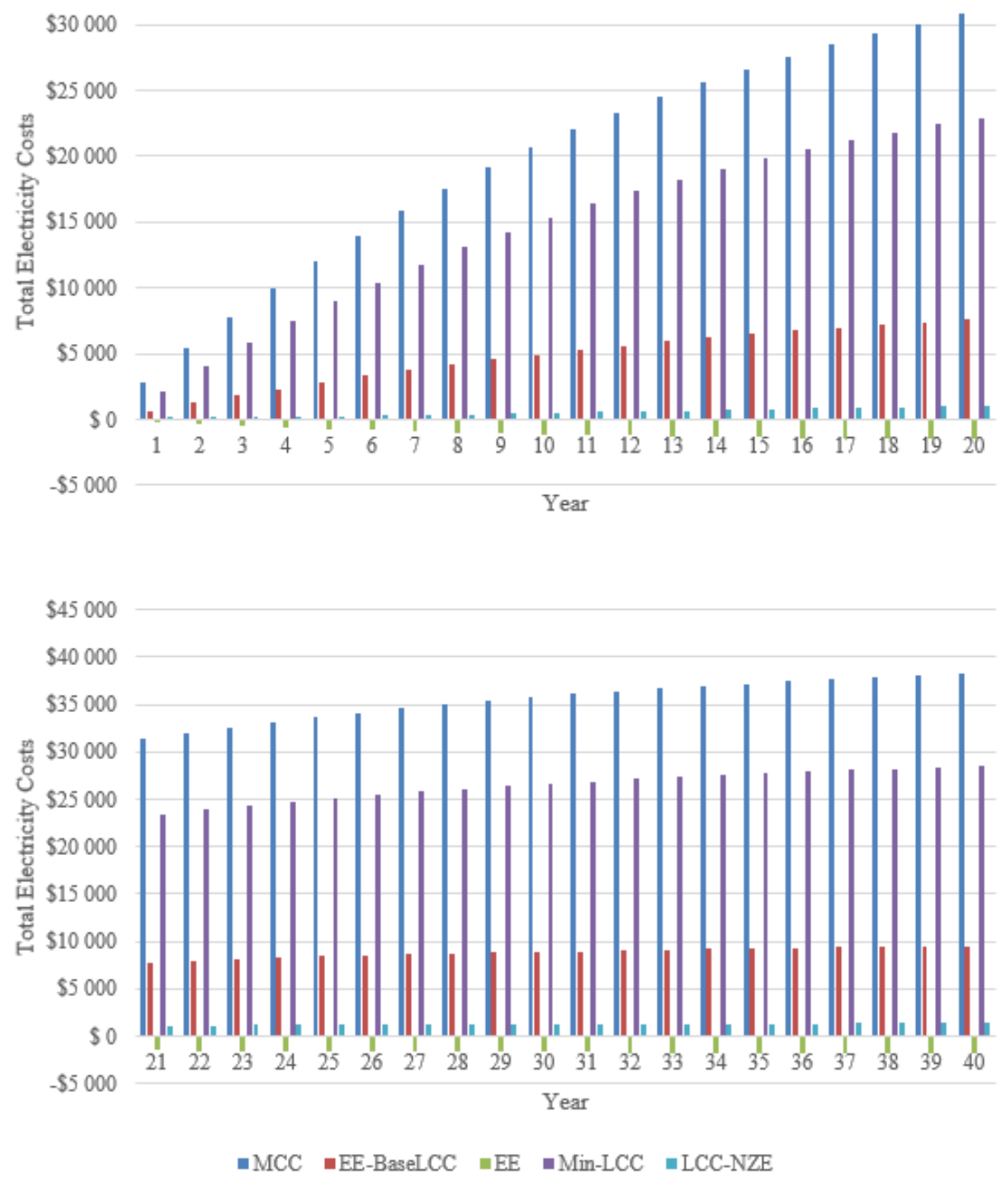

Figure 4-26 Present Value of Total Electricity Costs for Selected Designs - Case 5

Total MRR cost, shown in Figure 4-27, is the one area of costs where the discount rate actually favors greater energy efficiency because more energy efficient designs, specifically those with solar PV systems, typically realize higher future costs. By increasing the discount rate, the present value of these future costs are decreased, which reduces their impact on LCC relative to the baseline (MCC) design. However, the difference in energy costs is significantly greater than 
the difference in MRR costs, which leads to the decrease in energy cost savings from the higher discount rate to overwhelm the decrease in MRR costs. The difference between the EE design, which has the largest MRR costs, and the baseline (MCC) design shrinks from over \$35 000 in Case 1 to approximately $\$ 10000$ in Case 5. As previously mentioned, the difference in energy cost savings decreases from $\$ 87428$ in Case 1 to $\$ 47479$ in Case 5.

$$
\$ 25000
$$
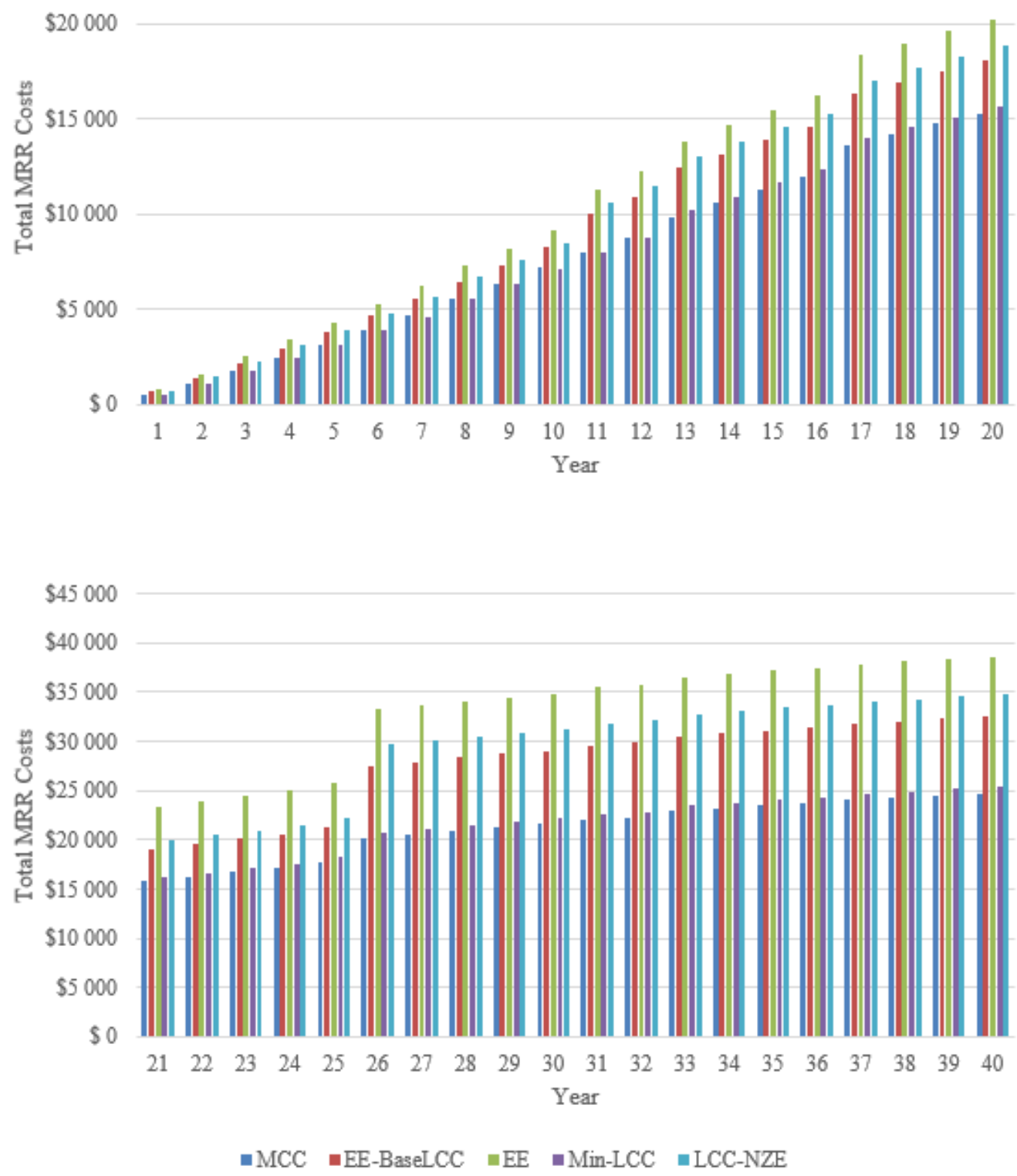

Figure 4-27 Present Value of Total MRR Costs for Selected Designs - Case 5

Similar to future costs, a higher discount rate decreases the present value of building's residual value for a given study period (see Figure 4-28). Total residual value is greater for more energy 
efficient designs because of their higher first costs. However, as the study period increases in length, residual value decreases at a faster rate due to the higher discount rate. For a 40-year study period, the most efficient (EE) design has a residual value of \$7483, a \$42 353 decrease relative to Case 1 value of $\$ 49836$ for the same design. The inability to regain some of the initial investment at the end of the study period (at resale) makes costlier designs less cost-competitive to the baseline design.
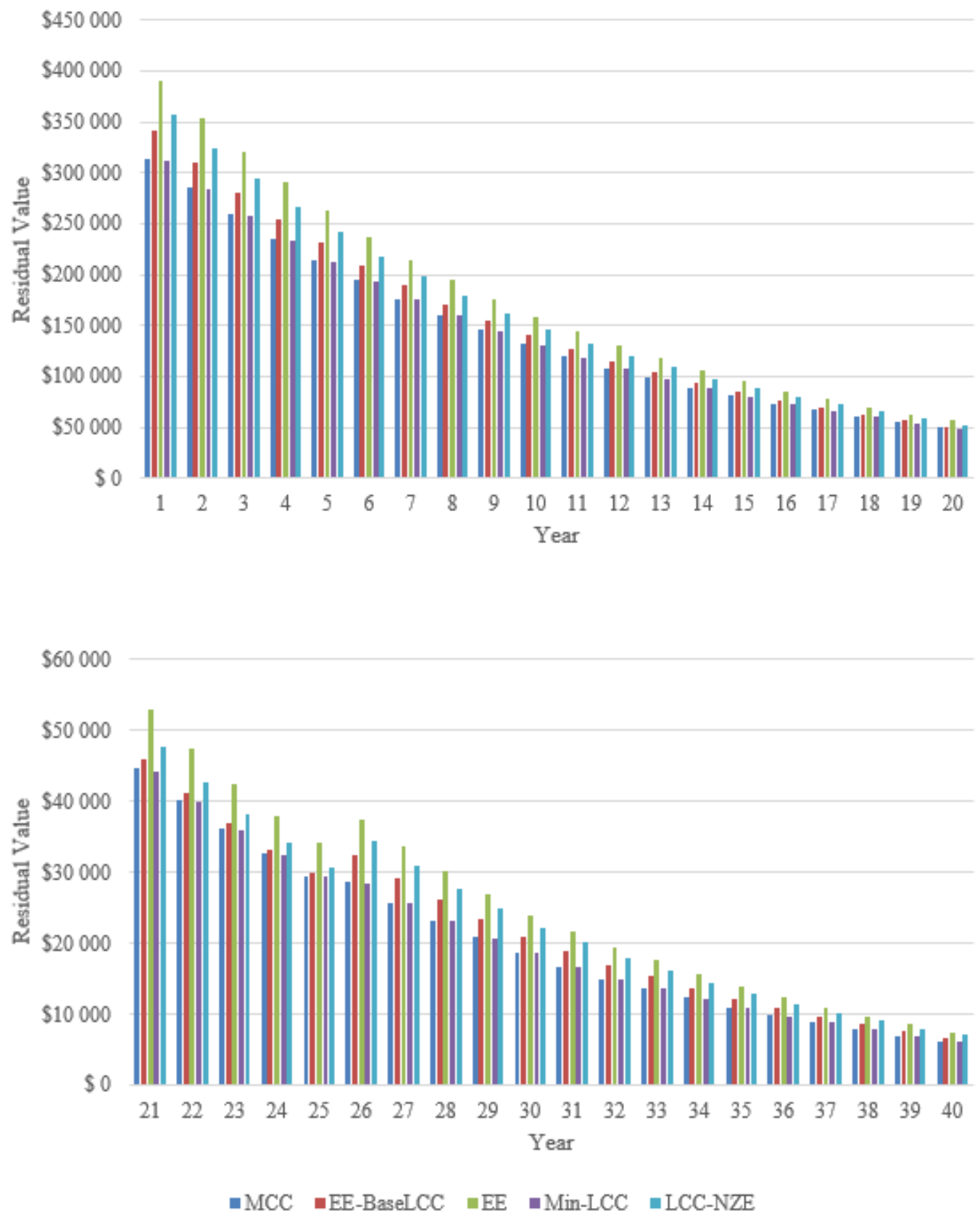

Figure 4-28 Present Value of Residual Value for Selected Designs - Case 5 


\subsubsection{LCC Analysis and Payback Period of Key Designs - Case 5}

Figure 4-29 shows the total LCC for the key designs for Case 5. When compared to Figure 4-6, the most energy efficient (EE) design shows an increase in LCC for a 40-year study period of \$8832 relative to Case 1 while the baseline (MCC) design realizes decreased LCC of \$21 984 . The higher discount rate decreases the energy cost savings for the EE design while decreasing the energy costs for the MCC design, leading to higher costs for the $\mathbf{E E}$ design and lower costs for the MCC design. Similar impacts are realized for the other key designs. Both impacts have a negative impact on the cost-effectiveness of increasing energy efficiency performance.
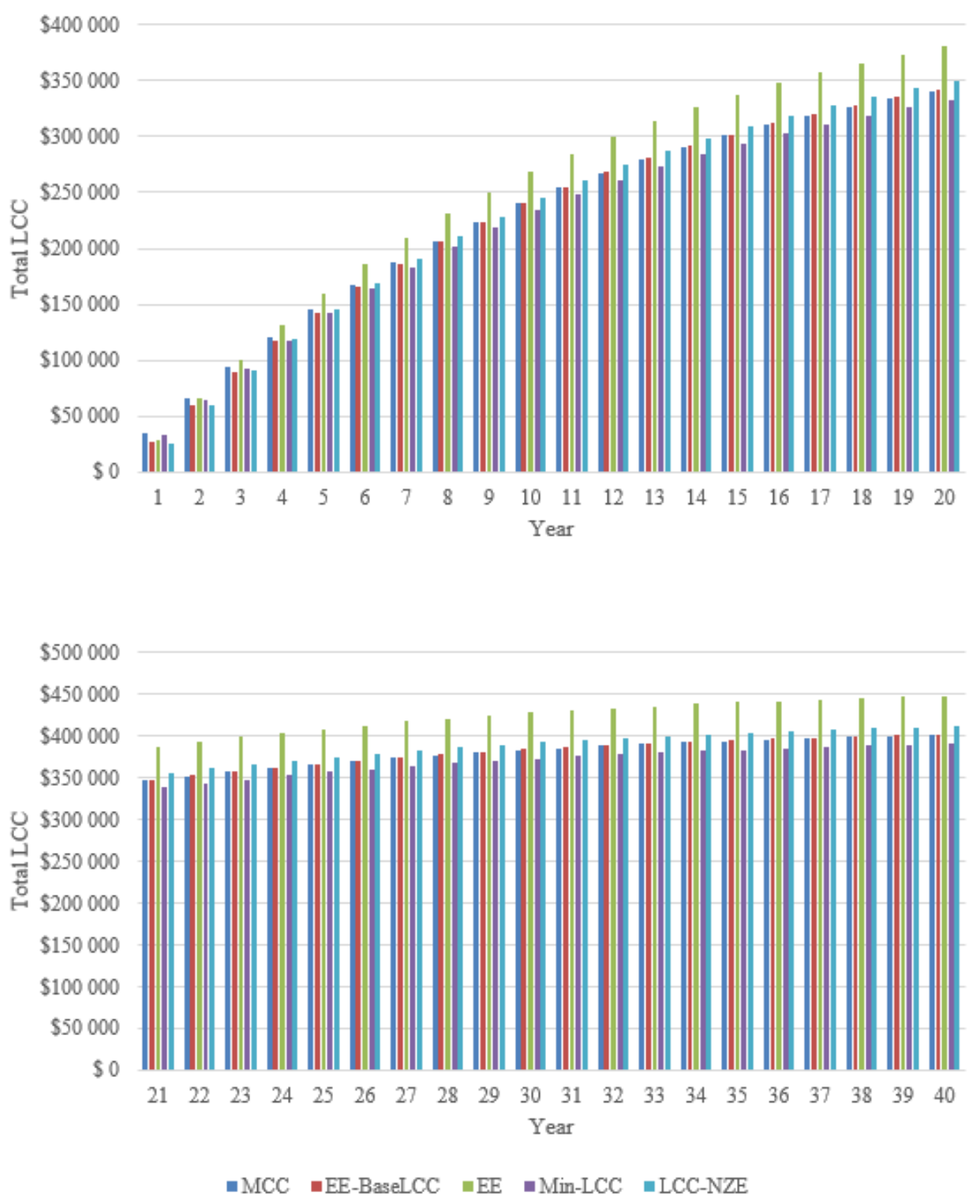

Figure 4-29 Present Value of Total LCC for Selected Designs - Case 5 
Figure 4-30 shows that the EE, Min-LCC, and LCC-NZE design each result in a greater difference in LCC relative to the baseline (MCC) design than in Case 1. The only design that remains consistently below the baseline LCC is the Min-LCC design, and the difference from the baseline has increased by approximately \$13 000. Meanwhile the EE design is approximately $\$ 25000$ greater than the difference in Case 1. By increasing the discount rate, the LCC competitiveness of more efficient designs decreases. 

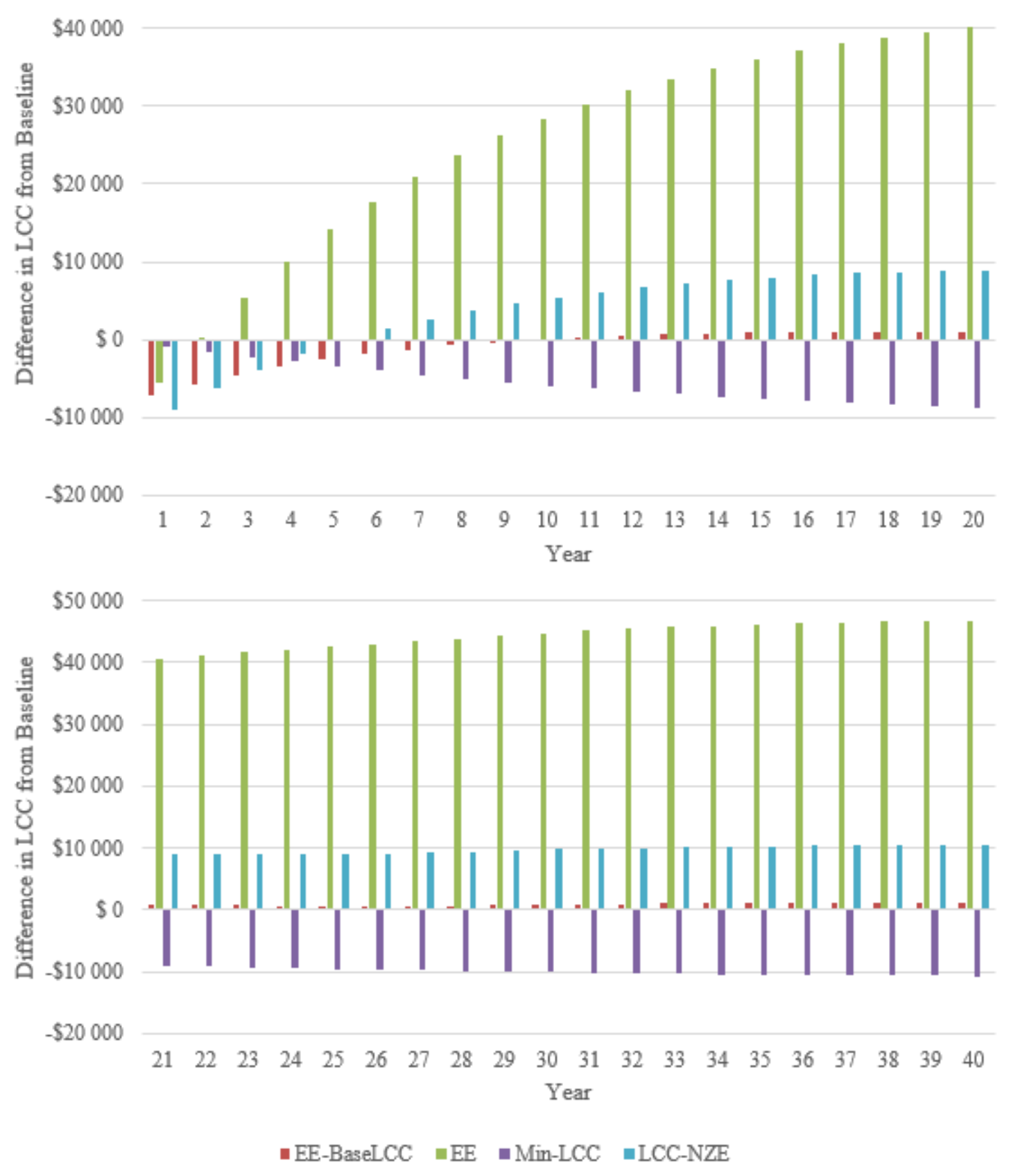

\section{Figure 4-30 Present Value of Incremental Change in LCC Relative to Baseline for Selected Designs - Case 5}

The modified payback periods for all designs except the minimum LCC (Min-LCC) design are at least 40 years, if they exist at all. The Min-LCC design has lower first costs than the baseline and, therefore, has a payback period of 0 years. While having an immediate payback relative to the baseline is beneficial, it should be noted that Min-LCC design would have the same payback 
period for any of the previously discussed cases. Focusing too much on payback period ignores the lower LCC achieved through other designs in other cases, making payback period a less informative measure.

\subsubsection{Environmental Impact Analysis of Key Designs - Case 5}

Changing the discount rate from $3 \%$ to $8 \%$ results in different EEMs being adopted in the Min-LCC and EE-BaseLCC designs. Since EE and LCC-NZE remain unchanged the analysis will focus on Min-LCC and EE-BaseLCC. Similar to Case 1, Figure 4-31 suggests that none of these designs outperform the baseline in all twelve impact categories as it performs as well or better than all of the alternatives in four or more categories. Again, the worst performance relative to the baseline occurs in the case of ecotoxicity, where the contributions of three designs (LCC-NZE, EE-BaseLCC, and EE) are more than three times as harmful as that of the baseline.
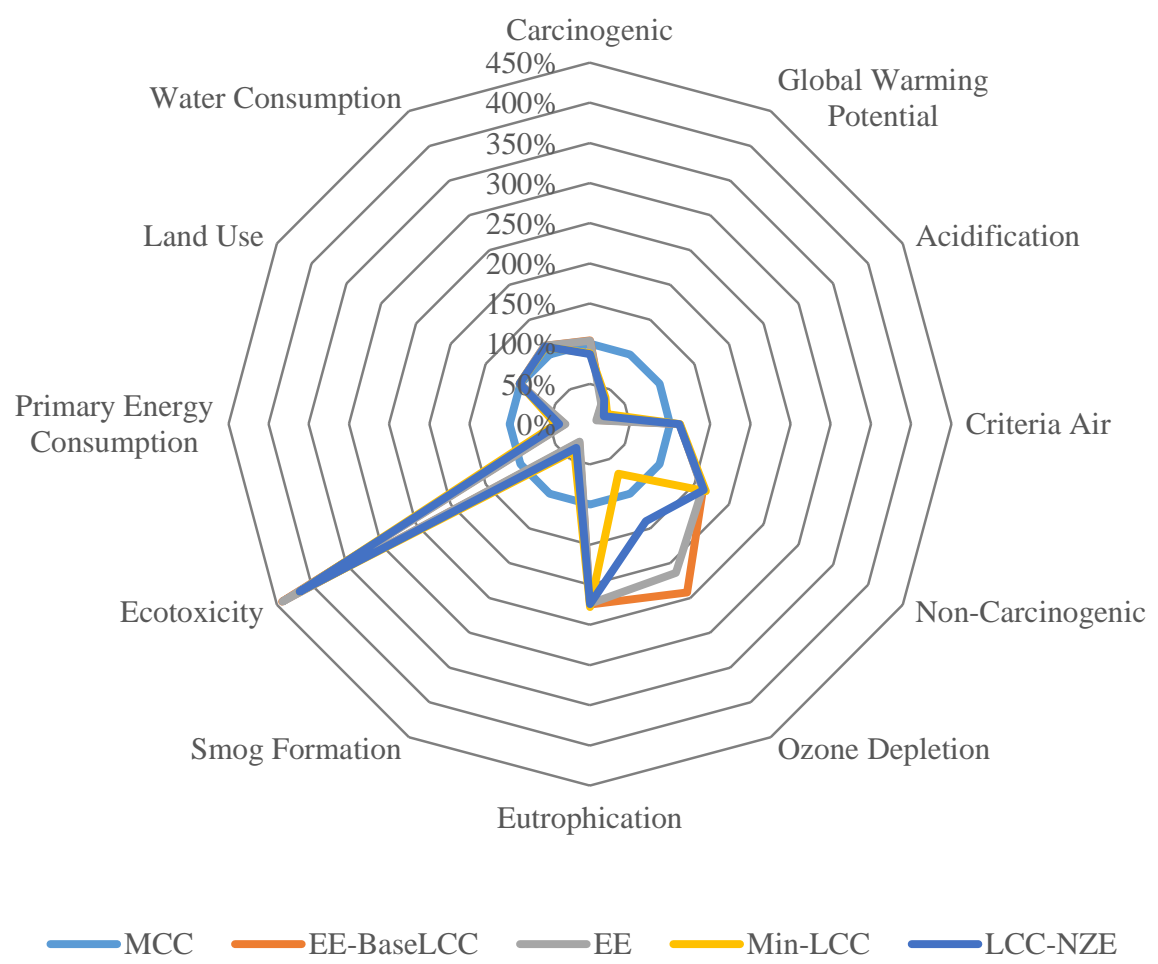

Figure 4-31 Environmental Impacts for Alternative Designs Relative to Baseline - Case 5

The normalized flow values in Table 4-14 shows that the most energy-efficient building design (EE), outperforms the baseline in the GWP, smog formation, acidification, and primary energy consumption categories - all of which are most directly impacted by operating energy use. The performance of the second-most energy-efficient design of the four alternatives (LCC-NZE) surpasses that of the baseline in the same four categories in addition to the carcinogenic impact 
category. This result is partly due to less energy consumption in response to improved energy efficiency. It is also partly due to fewer embodied emissions related to the use of $5.1 \mathrm{~cm} \mathrm{x} 15.2$ $\mathrm{cm}-61.0 \mathrm{~cm}$ (2 in x 6 in - 24 in) OC framing and less insulation installed in the basement wall assembly. The environmental performance of the EE-BaseLCC design beats that of the baseline in six out of the twelve impact categories: GWP, carcinogenic, smog formation, acidification, ozone depletion, and primary energy consumption. This outcome is best explained by the improved energy efficiency of the building and fewer embodied emissions as a result of using advanced framing and installing less blown-in cellulose insulation in the basement wall cavities. The Min-LCC design is the least energy-efficient of the four, but outperforms the baseline in all but four categories. Like the LCC-NZE design, the improved environmental performance by the Min-LCC design is traceable back to its improved energy efficiency; however, the reduction in embodied emissions stem from less insulation being installed on the roof/ceiling, exterior wall, and basement wall assemblies.

Similar to Section 4.2.5, the major takeaways from table of normalized flows are: (1) the more energy-efficient a design is, the less of an impact it has on GWP, smog formation, acidification, primary energy consumption; and (2) its impact on all other non-energy related environmental impact categories varies according to the level of insulation installed in the roof/ceiling and wall assemblies.

Table 4-14 Normalized Flows for Case 5

\begin{tabular}{lccccc}
\hline Impact Category & MCC & Min-LCC & LCC-NZE & EE-BaseLCC & EE \\
\hline Global Warming Potential & 8.40 & 7.19 & 3.02 & 4.18 & 2.39 \\
HH - Criteria Air & 1.05 & 1.01 & 1.17 & 1.13 & 1.17 \\
HH - Carcinogenic & 5.46 & 3.82 & 4.74 & 4.49 & 5.67 \\
\hline HH - Non-carcinogenic & 2.81 & 3.15 & 4.60 & 4.29 & 4.55 \\
Water Consumption & 2.67 & 2.92 & 2.98 & 2.95 & 3.01 \\
\hline Ecotoxicity & 0.10 & 0.11 & 0.40 & 0.33 & 0.42 \\
Eutrophication & 0.94 & 1.08 & 2.12 & 1.88 & 2.12 \\
\hline Land Use & 2.68 & 2.68 & 2.70 & 2.69 & 2.70 \\
\hline Smog Formation & 9.40 & 7.80 & 3.21 & 4.61 & 2.38 \\
\hline Acidification & 14.62 & 11.59 & 2.91 & 5.55 & 1.36 \\
\hline Ozone Depletion & 0.42 & 0.29 & 0.59 & 0.32 & 0.90 \\
\hline Primary Energy Consumption & 4.99 & 4.19 & 1.90 & 2.60 & 1.51 \\
\hline
\end{tabular}


Figure 4-32 and Figure 4-33 show the EISs and the individual contributions of the normalized flows under the Equal and BEES Weighting approaches and the SAB and Carbon Footprint Only Weighting approaches, respectively (the legend for these figures is located in Figure 4-34). Both figures indicate that the $\mathbf{E E}$ design is the most environmentally friendly of the five selected designs across all weighting approaches. The LCC-NZE design is the second-best performing building. Given the results, it is evident there exists an inverse relationship between a building's energy efficiency level and its overall environmental performance as indicated by its EIS. In other words, the greater the reduction in energy consumption the lower a building's EIS. The reduction in environmental impact from the energy savings is more than offset by the environmental impact due to use of additional building materials. Another interesting result is that the Min-LCC design has a lower EIS than the baseline design, which shows that the most cost-effective design also has smaller environmental impacts.
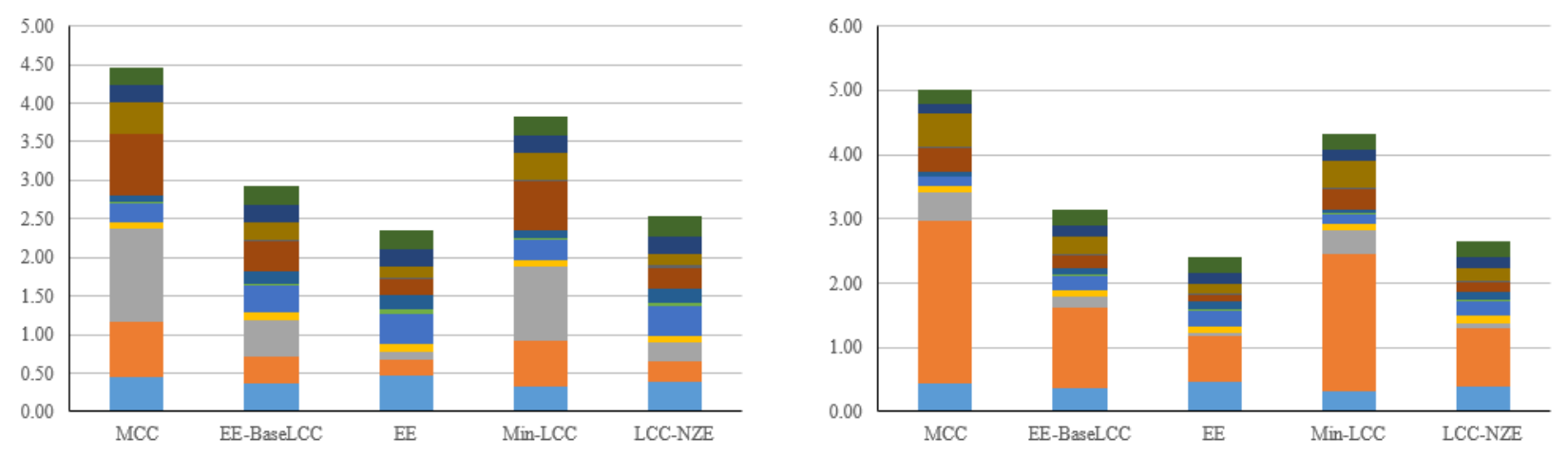

Figure 4-32 Environmental Impact Scores for the MCC and Alternative Designs using Equal (left) and BEES (right) Weighting Approaches - Case 5
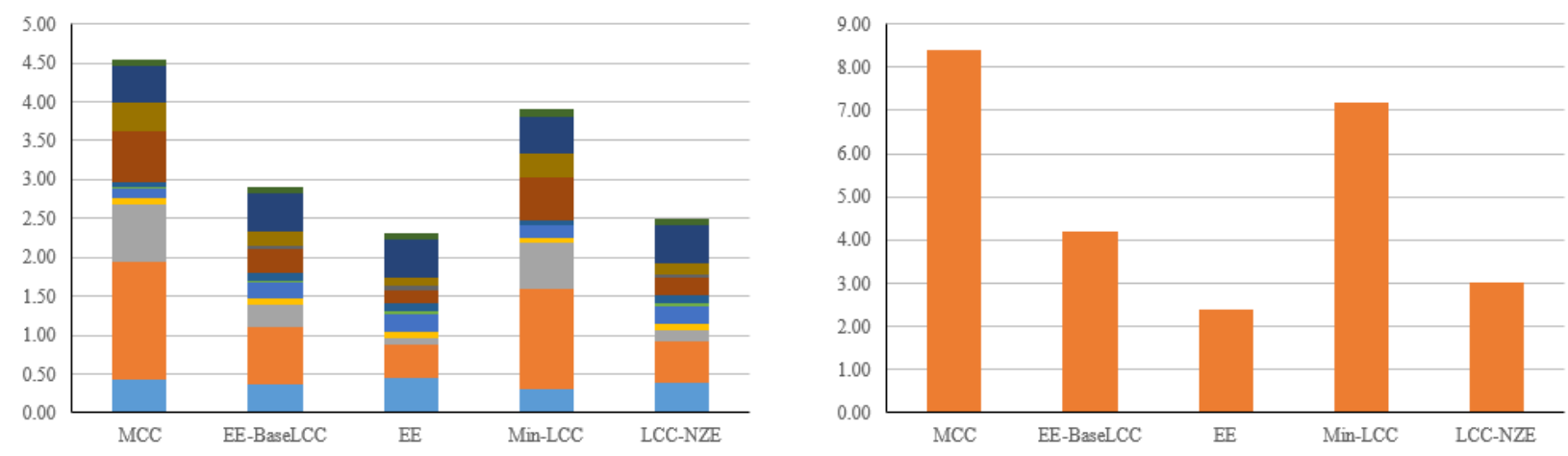

Figure 4-33 Environmental Impact Scores for the MCC and Alternative Design using SAB (left) and Carbon Footprint Only (right) Weighting Approaches - Case 5 


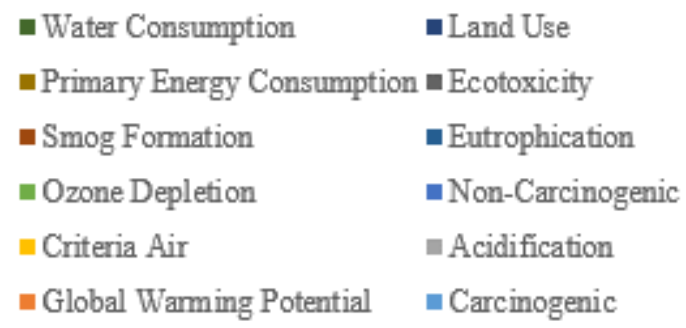

Figure 4-34 Legend for EIS Plots in Figure 4-32 and Figure 4-33

\subsection{Case 6: 8 \% Discount Rate, Average Construction Quality, 20 \% Down/80 \% Loan Financing}

Case 6 is identical to Case 5 ( $8 \%$ discount rate and average construction quality) except the financing option is a 30-year loan financing with $20 \%$ down payment. Applying the $20 \%$ down financing option to the $8 \%$ discount rate has a dramatic effect on the LCC of the different design alternatives. Figure 4-35 shows that financing the home purchase reverses the impact of switching from a $3 \%$ to $8 \%$ discount rate in Case 5 as discussed in Section 4.6 .1 and leads to similar optimal combinations from Case 1 (see Figure 3-1 and Figure 3-3). The combination of the reduction in the down payment from financing the home purchase coupled with the higher discount rate reducing the present value of future loan payments on LCC makes it optimal to include a solar PV system in a building design. 


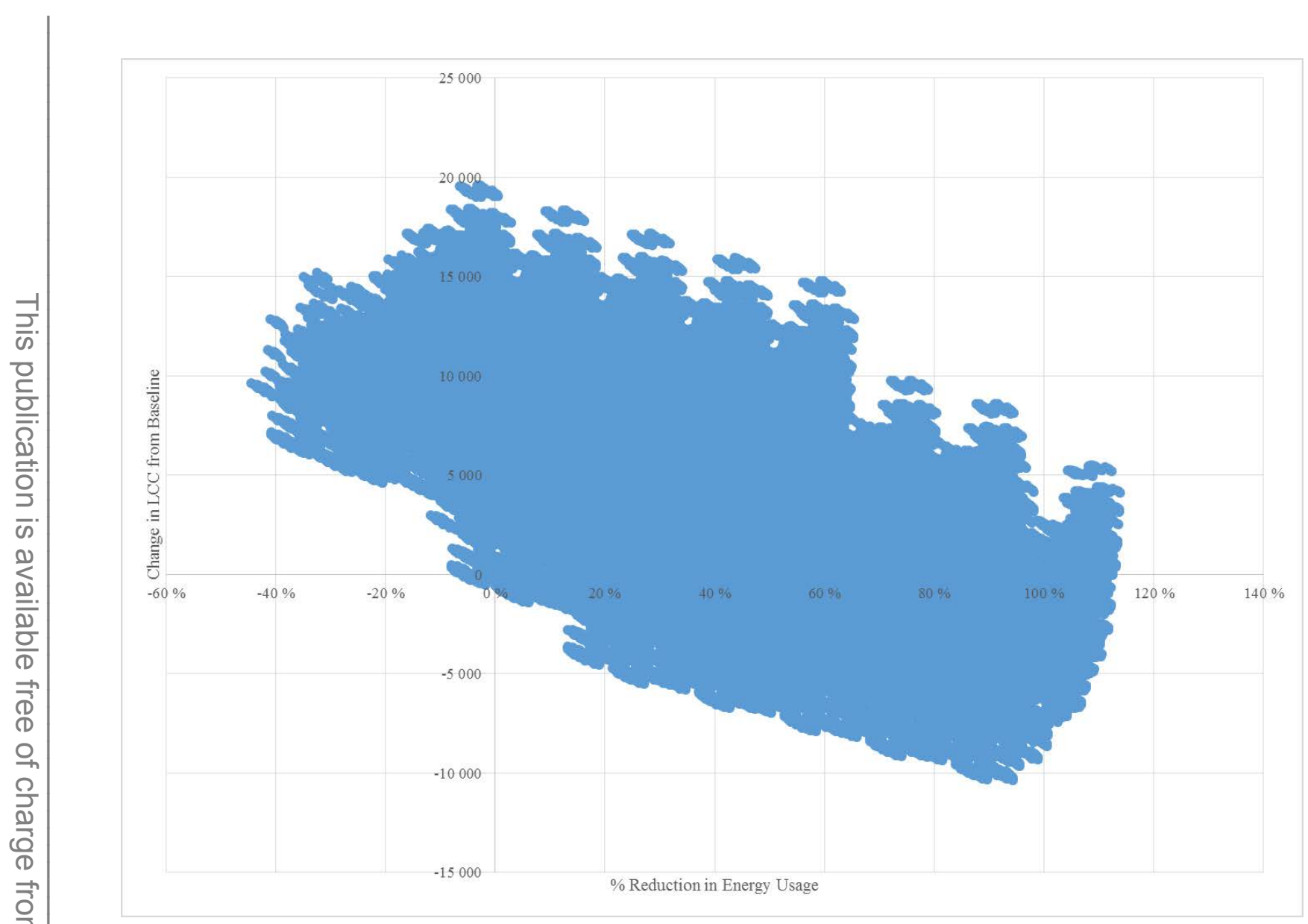

Figure 4-35 Energy Savings and Net Savings - 3 \% Discount Rate, “Average” Construction Quality, and $100 \%$ Cash Financing

\subsubsection{Summary of Key Designs - Case 6}

Similar to Case 2, Case 3, and Case 4, the key designs for Case 6 shown in Table 4-15 are identical to those in Case 1 except for EE-BaseLCC. Case 6 is the most similar case to Case 1, with only two EEM options different, which are shown in gray. 
Table 4-15 Selected Key Designs - Case 6

\begin{tabular}{|c|c|c|c|c|}
\hline $\begin{array}{c}\text { Design } \\
\text { Category }\end{array}$ & EE-BaseLCC & $\mathrm{EE}^{* *}$ & Min-LCC** & LCC-NZE** \\
\hline Windows & $\begin{array}{c}\text { U Factor: } \\
1.14 \mathrm{~W} / \mathrm{m}^{2}-\mathrm{K} \\
\left(0.2 \mathrm{Btu} / \mathrm{h} \cdot \mathrm{ft}^{2}-\mathrm{F}\right) \\
\text { SHGC: } 0.25\end{array}$ & $\begin{array}{c}\text { U Factor: } \\
1.14 \mathrm{~W} / \mathrm{m}^{2}-\mathrm{K} \\
\left(0.2 \mathrm{Btu} / \mathrm{h} \cdot \mathrm{ft}^{2}-\mathrm{F}\right) \\
\text { SHGC: } 0.25\end{array}$ & $\begin{array}{c}\text { U Factor: } \\
1.14 \mathrm{~W} / \mathrm{m}^{2}-\mathrm{K} \\
\left(0.2 \mathrm{Btu} / \mathrm{h} \cdot \mathrm{ft}^{2}-\mathrm{F}\right) \\
\text { SHGC: } 0.25\end{array}$ & $\begin{array}{c}\text { U Factor: } \\
1.14 \mathrm{~W} / \mathrm{m}^{2}-\mathrm{K} \\
\left(0.2 \mathrm{Btu} / \mathrm{h} \cdot \mathrm{ft}^{2}-\mathrm{F}\right) \\
\text { SHGC: } 0.25\end{array}$ \\
\hline HVAC & $\begin{array}{l}\text { Air-to-air heat pump } \\
\text { (SEER 16.5/ HSPF 9.1) }\end{array}$ & $\begin{array}{l}\text { Air-to-air heat pump } \\
\text { (SEER 16.5/ HSPF 9.1) }\end{array}$ & $\begin{array}{l}\text { Air-to-air heat pump } \\
\text { (SEER 13.0/ HSPF 7.7) }\end{array}$ & $\begin{array}{l}\text { Air-to-air heat pump } \\
\text { (SEER 13.0/ HSPF 7.7) }\end{array}$ \\
\hline Ventilation & Separate HRV system & Separate HRV system & Outdoor air* & Outdoor air* \\
\hline $\begin{array}{c}\text { Air Flow } \\
\text { Rate }\end{array}$ & $0.63 \mathrm{ACH}_{50}$ & $0.63 \mathrm{ACH}_{50}$ & $0.63 \mathrm{ACH}_{50}$ & $0.63 \mathrm{ACH}_{50}$ \\
\hline Lighting & $100 \%$ efficient fixtures & $100 \%$ efficient fixtures & $100 \%$ efficient fixtures & $100 \%$ efficient fixtures \\
\hline Solar PV & $10.2 \mathrm{~kW}$ & $10.2 \mathrm{~kW}$ & $10.2 \mathrm{~kW}$ & $10.2 \mathrm{~kW}$ \\
\hline DHW & $\begin{array}{c}\text { Heat pump water } \\
\text { heater }\end{array}$ & $\begin{array}{l}\text { Heat pump water heater } \\
\text { w/ solar thermal system }\end{array}$ & Heat pump water heater & Heat pump water heater \\
\hline Roof & $\begin{array}{c}\text { Roof insulation: } \\
\text { RsI-7.92 + 5.28 }^{(R-45+30)}\end{array}$ & 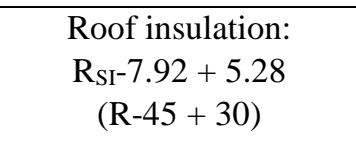 & $\begin{array}{c}\text { Ceiling Insulation: } \\
\mathrm{R}_{\mathrm{SI}}-8.63 \\
(\mathrm{R}-49)\end{array}$ & $\begin{array}{c}\text { Ceiling Insulation: } \\
\mathrm{R}_{\mathrm{SI}}-8.63 \\
(\mathrm{R}-49)\end{array}$ \\
\hline Wall & $\begin{array}{c}\text { Framing: Advanced } \\
\text { Insulation: } \mathrm{R}_{\mathrm{SI}}-3.5+4.2 \\
(\mathrm{R}-20+24)\end{array}$ & $\begin{array}{c}\text { Framing: Advanced } \\
\text { Insulation: } \mathrm{R}_{\mathrm{SI}}-3.5+4.2 \\
(\mathrm{R}-20+24)\end{array}$ & $\begin{array}{c}\text { Framing: Advanced } \\
\text { Insulation: } \mathrm{R}_{\mathrm{SI}}-3.5 \\
(\mathrm{R}-20+0)\end{array}$ & $\begin{array}{c}\text { Framing: Advanced } \\
\text { Insulation: } \mathrm{R}_{\mathrm{SI}}-3.5+2.1 \\
(\mathrm{R}-20+12) \\
\end{array}$ \\
\hline $\begin{array}{c}\text { Foundation } \\
\text { Wall }\end{array}$ & $\begin{array}{c}\text { RsI-1.76 } \\
\text { (R-10) }\end{array}$ & $\begin{array}{l}\mathrm{R}_{\mathrm{SI}}-3.9 \\
(\mathrm{R}-22)\end{array}$ & $\begin{array}{c}\mathrm{R}_{\mathrm{SI}}-1.41 \\
\text { (R-8) }\end{array}$ & $\begin{array}{c}\mathrm{R}_{\mathrm{SI}}-1.41 \\
(\mathrm{R}-8)\end{array}$ \\
\hline $\begin{array}{l}\text { Foundation } \\
\text { Floor }\end{array}$ & $\begin{array}{l}\mathrm{R}_{\mathrm{SI}}{ }^{-0} \\
(\mathrm{R}-0)\end{array}$ & $\begin{array}{l}\mathrm{R}_{\mathrm{SI}}{ }^{-0} \\
(\mathrm{R}-0)\end{array}$ & $\begin{array}{l}\mathrm{R}_{\mathrm{SI}}{ }^{-0} \\
(\mathrm{R}-0)\end{array}$ & $\begin{array}{l}\mathrm{R}_{\mathrm{SI}}{ }^{-0} \\
(\mathrm{R}-0)\end{array}$ \\
\hline $\begin{array}{c}\text { Energy } \\
\text { Reduction } \\
(\%) \\
\end{array}$ & $113 \%$ & $114 \%$ & $94 \%$ & $101 \%$ \\
\hline $\begin{array}{l}\text { Change in } \\
\text { LCC (10-yr) }\end{array}$ & $\$ 97$ & $\$ 4130$ & $-\$ 10350$ & $-\$ 8653$ \\
\hline
\end{tabular}

Case 6 is most comparable to Case 2, which also includes financing using an 80/20 loan with "average" construction quality. The differences in the EE-BaseLCC design for Case 6 relative to Case 2 are the exclusion of the solar thermal system and reduction in the amount of insulation in the roof/ceiling and basement wall and floor assemblies. The higher discount rate increases the costs of the EEMs in Case 2, although the impact on overall energy efficiency was unchanged. Due to the higher discount rate in Case 6, the EE design realizes an additional \$4310 in LCC relative to the baseline design while the same $\mathbf{E E}$ design realizes net savings of \$1097 in Case 2. Similarly, the Min-LCC and LCC-NZE designs realize smaller net savings than the same designs in Case 2. 
When compared to Case 5, the EE-BaseLCC and Min-LCC designs are more energy efficient. Financing the home purchase, with the same construction quality and discount rate, leads to more expensive EEMs that were not economically viable in Case 5 are now feasible from a LCC perspective. The EE, Min-LCC, and LCC-NZE designs all realize better economic performance than for the same designs in Case 5 with reductions in LCC of \$24 207, \$4446, and 14047 , respectively. Not only does the LCC-NZE design realize a lower LCC, but the design realizes lower LCC than the baseline design with a net savings of \$8653, which does not occur in Case 5.

\subsubsection{First Cost Analysis of Key Designs - Case 6}

Similar to Case 2, the total down payment for the selected designs decreases since only $20 \%$ of the total construction costs are required as a down payment. The first costs are reduced by $80 \%$ relative to Case 5 for all designs as illustrated in Figure 4-36.

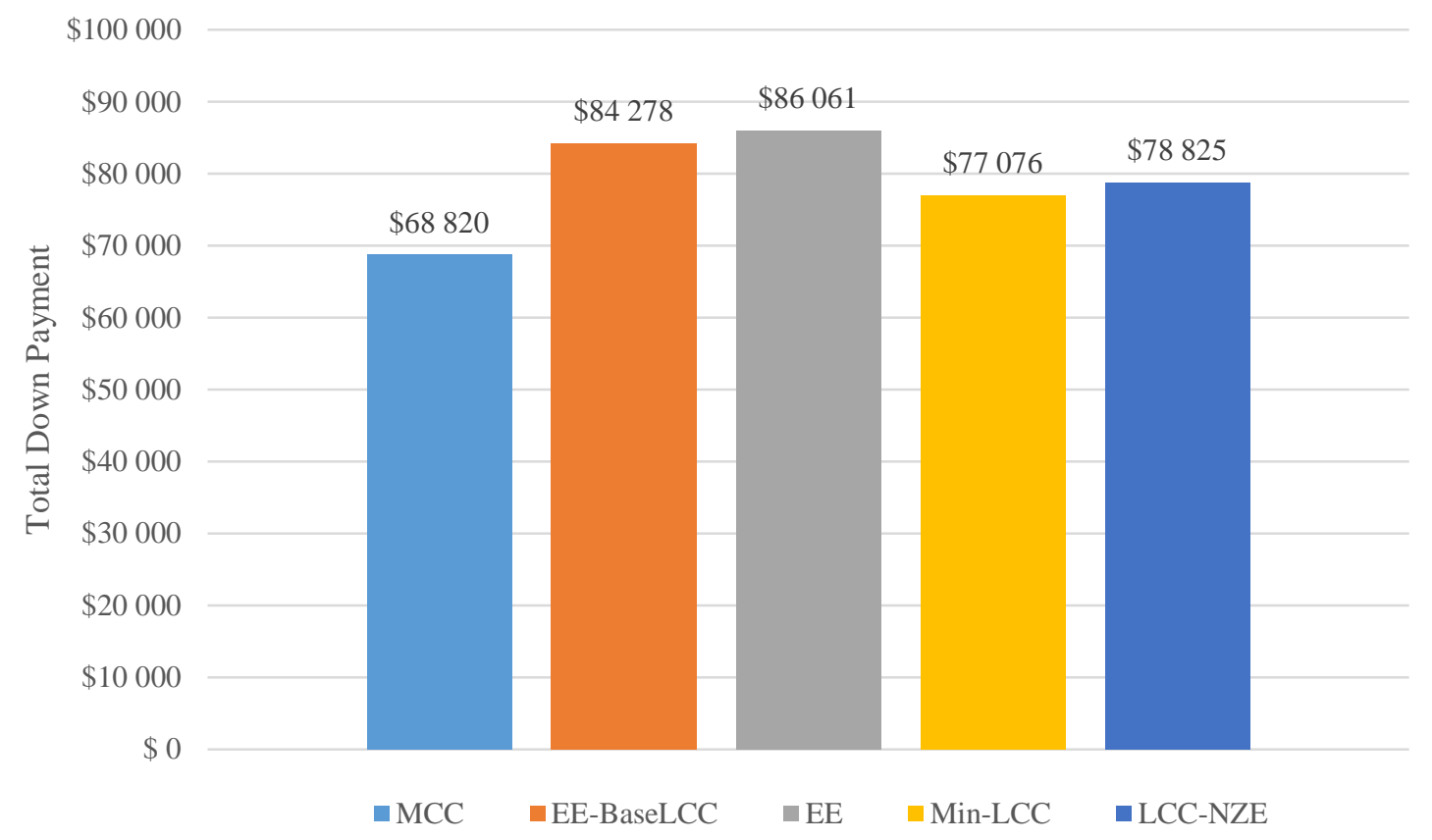

Figure 4-36 Present Value of Total First Costs for Selected Designs - Case 6

The incremental first costs shown in Figure 4-37 are identical to those in Case 2 with the exception of the EE-BaseLCC design. For the EE, Min-LCC, and LCC-NZE designs, Case 2 and Case 6 will have the same incremental costs because the only assumption that differs between the two cases is the discount rate, which does not impact first costs that occur in Year 0. The EE-BaseLCC design has a reduction of \$2331 in its first costs relative to Case 2, which is due to less insulation installed in the foundation assemblies and exclusion of the solar thermal system. 


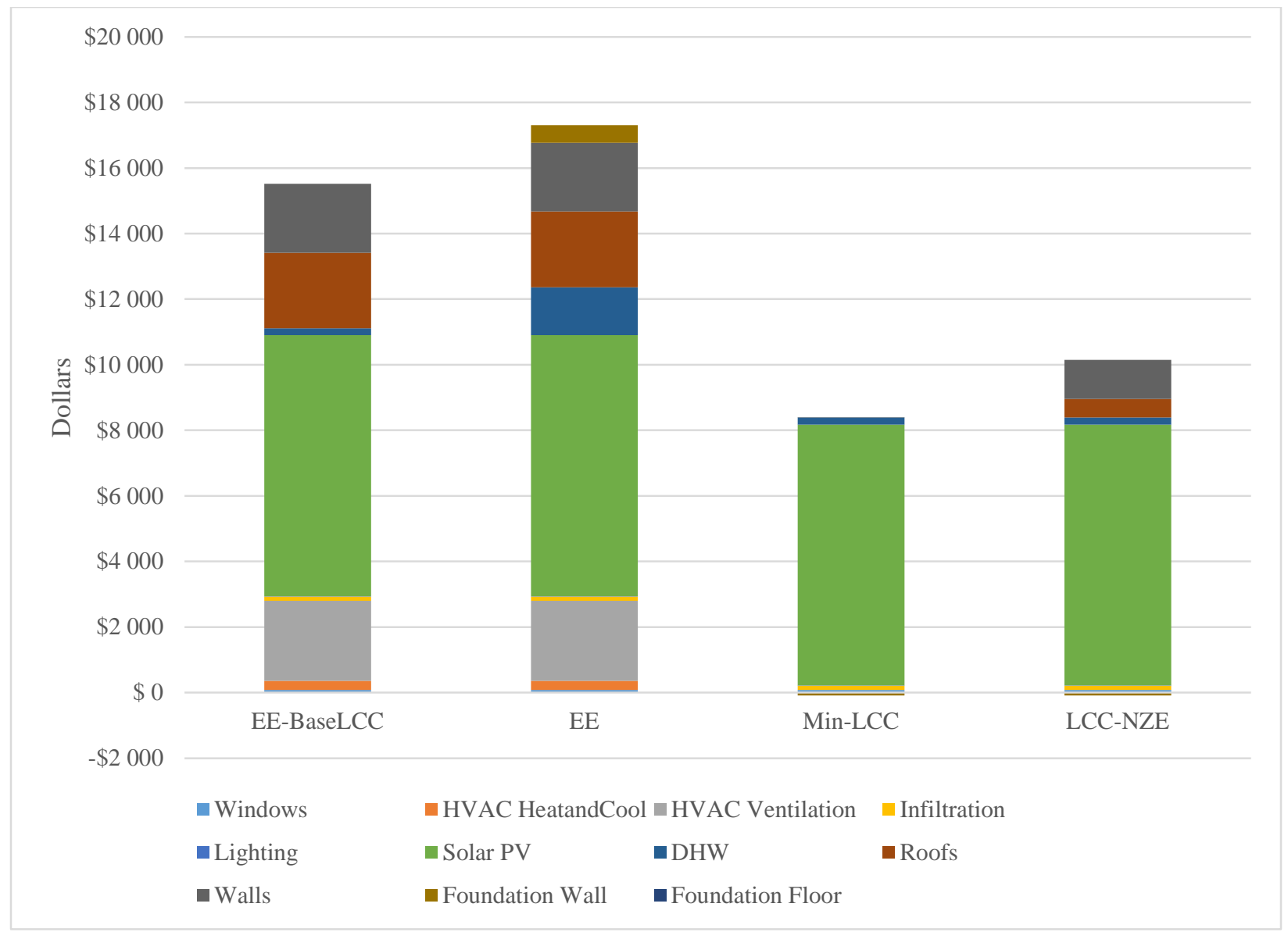

Figure 4-37 Present Value of Incremental First Costs Relative to Baseline for Selected Designs - Case 6

\subsubsection{Future Cost Analysis of Key Designs - Case 6}

The loan payments in Figure 4-38 show that financing the home purchase while having the higher (8 \%) discount rate impacts the key design selections. By Year 9 the discounted loan payments are roughly half of those for Year 1. Similar to Case 2, the Min-LCC design is more cost-effective to select the 80/20 loan financing option, and by a wider margin. A combination of the down payment ( $\$ 77$ 076) plus the total discounted loan payments ( $\$ 164$ 307) equals $\$ 241383$ and is less costly than the total construction costs by $\$ 132074$, which is a much larger difference than realized in Case 2 (\$26 711). 


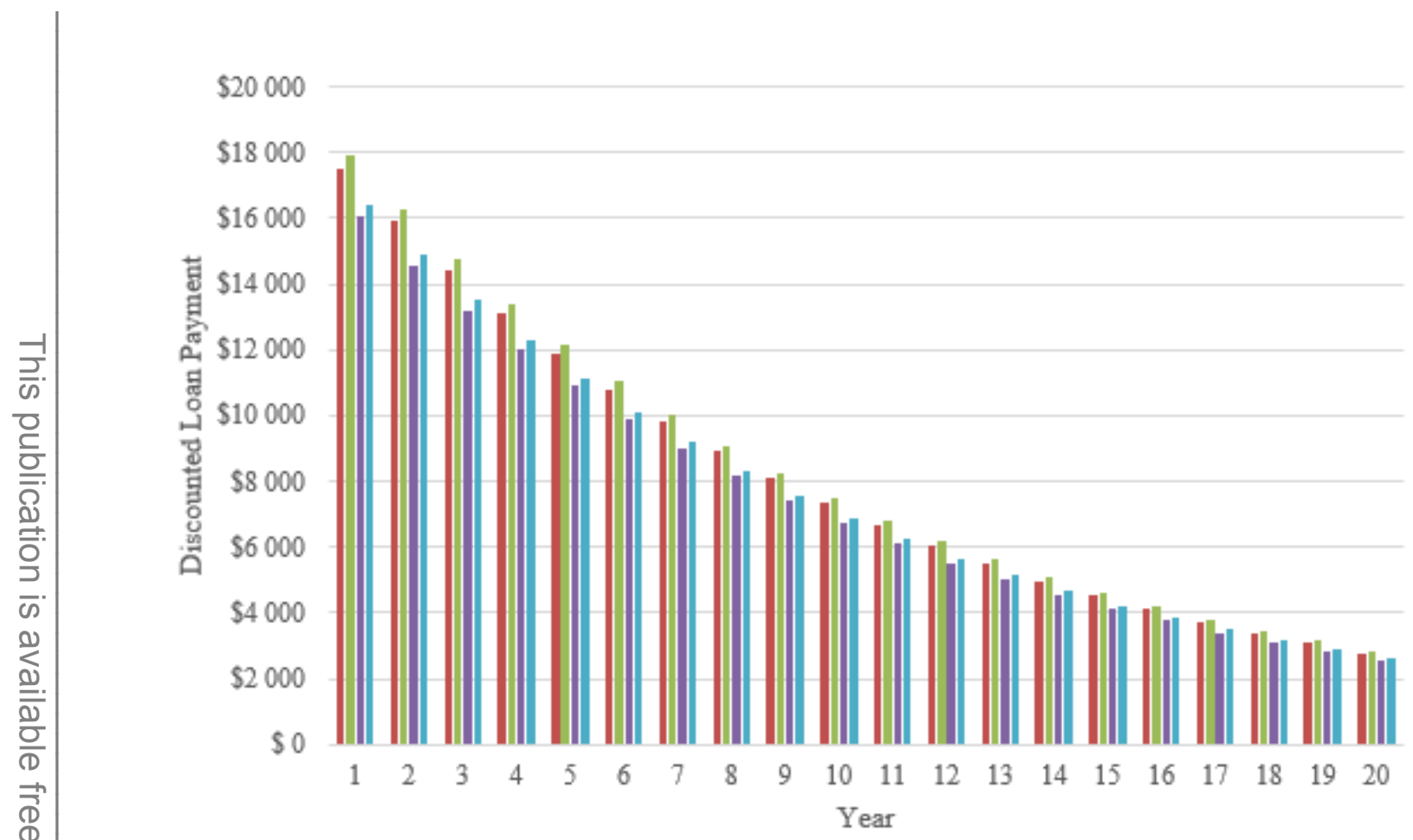

$\$ 3000$

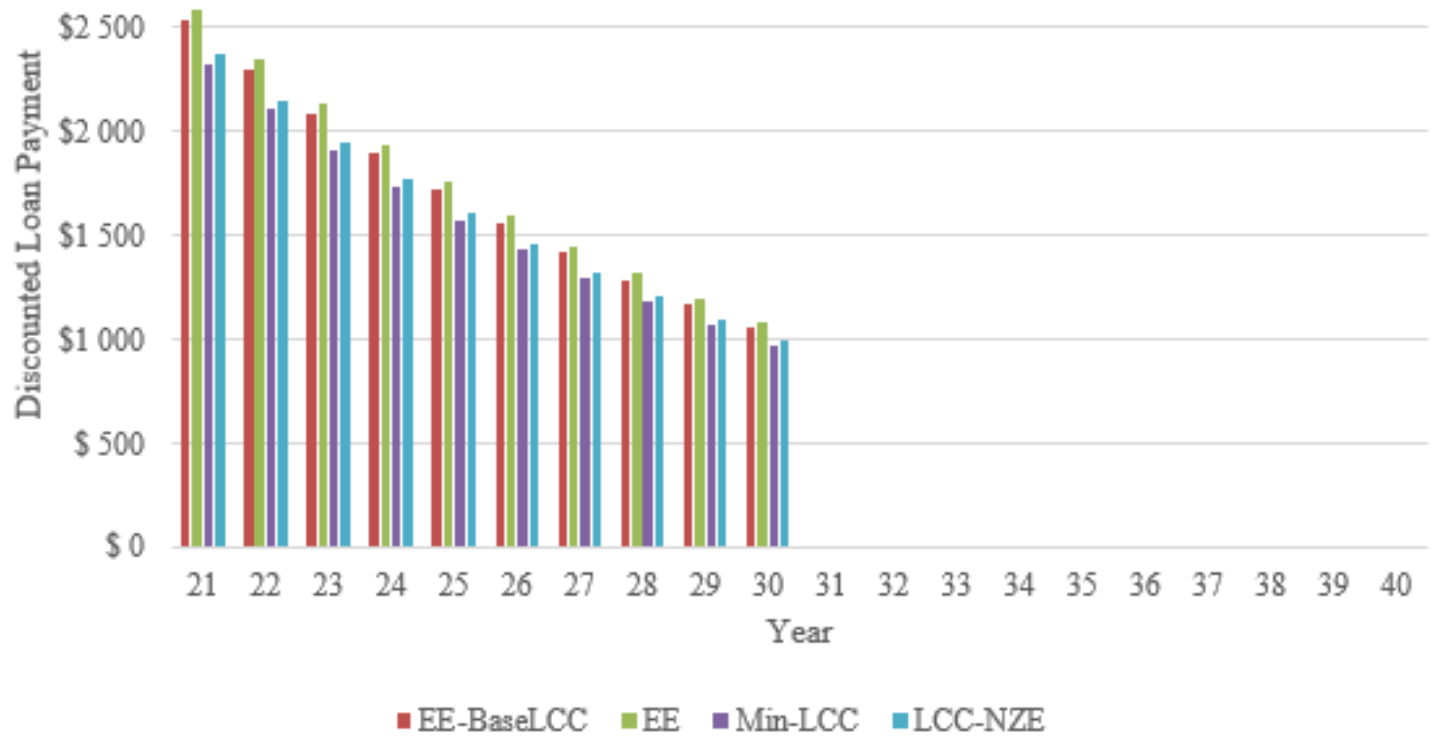

Figure 4-38 Discounted Loan Payments for Selected Designs - Case 6

Figure 4-39 shows that the trends in total electricity costs for Case 6 are similar to those for Case 1 and Case 2. However, the values decrease at a faster rate due to the higher discount rate. Case 1 and Case 2 both had cumulative electricity costs over $\$ 80000$ over a 40-year study period for the baseline design. Case 6 realizes over a $50 \%$ reduction for the baseline design at less than $\$ 40$ 000. Similar impacts occur for all other designs with designs that reach net-zero 
energy performance, such as the EE and EE-BaseLCC designs, realizing reductions in energy cost savings of over $50 \%$ reduction. Note that the smaller scale of the energy savings leads to an overall smaller impact in terms of dollar value. Total MRR costs, Figure 4-40, show similar trends, though the reductions in later years are not as pronounced.
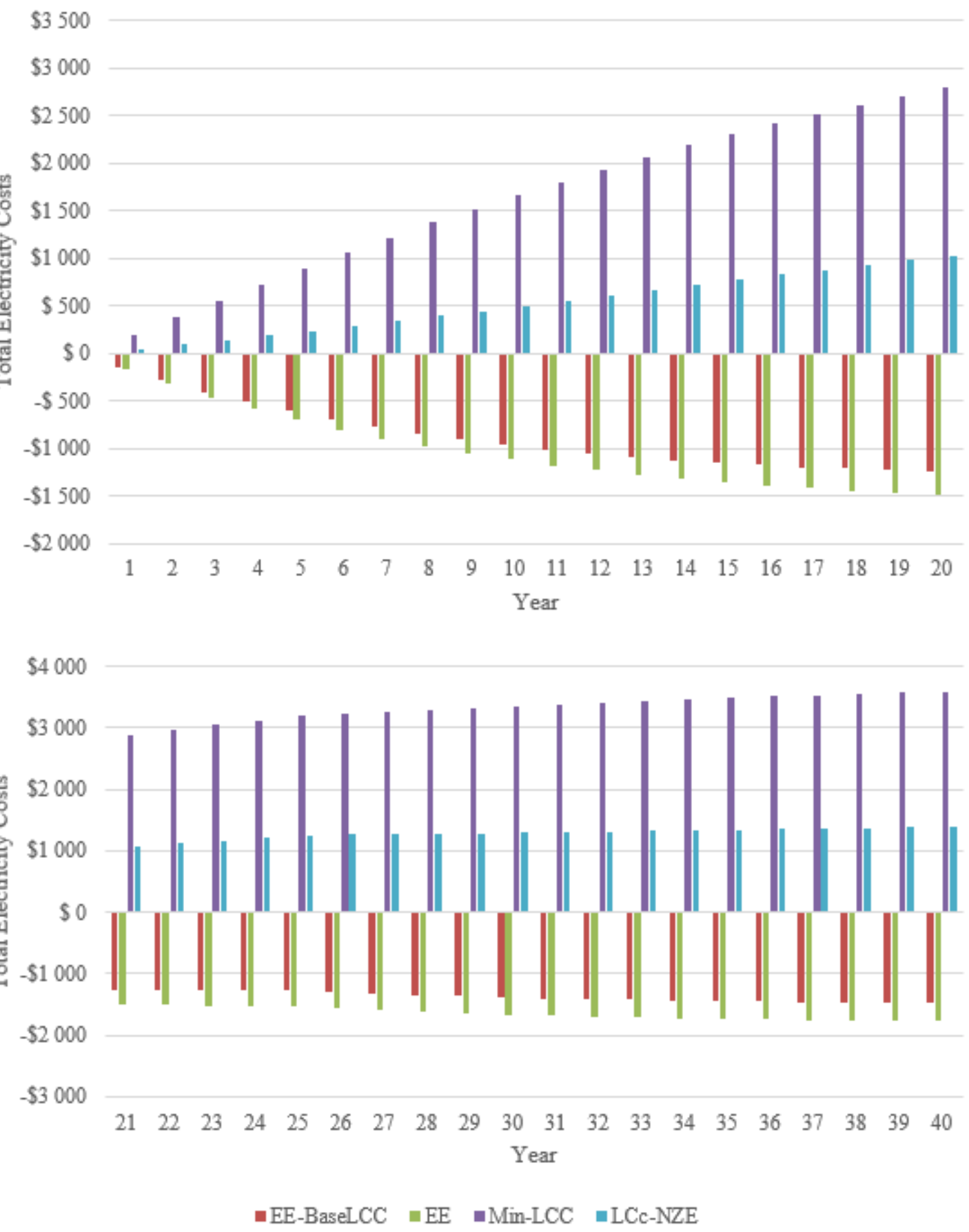

Figure 4-39 Present Value of Total Electricity Costs for Selected Designs - Case 6 

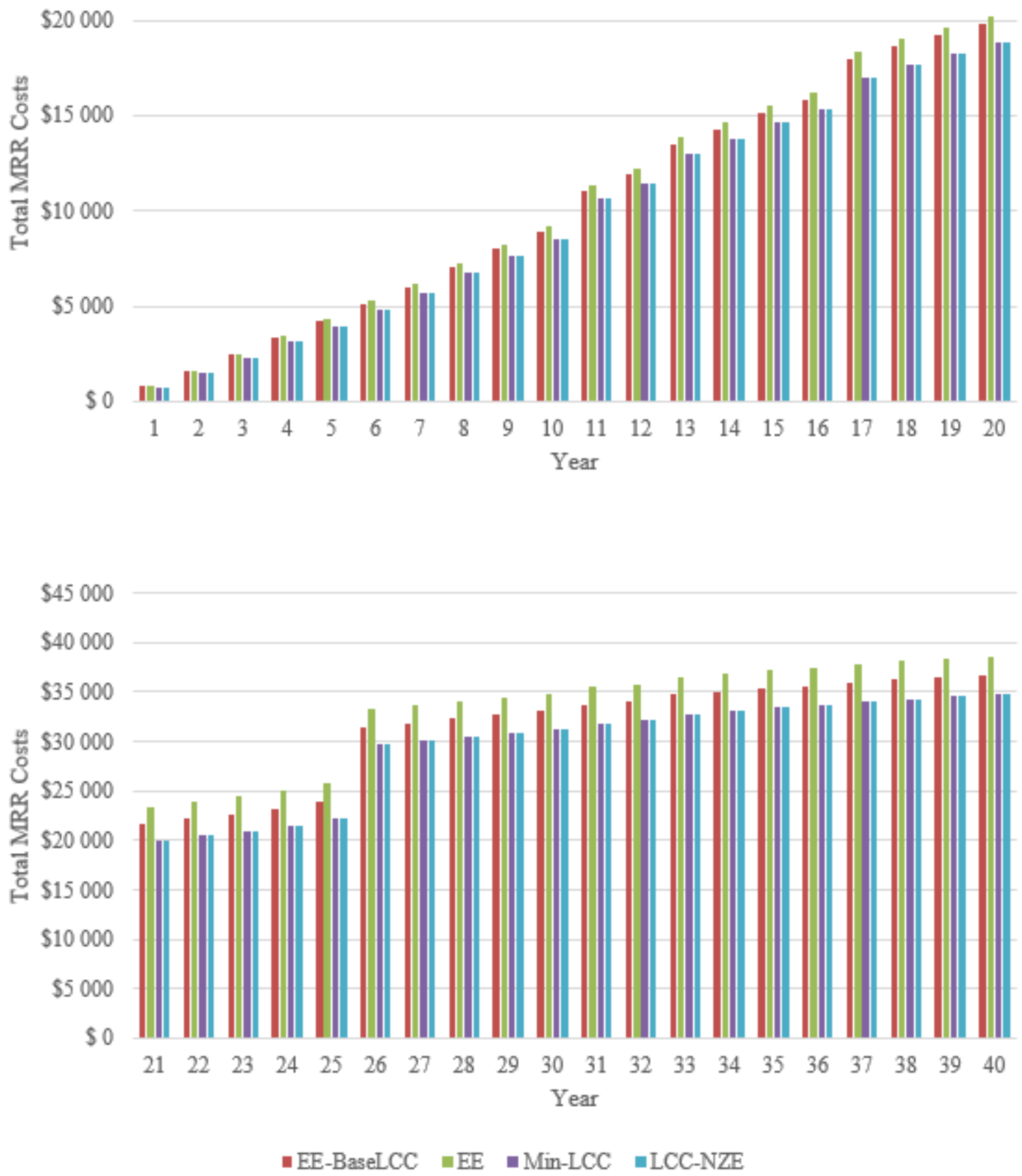

Figure 4-40 Present Value of Total MRR Costs for Selected Designs - Case 6

The effect of the $8 \%$ discount rate on the residual value, Figure 4-41, is slightly different. Unlike total MRR costs and total electricity costs, the residual value component of the LCC starts at a high value and decreases over time. This trend means that, in early years, the reduction due to the residual value is less affected by the discount rate. For comparison purposes there is a reduction in residual value of less than $\$ 20000$ for the baseline design relative to Case 1 and Case 2 while 
the reduction in total electricity costs is over $\$ 40000$ for a 40 -year study period from Case 1 and Case 2. Therefore, residual value’s role is minimized under the higher discount rate.

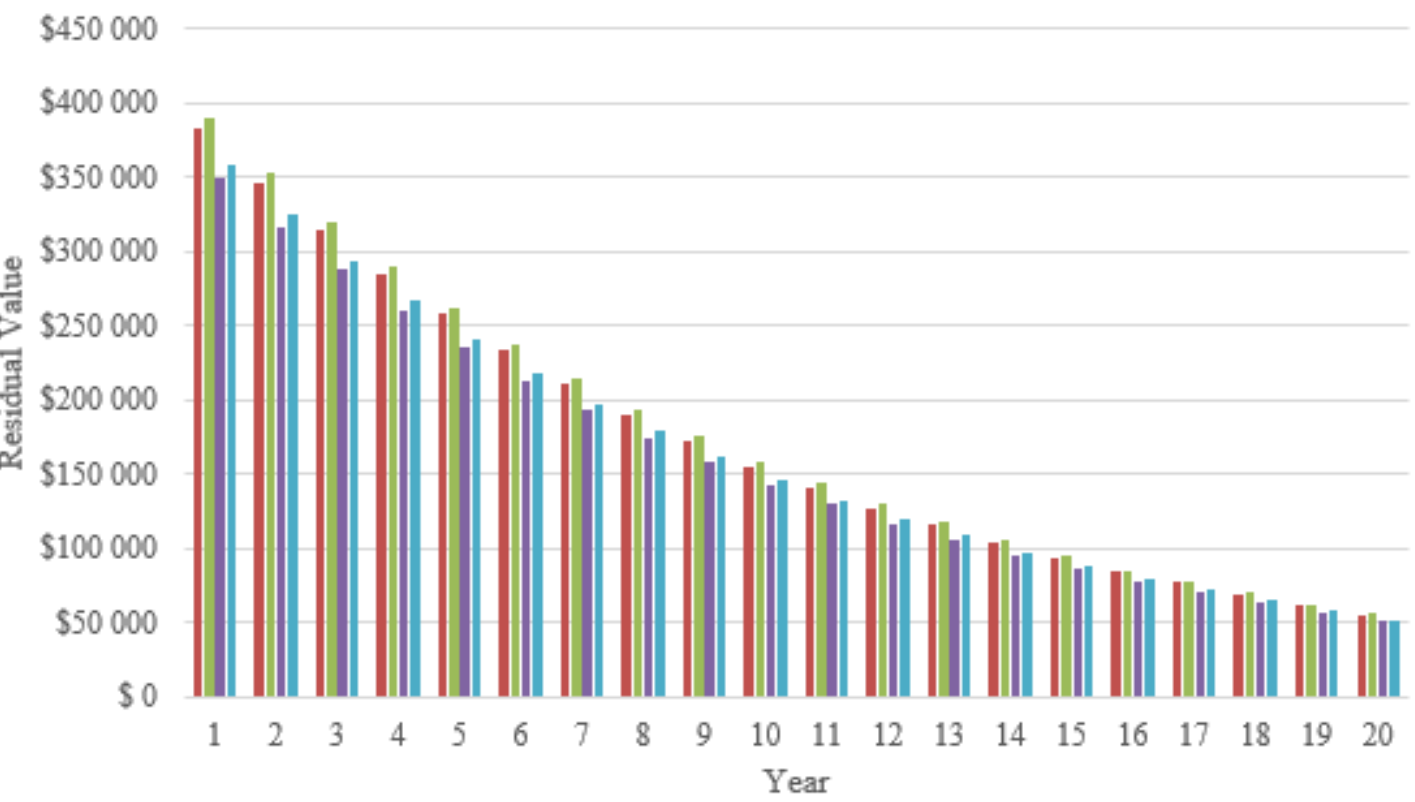

$\$ 60000$

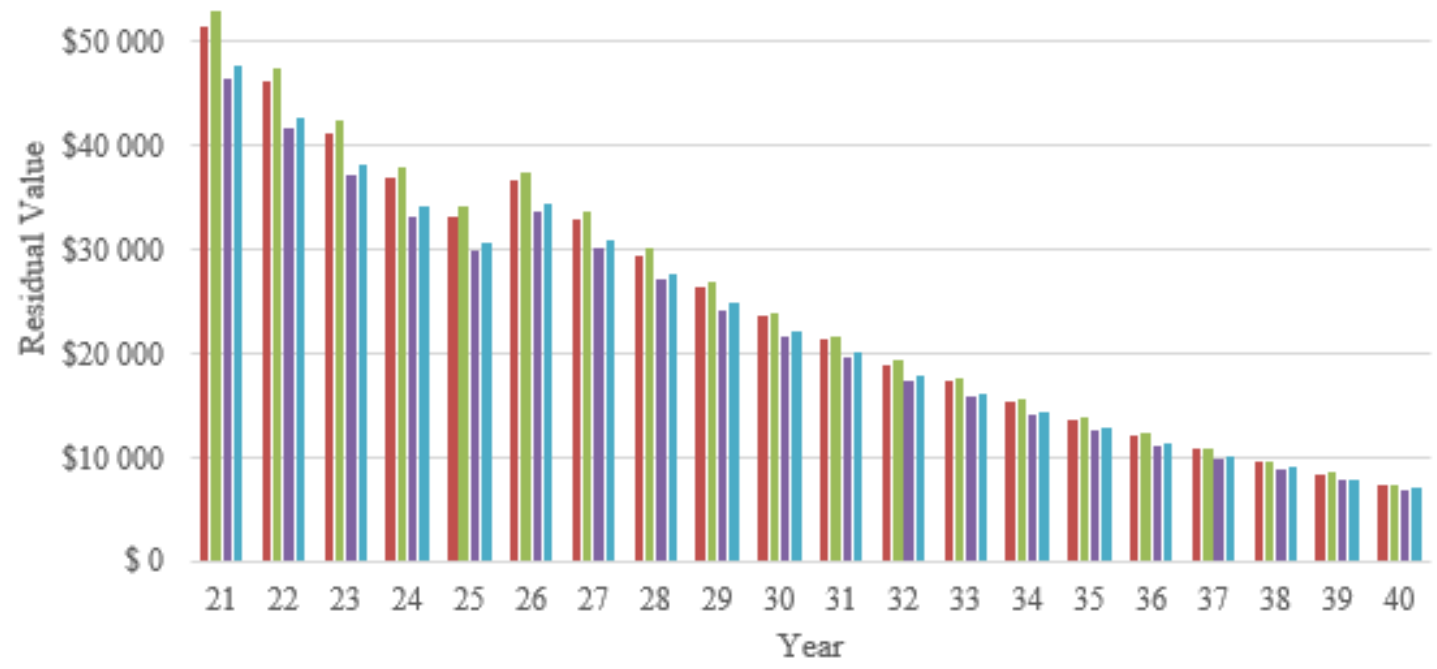

-EE-BaseLCC $\|\mathrm{EE} \quad\|$ Min-LCC $\|$ LCC-NZE

Figure 4-41 Present Value of Residual Value Costs for Selected Designs - Case 6 


\subsubsection{LCC Analysis and Payback Period of Key Designs - Case 6}

The total LCC, Figure 4-42, and difference in LCC, Figure 4-43, reveal significant differences when compared with Case 5, while maintaining many similarities in terms of overall trends when compared with Case 1 and Case 2. In Case 5, the most efficient (EE) design quickly surpassed all other designs in terms of total LCC to the point it had a noticeably larger total LCC relative to any other design. The EE design is still more costly in terms of LCC, however, it is much closer to the rest of the designs. The minimum LCC (Min-LCC) design for Case 6 does not produce as much LCC savings over the baseline as the Min-LCC design for Case 5, although it does realize greater energy savings. The minimum LCC design that reaches net-zero energy performance (LCC-NZE) is the same for both cases in terms of building characteristics, but the relative economic performance shifts from realizing higher LCC than the baseline design using $100 \%$ upfront cash purchase in Case 5 to realizing lower LCC using the loan financing option. 

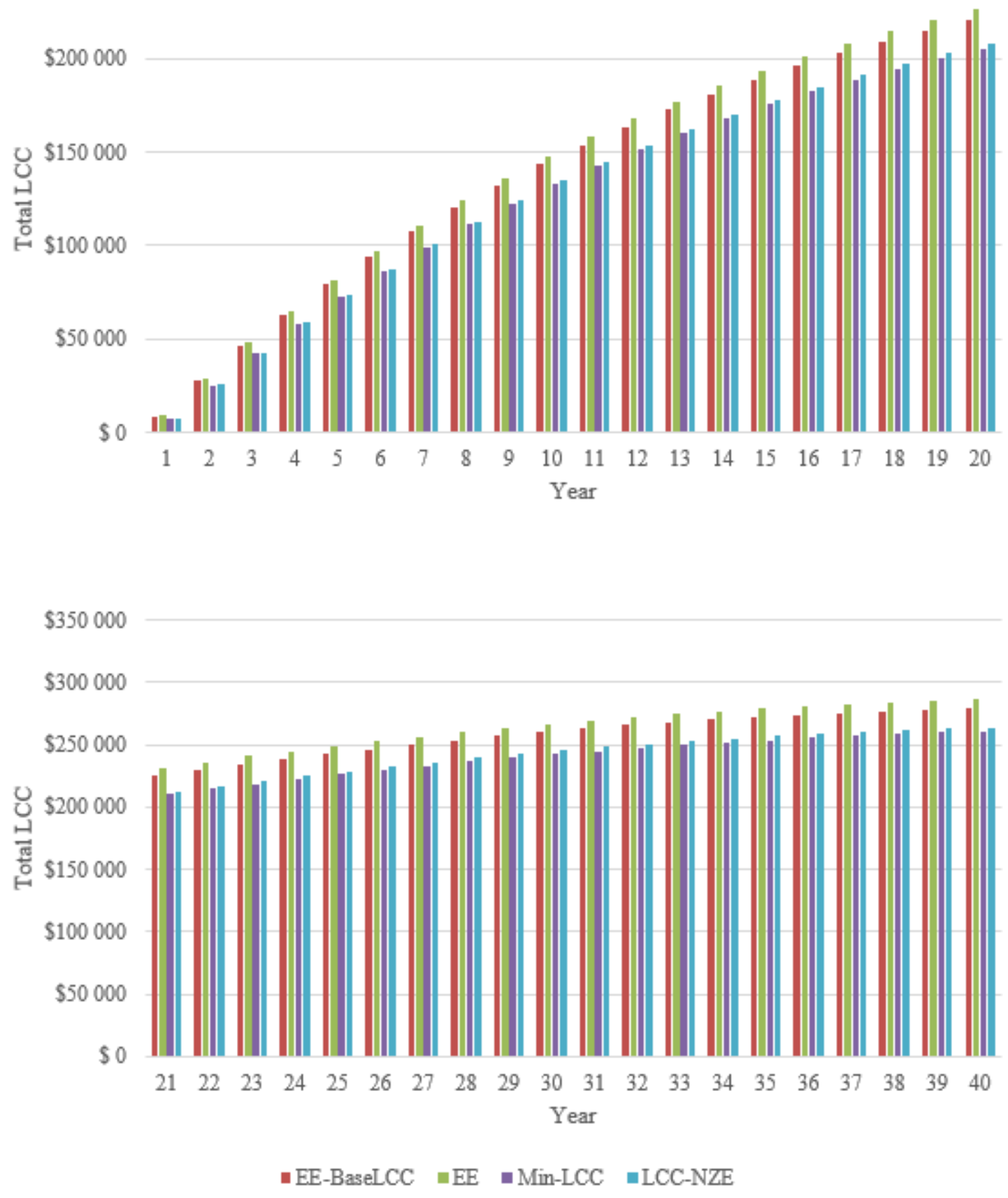

Figure 4-42 Present Value of Total LCC for Selected Designs - Case 6

Comparing the differences in LCC for Case 6 shown in Figure 4-43 to those for Case 5 in Figure 4-30, it becomes apparent that financing the home purchase instead of purchasing with $100 \%$ cash upfront leads to significant differences in terms of the key design characteristics, energy performance, and/or LCC performance. The most energy efficient (EE) design's difference in LCC relative to the baseline design for a 40 -year study period decreases from approximately $\$ 40$ 
000 in Case 5 to just under $\$ 15000$ dollars in Case 6. Savings in the minimum LCC (Min-LCC) design remain relatively similar, though the Min-LCC design Case 6 realizes greater energy savings than in Case 5. The minimum LCC design that reaches net-zero energy performance

(LCC-NZE) shows a significant reduction in LCC for a 40-year study period for Case 6 (\$18 691) relative to Case 5. 


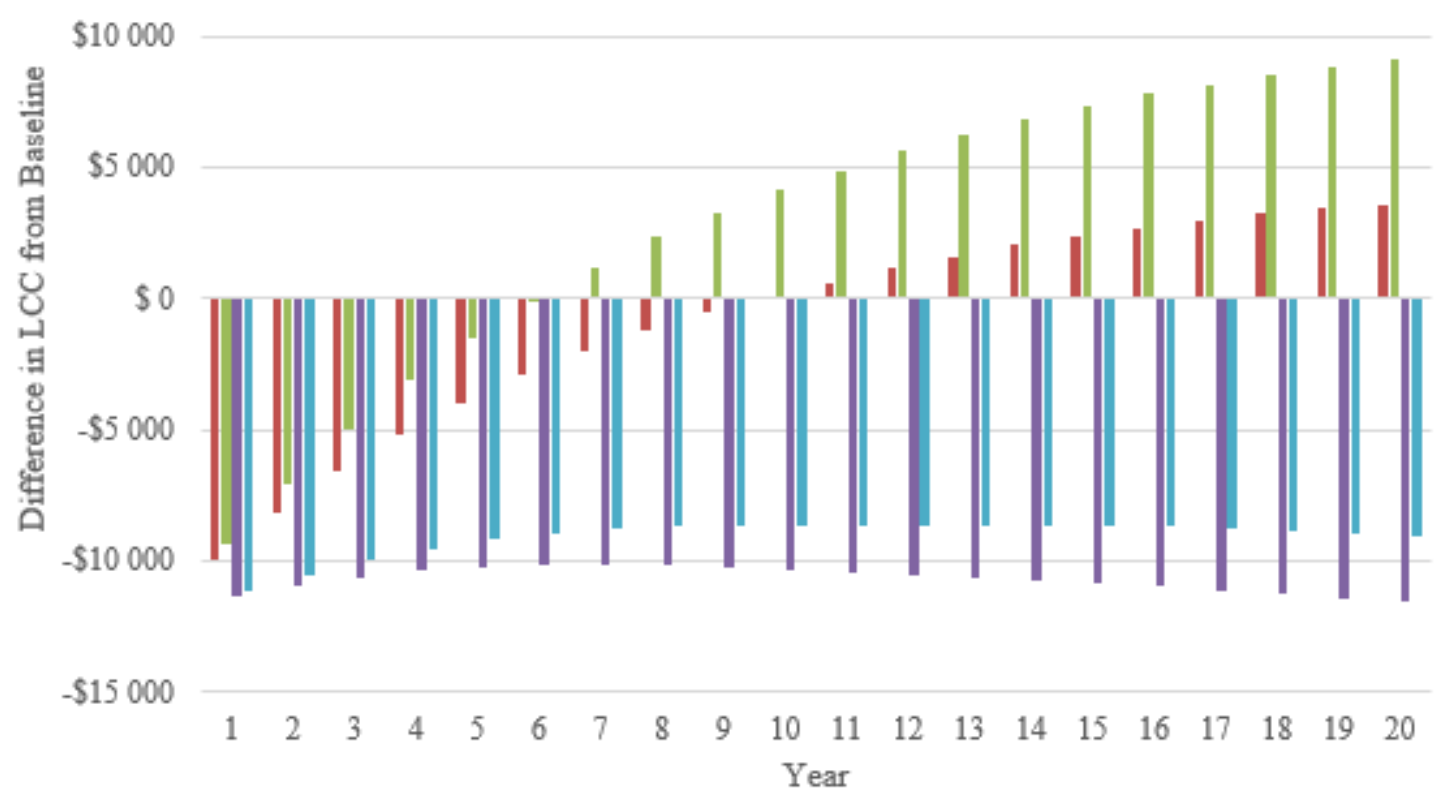

$\$ 20000$

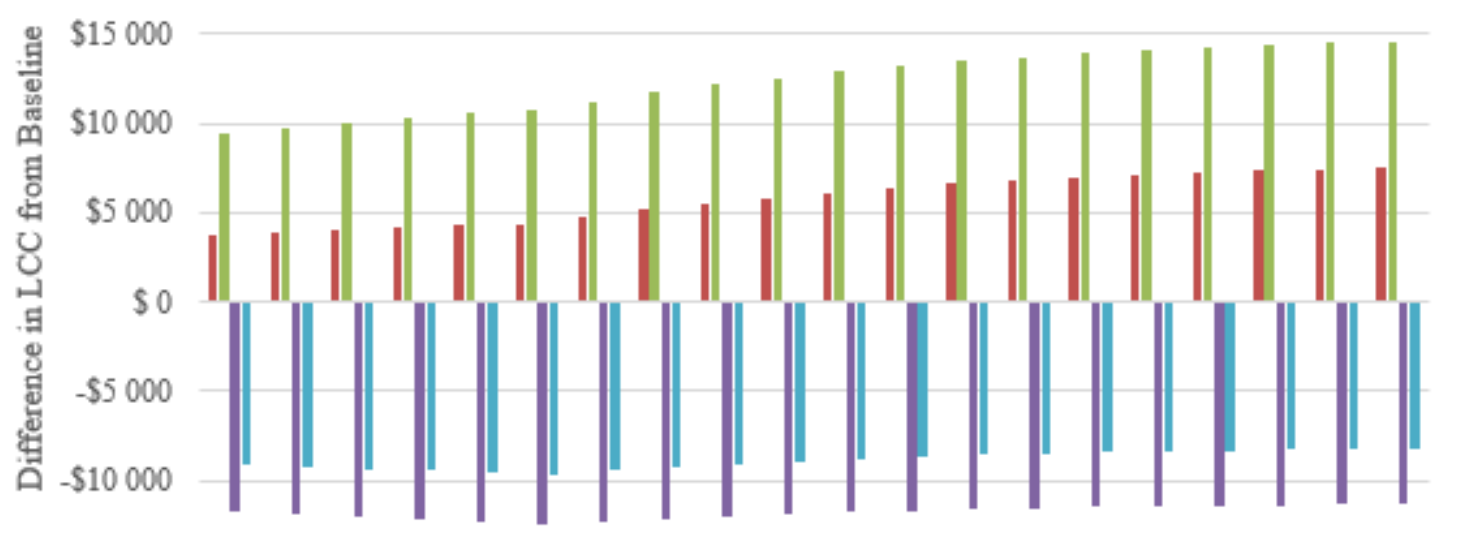

$-\$ 15000$

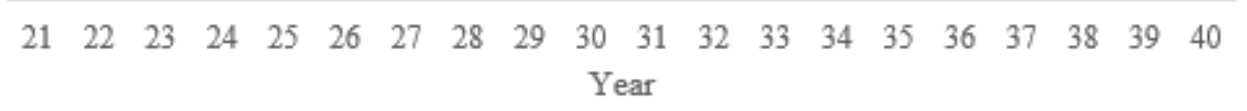

-EE-BaseLCC $\quad=\mathrm{EE} \quad-\mathrm{Min}-\mathrm{LCC} \quad \square \mathrm{LCC}-\mathrm{NZE}$

Figure 4-43 Present Value of Incremental LCC Relative to Baseline for Selected Designs Case 6

The payback periods for the selected designs are found in Table 4-16, which are identical to those for the Case 2, with the same interpretations. As with Case 1, the use of the payback period method does not inform the home purchaser to the same extent that the LCC methodology is capable. 
Table 4-16 Modified Payback Period for Selected Key Designs - Case 6

\begin{tabular}{|c|c|}
\hline Design & Payback Period* \\
\hline EE-BaseLCC & N/A \\
\hline EE & N/A \\
\hline Min-LCC & 15 years** \\
\hline LCC-NZE & \\
\hline & $\begin{array}{l}\text { * N/A indicates that the option has a payback } \\
\text { period of longer than } 40 \text { years, if one exists at all } \\
* * \text { Obtained using linear interpolation; rounded } \\
\text { up to the next year }\end{array}$ \\
\hline
\end{tabular}

\subsubsection{Environmental Impact Analysis of Key Designs - Case 6}

Switching to the $80 \%$ loan financing option only impacts the key designs that change in terms of their building characteristics: EE-BaseLCC and Min-LCC. Both designs realize greater reductions in energy consumption, leading to lower environmental impacts in those areas that are driven by energy consumption. The EE-BaseLCC design in Case 6 includes a larger solar PV system and additional rigid insulation in both the roof assembly and the exterior wall assembly. The embodied emissions associated with these additional features have considerable negative impacts on most non-energy related flows (i.e., criteria air, non-carcinogenic, ozone depletion, ecotoxicity, and land use). Similarly, the additional features included in the Min-LCC design (i.e., solar PV system, additional insulation in the roof and wall assemblies) lead to greater negative impacts on all non-energy related environmental flows. Although both designs realize higher embodied emissions, the lower energy-related emissions from greater energy savings overwhelms those impacts and leads to lower overall environmental impacts as measured by the EIS relative to Case 5.

\subsection{Case 7 and Case 8}

Since Case 7 and Case 8 are similar in nature to Cases 3 and 4 in that they provide the same results relative to the baseline while only adding a premium to the first costs, the two cases have been combined for conciseness. Table 4-17 summarizes a selection of the additional premium results for the two cases. For reference, Case 7 represents the $8 \%$ discount rate, luxury construction quality, and $100 \%$ down option while Case 8 represents the $8 \%$ discount rate, luxury construction quality, and $20 \%$ down option. All results relative to the baseline are unchanged when comparing Case 5 to Case 7 and Case 6 to Case 8. 
Table 4-17 Premiums from Luxury Construction Quality for Case 7 and Case 8

\begin{tabular}{|c|c|c|c|}
\hline Case & $\begin{array}{l}\text { Selected designs } \\
\text { identical to: }\end{array}$ & $\begin{array}{l}\text { Additional Premium } \\
\text { Added to: }\end{array}$ & $\begin{array}{l}\text { Premium } \\
\text { Value }\end{array}$ \\
\hline 7 & Case 5 & $\begin{array}{l}\text { Down payment } \\
\text { 1-year residual value } \\
\text { 40-year total LCC }\end{array}$ & $\begin{array}{r}\$ 118638 * \\
\$ 108160 \\
\$ 116538\end{array}$ \\
\hline 8 & Case 6 & $\begin{array}{l}\text { Down payment } \\
\text { 1-year residual value } \\
\text { 40-year total LCC }\end{array}$ & $\begin{array}{r}\$ 23727 * * \\
\$ 108160 \\
\$ 72208\end{array}$ \\
\hline
\end{tabular}

The greater total LCC for a 40-year study period for Case 7 relative to Case 5 is due to paying all cash up front in combination with a higher discount rate. Future savings from the residual value have a smaller impact in reducing the total LCC. The greater total LCC for Case 8 relative to Case 6 is due to future loan payments being discounted at a higher rate.

As discussed in Section 2.6, homes of "luxury" construction quality offer more amenities than those of "average" construction quality. As discussed in Section 3.3, the BIRDS low-energy residential database assumes the additional costs of the luxury quality construction are associated with additional embodied flows based on the industry average flows per dollar of expenditure, which is applied to all designs. Therefore, the total flows for each impact category increase by the same amount for each design. These changes are minimized in the normalization and weighting process and lead to no change in the EIS value. Therefore, the same interpretations hold for Case 7 and Case 8 as for those discussed for Case 1 in Section 4.2.5. 


\section{Conclusion, Limitations, and Future Research}

This study analyzes the recently released BIRDS low-energy residential database across 240000 building designs, 40 study periods, and 8 different sets of assumptions. This chapter will summarize those results, discuss limitations in the analysis, and suggest potential future research expanding on this analysis and the associated database.

\subsection{Summary}

Pareto frontiers, which establish minimum LCC design to reach a given level of percent energy savings relative to a Maryland code-compliant design based on the 2015 IECC, were developed for each of the 8 cases identified and 5 key building designs were selected based on different potential goals of a home purchaser: (1) minimize LCC, (2) maximize energy savings, (3) maximize energy savings without increasing LCC relative to the baseline design, and (4) minimize LCC while reaching net-zero energy performance.

The most detailed analysis is completed for the initial set of assumptions, which assumes a $3 \%$ discount rate, "average" construction quality, and $100 \%$ all cash upfront purchase. Reaching higher levels of energy efficiency typically requires additional investments during construction in order to obtain future energy cost savings. The most energy efficient design leads to energy savings of $114 \%$ relative to the baseline design, which means there is excess electricity production that is sold back to the utility, although the design realizes LCC that are \$4282 greater than the baseline design. The higher first costs are not offset by the future energy cost savings. The most energy efficient design that has the same LCC as the baseline design realizes nearly the same level of energy savings (113\%) as the most energy efficient design, but at lower LCC ( $\sim 0)$. The design that reaches net-zero energy performance at the lowest LCC realizes lower LCC than the baseline design by $\$ 10749$, implying that it is feasible to reach net-zero cost-effectively given the underlying assumptions. The design that leads to the lowest LCC leads to energy savings of $94 \%$ and LCC savings of \$12 344 relative to the baseline design. Based on the underlying assumptions, it is possible to reach near net-zero performance cost-effectively.

Analyses of the other 7 cases focus on how changing the 3 key assumptions impact the results. Some of the results vary depending on the combination of assumptions. However, even under the worst set of assumptions considered, the design that leads to the lowest LCC still leads to energy savings of $26 \%$ relative to the baseline design and the greatest energy savings for the same LCC as the baseline design is $78 \%$, showing that energy efficiency requirements in current energy codes can continue to be increased in a cost-effective manner.

The selection of the construction quality impacts the first costs of a building design because increasing the quality of building components, such as high-end cabinets or trim, leads to greater construction costs. However, the quality of the construction is assumed not to impact the energy performance of a building design. As a result, changing the construction quality assumption from "average" to "luxury" leads to no change in the relative energy performance of the building 
design. Additionally, both the baseline design and the key design of interest realize the same increase in first costs while not impacting future costs. Therefore, the difference in LCC between the two designs remains the same regardless of the assumed construction quality.

Overall, a higher discount rate decreases the cost-competiveness of designs with high levels of energy savings while financing a purchase through an 80/20 loan instead of $100 \%$ cash upfront increases the cost-competitiveness of designs with additional energy savings. The combination of the assumed discount rate and selected financing option has a significant impact on the energy and economic performance of the key designs considered in this study. For an all cash purchase, a higher discount rate decreases the energy savings for both the minimum LCC design and the design that realizes the greatest energy savings for the same LCC as the baseline design. Additionally, the minimum LCC design realizes a decrease in net savings from $\$ 12344$ to $\$ 5904$. While the energy savings for the most energy efficient design and the lowest LCC design that reaches net-zero energy performance are not impacted by the discount rate, the change in LCC is increased by over $\$ 24000$ and $\$ 16000$, respectively. The lowest LCC design that reaches net-zero energy performance shifts from being cost-effective relative to the baseline design under a $3 \%$ discount rate to realizing higher LCC than the baseline under an $8 \%$ discount rate.

The impacts of increasing the discount rate differ under an 80/20 loan as the financing option. The impact of using a higher discount rate does not change the relative energy performance (less than $1 \%$ ) while increasing LCC for all designs. The most energy efficient design shifts from having lower LCC than the baseline design by $\$ 1097$ to having higher LCC by $\$ 4130$. The minimum LCC design and design that reaches net-zero energy performance at the lowest LCC maintain lower LCC than the baseline design, although the net savings is decreased for both designs.

Another key factor that is not explicitly addressed in the case-by-case analysis and that impacts the economic performance of the key designs relative to the baseline is financial incentives for energy efficiency and renewable energy. The only incentive included in this analysis is the $30 \%$ federal tax credit for installing a solar PV system. However, the BIRDS low-energy residential database does not include any financial incentives at this time. This financial incentive, as well as others, should be included as options within future versions of BIRDS because they can have significant impacts on home purchasers.

\subsection{Limitations and Future Research}

The analysis in this study is limited in scope and would be strengthened by including sensitivity analysis and expanding the BIRDS database and metrics. Additional energy efficiency measures (EEMs), fuel types, discount rates, building constructions (e.g., wall types), and building types (e.g., single-story home or low-rise apartment building) would expand the scope of the database. Uncertainty analysis on these factors as well as other factors, such as occupancy and behavior patterns and additional discount rates and financing options, should be considered in future 
analysis. Given their potential, financial incentives, federal-, state-, and utility-level, should be incorporated into BIRDS. Another area to pursue is more realistic (complex) rate schedules for electricity and natural gas consumption.

Energy, environmental, and economic performance are but three attributes of building performance. The BIRDS model assumes that its building prototypes all meet minimum technical performance requirements. However, there may be significant differences in technical performance not evaluated in BIRDS, such as indoor environmental quality performance, which may affect energy, environmental, and economic considerations.

The extensive BIRDS low-energy residential database can be used to answer many more questions than posed in this report, and is available to the public through BIRDS v3.0 that allows others access to the database for their own research on building energy efficiency and sustainability.

\subsection{Results Summary}

After completion of the detailed analysis of each of the eight cases, it is of interest to compare those results at a high level to determine the impact on energy performance (Table 5-1) and economic performance (Table 5-2) of changing three key assumptions: discount rate, financing option, and construction quality. In addition, there will be a brief discussion of the impact from the federal tax credit for renewable energy systems.

The selection of the construction quality impacts the first costs of a building design because increasing the quality of building components, such as high-end cabinets or trim, leads to greater construction costs. However, the quality of the construction is assumed not to impact the energy performance of a building design. As a result, changing the construction quality assumption from "average" to "luxury" leads to no change in the relative energy performance of the building design. Additionally, both the baseline design and the key design of interest realize the same increase in first costs while not impacting future costs. Therefore, the difference in LCC between the two designs remains the same regardless of the assumed construction quality. For these reasons Case 3, Case 4, Case 7, and Case 8 are excluded from further analysis as shown in Table 5-1 and Table 5-2.

Table 5-1 Energy Savings for Selected Key Designs by Case

\begin{tabular}{|l|c|c|c|r|r|r|r|}
\hline $\begin{array}{c}\text { Design } \\
\text { Category }\end{array}$ & $\begin{array}{c}\text { Discount } \\
\text { Rate }\end{array}$ & Financing & Quality & EE-BaseLCC & EE & Min-LCC & LCC-NZE \\
\hline Case 1 & $3 \%$ & $100 \%$ Cash & Average & $113 \%$ & $114 \%$ & $94 \%$ & $101 \%$ \\
\hline Case 2 & $3 \%$ & $80 / 20$ Loan & Average & $112 \%$ & $114 \%$ & $94 \%$ & $101 \%$ \\
\hline Case 5 & $8 \%$ & $100 \%$ Cash & Average & $78 \%$ & $114 \%$ & $26 \%$ & $101 \%$ \\
\hline Case 6 & $8 \%$ & $80 / 20$ Loan & Average & $113 \%$ & $114 \%$ & $94 \%$ & $101 \%$ \\
\hline *Same LCC as baseline design + / - \$100.
\end{tabular}


Overall, a higher discount rate decreases the cost-competiveness of designs with high levels of energy savings, while financing a purchase through an 80/20 loan instead of $100 \%$ cash upfront increases the cost competitiveness of designs with additional energy savings. The combination of the assumed discount rate and selected financing option has a significant impact on the energy and economic performance of the key designs considered in this study. For an all cash purchase, a higher discount rate decreases the energy savings for both the minimum LCC (Min-LCC) design and the design that realizes the greatest energy savings for the same LCC as the baseline design (EE-BaseLCC). The EE-BaseLCC design realizes a decrease in energy savings from $113 \%$ to $78 \%$. Similarly, the Min-LCC design realizes a decrease in energy savings from $94 \%$ to $26 \%$ while net savings decreases from \$12 344 to \$5904. While the energy savings for the most energy efficient (EE) design and the lowest LCC design that reach net-zero energy performance (LCC-NZE) are not impacted by the discount rate, the change in LCC is increased by over \$24 000 and \$16 000, respectively. The LCC-NZE design shifts from being costeffective relative to the baseline design under a $3 \%$ discount rate to realizing higher LCC than the baseline under an $8 \%$ discount rate.

Table 5-2 Change in LCC for Selected Key Designs by Case

\begin{tabular}{|l|c|c|c|r|r|r|r|}
\hline $\begin{array}{c}\text { Design } \\
\text { Category }\end{array}$ & $\begin{array}{c}\text { Discount } \\
\text { Rate }\end{array}$ & Financing & Quality & EE-BaseLCC* & EE & Min-LCC & LCC-NZE \\
\hline Case 1 & $3 \%$ & $100 \%$ Cash & Average & $\$ 67$ & $\$ 4282$ & $-\$ 12344$ & $-\$ 10749$ \\
\hline Case 2 & $3 \%$ & $80 / 20$ Loan & Average & $-\$ 8$ & $-\$ 1097$ & $-\$ 14919$ & $-\$ 13870$ \\
\hline Case 5 & $8 \%$ & $100 \%$ Cash & Average & $-\$ 47$ & $\$ 28337$ & $-\$ 5904$ & $\$ 5394$ \\
\hline Case 6 & $8 \%$ & $80 / 20$ Loan & Average & $\$ 97$ & $\$ 4130$ & $-\$ 10350$ & $-\$ 8653$ \\
\hline
\end{tabular}

The impacts of increasing the discount rate differ under an 80/20 loan as the financing option. The impact of using a higher discount rate does not change the relative energy performance (less than $1 \%$ ) while increasing LCC for all designs. The EE design shifts from having lower LCC than the baseline design by $\$ 1097$ to having higher LCC by $\$ 4130$. The Min-LCC and LCC-NZE designs maintain lower LCC than the baseline design, although the net savings is decreased for both designs.

A key factor that impacts the economic performance of the key designs relative to the baseline is the $30 \%$ federal tax credit for installing a solar PV system. Since the tax credit is a reduction in first costs, it can be directly subtracted from the difference in LCC to determine if the tax credit impacts a home purchaser's decision-making. Table 5-3 shows an example of these impacts by comparing the difference in LCC for the LCC-NZE design, which includes a $10.2 \mathrm{~kW}$ solar PV system, relative to the baseline design with and without the federal tax credit. The $30 \% \operatorname{tax}$ credit results in an increase in LCC of \$11 934 for all 8 cases, which leads to a different decision for half (4) of the cases. Financial incentives, including the federal tax credit, can have significant impacts on home purchasers and should be considered in analysis related to solar PV installation decisions. 
Table 5-3 Change in LCC for LCC-NZE Design With/Without Federal Renewable System Tax Credit by Case

\begin{tabular}{|c|c|c|c|c|c|}
\hline \multirow{2}{*}{$\begin{array}{c}\text { Design } \\
\text { Category }\end{array}$} & \multirow{2}{*}{$\begin{array}{c}\text { Discount } \\
\text { Rate }\end{array}$} & \multirow[t]{2}{*}{ Financing } & \multirow[t]{2}{*}{ Quality } & \multicolumn{2}{|c|}{ LCC-NZE } \\
\hline & & & & $\bar{W} /$ & W/Out \\
\hline Case 1 & $3 \%$ & $100 \%$ Cash & Average & $-\$ 10749$ & $\$ 1185$ \\
\hline Case 2 & $3 \%$ & 80 / 20 Loan & Average & $-\$ 13870$ & $-\$ 1936$ \\
\hline Case 5 & $8 \%$ & $100 \%$ Cash & Average & $\$ 5394$ & $\$ 17328$ \\
\hline Case 6 & $8 \%$ & 80 / 20 Loan & Average & $-\$ 8653$ & $\$ 3281$ \\
\hline \multicolumn{6}{|c|}{$\begin{array}{l}\text { Note 1: Tax Credit is } 30 \% \text { of Installed Cost of Solar PV System (\$11 } 934 \text { of } \\
\$ 39780 \text { for a } 10.2 \mathrm{~kW} \text { system). } \\
\text { Note 2: Results for luxury construction quality are the same. }\end{array}$} \\
\hline
\end{tabular}




\section{References}

Barbose, G. and N. Darghouth (2015). Tracking the Sun VIII: The Installed Price of Residential and Non-Residential Photovoltaic Systems in the United States. Berkeley, CA, Lawrence Berkely National Laboratory.

Fuller, S. and S. Petersen (1996). Life-Cycle Costing Manual for the Federal Energy Management Program, 1995 Edition. NIST handbook 135. National Institute of Standards and Technology.

Fuller, S. and S. Petersen (1996). "Life-Cycle Costing Manual for the Federal Energy Management Program, 1995 Edition." NIST handbook 135.

Halverson, M., et al. (2011a). ANSI/ASHRAE/IESNA Standard 90.1-2007 Final Determination Quantitative Analysis. Pacific Northwest National Laboratory. Richland, WA.

Halverson, M., et al. (2011b). ANSI/ASHRAE/IESNA Standard 90.1-2010 Final Determination Quantitative Analysis. Pacific Northwest National Laboratory. Richland, WA.

Halverson, M., et al. (2014). ANSI/ASHRAE/IES Standard 90.1-2013 Preliminary Determination: Quantitative Analysis. Pacific Northwest National Laboratory. Richland, WA.

Hendron, R. and C. Engebrecht (2010). Building America House Simulation Protocols. Energy Efficiency and Renewable Energy, National Renewable Energy Laboratory.

Kneifel, J. (2010). "Life-Cycle Carbon and Cost Analysis of Energy Efficiency Measures in New Commercial Buildings." Energy and Buildings 42(3): 333-340.

Kneifel, J. (2011a). "Beyond the code: Energy, carbon, and cost savings using conventional technologies." Energy and Buildings 43(4): 951-959.

Kneifel, J. (2013a). "Benefits and Costs of Energy Standard Adoption in New Commercial Buildings." NIST Special Publication 1147.

Kneifel, J. (2013b). "Benefits and Costs of Energy Standard Adoption in New Commercial Buildings: Northeast Census Region." NIST Special Publication 1148-1. 
Kneifel, J. (2013c). "Benefits and Costs of Energy Standard Adoption in New Commercial Buildings: Midwest Census Region." NIST Special Publication 1148-2.

Kneifel, J. (2013d). "Benefits and Costs of Energy Standard Adoption in New Commercial Buildings: South Census Region." NIST Special Publication 1148-3.

Kneifel, J. (2013e). "Benefits and Costs of Energy Standard Adoption in New Commercial Buildings: West Census Region." NIST Special Publication 1148-4.

Kneifel, J. (2013f). "Benefits and Costs of Energy Standard Adoption in New Commercial Buildings: National Summary." NIST Special Publication 1161.

Kneifel, J. and E. O'Rear (2015). "Sustainability Performance of the NIST Net-Zero Energy Residential Test Facility Relative to a Maryland Code-Compliant Design." NIST Special Publication 1187.

Kneifel, J. and E. O'Rear (2015b). "Benefits and Costs of Energy Standard Adoption for New Residential Buildings: National Summary." NIST Special Publication 1194.

Lippiatt, B., et al. (2013). "Building Industry Reporting and Design for Sustainability (BIRDS) Technical Manual and User Guide." NIST Technical Note 1814.

Lucas, R., et al. (2012). National Energy and Cost Savings for New Single-and Multifamily Homes: A Comparison of the 2006, 2009, and 2012 Editions of the IECC. Pacific Northwest National Laboratory (PNNL). Richland, WA.

Mendon, V., et al. (2013). Cost-Effectiveness Analysis of the 2009 and 2012 IECC Residential Provisions: Technical Support Document. Pacific Northwest National Laboratory (PNNL). Richland, Washington.

Mendon, V., et al. (2014). 2015 IECC Determination of Energy Savings: Preliminary Technical Analysis. Pacific Northwest National Laboratory (PNNL). Richland, WA.

National Association of Home Builders (NAHB) Research Center (2012a). Methodology for Calculating Energy Use in Residential Buildings. Upper Marlboro, MD, National Association of Homebuilders. 
National Association of Home Builders (NAHB) Research Center (2012b). 2009 IECC Cost Effectiveness Analysis. Upper Marlboro, MD, National Association of Home Builders.

National Association of Home Builders (NAHB) Research Center (2012c). 2012 IECC Cost Effectiveness Analysis. Upper Marlboro, MD, National Association of Home Builders.

Pacific Northwest National Laboratory (PNNL) (2009a). Impacts of Standard ASHRAE 90.12007 for Commercial Buildings at State Level. U.S. Department of Energy Building Energy Codes Program. Richland, WA.

Pacific Northwest National Laboratory (PNNL) (2009b). Impacts of the 2009 IECC for Residential Buildings at State Level. U.S. Department of Energy Building Energy Codes Program. Richland, WA.

RSMeans (2015). "CostWorks Databases." from http://www.meanscostworks.com/.

Suh, S. and B. C. Lippiatt (2012). "Framework for hybrid life cycle inventory databases: a case study on the Building for Environmental and Economic Sustainability (BEES) database." The International Journal of Life Cycle Assessment 17(5): 604-612. 